NBER WORKING PAPER SERIES

\title{
FAMILY DISADVANTAGE AND THE GENDER GAP IN BEHAVIORAL AND EDUCATIONAL OUTCOMES
}

\author{
David Autor \\ David Figlio \\ Krzysztof Karbownik \\ Jeffrey Roth \\ Melanie Wasserman \\ Working Paper 22267 \\ http://www.nber.org/papers/w22267
}

\author{
NATIONAL BUREAU OF ECONOMIC RESEARCH \\ 1050 Massachusetts Avenue \\ Cambridge, MA 02138 \\ May 2016, September 2017
}

We thank Josh Angrist, Marianne Bertrand, Raj Chetty, John Ham, Nathan Hendren, Louis Kaplow, Mikael Lindahl, Jeremy Majerovitz, Richard Murnane, Jessica Pan, Kjell Salvanes, Till von Wachter, and numerous seminar participants at AEFP, CESifo Program on the Economics of Education, Federal Reserve Bank of Atlanta, Harvard University, Hitotsubashi University, IZA, Maastricht University, Miami University, MIT, National University of Singapore, the NBER Education Program, Northwestern University, Queens University, Simon Fraser University, University of Chicago, University of Erlangen-Nurnberg, University of Leicester, University of Oregon, University of Quebec at Montreal, University of Southampton, University of Toronto, Uppsala University, Washington University in Saint Louis, and the Yrjö Jahnsson Foundation 60th Anniversary Conference on Inequality and Health for valuable suggestions that helped to improve the paper. Autor acknowledges support from the Russell Sage Foundation (Grant \#85-12-07). Figlio and Roth acknowledge support from the National Science Foundation and the Institute for Education Sciences (CALDER grant), and Figlio acknowledges support from the National Institute of Child Health and Human Development and the Bill and Melinda Gates Foundation. Wasserman acknowledges support from the NSF Graduation Research Fellowship, NIA Grant \#T32-AG000186, and NICHD Grant \#HD007339-30. We are grateful to the Florida Departments of Education and Health for providing the de-identified, matched data used in this analysis. The conclusions expressed in this paper are those of the authors and do not represent the positions of the Florida Departments of Education and Health, nor those of our funders, nor the views of the National Bureau of Economic Research.

NBER working papers are circulated for discussion and comment purposes. They have not been peer-reviewed or been subject to the review by the NBER Board of Directors that accompanies official NBER publications.

(C) 2016 by David Autor, David Figlio, Krzysztof Karbownik, Jeffrey Roth, and Melanie Wasserman. All rights reserved. Short sections of text, not to exceed two paragraphs, may be quoted without explicit permission provided that full credit, including ( $)$ notice, is given to the source. 
Family Disadvantage and the Gender Gap in Behavioral and Educational Outcomes

David Autor, David Figlio, Krzysztof Karbownik, Jeffrey Roth, and Melanie Wasserman

NBER Working Paper No. 22267

May 2016, September 2017

JEL No. I24,J12,J13,J16

\author{
ABSTRACT \\ Using birth certificates matched to schooling records for Florida children born 1992-2002, we \\ assess whether family disadvantage disproportionately impedes the pre-market development of \\ boys. We find that, relative to their sisters, boys born to disadvantaged families have higher rates \\ of disciplinary problems, lower achievement scores, and fewer high-school completions. \\ Evidence supports that this is a causal effect of the post-natal environment; family disadvantage \\ is unrelated to the gender gap in neonatal health. We conclude that the gender gap among black \\ children is larger than among white children in substantial part because black children are raised \\ in more disadvantaged families. \\ David Autor \\ Department of Economics, E52-438 \\ MIT \\ 77 Massachusetts Avenue \\ Cambridge, MA 02139 \\ and NBER \\ dautor@mit.edu \\ David Figlio \\ Institute for Policy Research \\ Northwestern University \\ 2040 Sheridan Road \\ Evanston, IL 60208 \\ and NBER \\ figlio@northwestern.edu \\ Krzysztof Karbownik \\ Institute for Policy Research \\ Northwestern University \\ 2040 Sheridan Road \\ Evanston, IL 60208 \\ krzysztof.karbownik@northwestern.edu \\ Jeffrey Roth \\ Department of Pediatrics \\ University of Florida \\ PO Box 100296 \\ Gainesville, FL 32610-0296 \\ jeffroth@ufl.edu \\ Melanie Wasserman \\ Department of Economics \\ MIT \\ 50 Memorial Drive \\ Cambridge, MA 02139 \\ melanie.wasserman@anderson.ucla.edu
}




\section{Introduction}

The last four decades have witnessed a swift and substantial reversal of the gender gap in educational attainment in the U.S. and much of the developed world. Between 1970 and 2010, the high school graduation rate of U.S. women rose by six percentage points, from 81 to 87 percentage points, while the U.S. male high school graduation rate was unchanged (Murnane, 2013). ${ }^{1}$ Contemporaneously, women have overtaken and surpassed men in higher education: in 2011, the ratio of female to male college attainment among adults ages 25 - 34 exceeded unity in 28 of 34 OECD countries, with a median above 1.4 (OECD, 2013). Amidst this widely remarked rise in female educational attainment hides a striking and comparatively unremarked puzzle: the female advantage in high school graduation and college attainment is larger and has risen by substantially more among children of minority families. For example, while the overall female advantage in high school completions among U.S. adults ages 20 through 24 was 6.2 percentage points in 2010, it was 4.5 percentage points among whites, 12.2 percentage points among blacks, and 7.8 percentage points among U.S. born Hispanics (Murnane, 2013, Table 3). ${ }^{2}$ Contemporaneous race gaps in college attainment among young U.S. adults are equally pronounced (U.S. National Center for Education Statistics, 2013, Table 104.20). ${ }^{3}$

What accounts for the systematically larger gender gaps in educational outcomes among minorities? One possible explanation - the focus of this paper - is family disadvantage, defined as lower levels of the quality and quantity of available household resources, child-rearing inputs (e.g., nutrition, safety in the home, stimuli), and parental attention. We hypothesize that family disadvantage differentially inhibits the behavioral and academic development of boys relative to girls, either because these outcomes are more elastic to family circumstances among boys than girls, or because differential parental investment in girls relative to boys varies inversely with household socioeconomic status (SES). Our goals in this paper are: (a) to test whether family disadvantage levies a disproportionate effect on the educational and behavioral outcomes of school-age boys relative to girls; (b) to differentiate this hypothesis from a 'fetal origins' alternative as well as from a neighborhoodand-school-quality explanation; and (c) to utilize the resulting estimates to quantify the degree to which higher rates of family disadvantage among minority populations can partly explain the larger gender gaps in educational outcomes we observe among minorities. ${ }^{4}$

\footnotetext{
${ }^{1}$ High school graduation rates refer to the status completion rate of U.S. born adults ages 20-24, and they include both traditional high school graduates and GED holders. Thus, 1970 graduation rates refer to cohorts born 1947-50, and 2010 graduation rates refer to cohorts born 1986-1990.

${ }^{2}$ By comparison, the gap in 1970 was zero overall, -0.4 percentage points among whites, 5.1 percentage points among blacks, and -2.5 percentage points among U.S. born Hispanics. Thus, the increase in the gap among whites, blacks, and Hispanics in this 40 year period was $4.9,7.1$, and 10.3 percentage points, respectively

${ }^{3}$ Whereas white women ages 25 to 29 were 22 percent more likely to hold a B.A. than white males in 2010 , the corresponding gap was 55 percent among both blacks and Hispanics. Goldin et al. (2006) document that among the high school graduating class of 1992, the female advantage in B.A. attainment was far higher among children of families in the bottom two SES quartiles than among the top two quartiles, and, moreover, the gender gap in the lower two quartiles had risen by substantially more than among the upper quartiles in the prior twenty years.

${ }^{4}$ Prevailing gender norms historically inhibited women from attaining education commensurate with their ability. As documented by Goldin et al. (2006) and Fortin et al. (2015), U.S. girls outranked U.S. boys in high school grade point averages for many decades. And yet, until the early 1980s, girls were substantially less likely than boys with
} 
In quantifying the contribution of family disadvantage to the gender gap in behavioral and academic outcomes, we face two principal obstacles: suitable data and credible identification. To address the data and measurement challenge, we draw upon a matched database of birth certificate, and academic, disciplinary, and high school graduation records for over one million children born in Florida between 1992 and 2002. ${ }^{5}$ Florida is particularly well-suited to this research because it has a large, demographically diverse, and socioeconomically heterogeneous population. Our longitudinal data offer remarkable detail on family characteristics, infant and maternal health at birth, early educational outcomes (including assessments of kindergarten readiness at the start of formal schooling), third through eighth grade test scores, absenteeism, disciplinary outcomes, disability, and high school graduation for the oldest cohorts in our sample. Since family disadvantage is imperfectly observable even in this rich database, we combine multiple variables to proxy for this underlying construct, focusing particularly on maternal education, household poverty, and marital status/father presence or absence at the time of birth.

The second obstacle to our inquiry is that family environment is intrinsically confounded with congenital and hereditary factors that likely affect children's outcomes independent of their impact on family environment. For example, highly educated parents reside in safer neighborhoods, enroll their children in higher quality schools, are disproportionately likely to have stable marriages, and may have children with above average latent ability. ${ }^{6}$ Our challenge is thus to separate the direct impact of family environment (e.g., quality and quantity of parental inputs) from the heredity and environmental confounds that would almost surely lead to disparate outcomes among children absent any causal effect of family environment on children's development. Our empirical approach purges these confounds by contrasting the outcomes of opposite-sex siblings linked by birth and schooling records to the same mother. This strategy provides valid identification of the differential effect of child-rearing environment on boys relative to girls under two conditions. The first is that siblings raised by the same mother are (on average) exposed to the same family environment, an assumption that we find ex ante plausible. The second, more stringent, condition is that the gender gap in potential outcomes between siblings is uncorrelated with our measures of family environment at the time of birth; that is, any intrinsic genetic or biological advantage that girls may possess at birth relative to their male siblings is not systematically larger or smaller in less relative to more disadvantaged families. While this strong unconfoundedness assumption is not fully testable, our detailed and precise measures of infant and maternal health, obtained from vital statistics, offer a compelling confirmation of its plausibility. ${ }^{7}$

comparable class ranks or IQ scores to enter and complete college. But the overall relaxation of the gender norms does not immediately explain why the gender gap has reversed to a substantially larger extent among children of minority, low-income, and non-married families.

${ }^{5}$ These data are also used by Figlio et al. (2014).

${ }^{6}$ Consider, for example, the impact of father absence on the gender gap in children's outcomes. Boys may be differentially sensitive to this father absence since for boys, it also implies the potential lack of a same-sex role model in the home (Autor and Wasserman, 2013). On the other hand, existing literature finds that mothers typically spend more parenting time with daughters and fathers typically spend more parenting time with sons (Lundberg et al., 2007; Baker and Milligan, 2013; Bertrand and Pan, 2013; Gayle et al., 2014), so girls may receive relatively larger parental time investments in father-absent households.

${ }^{7}$ We probe this assumption by assessing whether family disadvantage is correlated with a large set of health 
We demonstrate that post-natal factors relating to family disadvantage, above and beyond the neighborhoods children inhabit and the schools they attend, substantially and differentially influence the likelihood that boys thrive relative to their sisters. We begin by documenting that the cross-race differences in the gender gap in long-term educational attainment emerge early in students' academic trajectories and are apparent in both cognitive and behavioral outcomes. For example, 12.4 percent of Florida public school children are suspended at least once between third and eighth grade. But suspensions are 7.0 percentage points higher among white boys than girls, and an additional 6.2 percentage points higher among black boys relative to black girls. We then implement our primary analysis which, by comparing siblings, demonstrates that boys born to low-SES households perform worse on standardized tests throughout elementary and middle school, have higher rates of absences and behavioral problems, and are less likely to graduate high school than are their sisters. ${ }^{8}$ These within-household differentials are economically large and explain a substantial share of cross-race group differences in the gender gap. Accounting for the differential effect of family disadvantage on boys relative to girls, reduces the cross-race suspension gap to 2.3 percentage points - meaning that 4.1 percentage points of the observed black-white gender gap is proximately explained by higher levels of disadvantage to which both black boys and girls are exposed. Among families of comparable SES, we would predict the black-white gender gap to be 64 percent smaller. Carrying this exercise forward to longer-term outcomes, our estimates of the causal effect of family disadvantage on the gender gap can explain one-third of the excess high school dropout differential among black males versus black females relative to white males versus white females.

Another implicit assumption of our analytic approach is that the causal effect of family disadvantage on the gender gap is comparable across race and ethnic groups - for example, father absence is equally consequential for the brother-sister gap in downstream outcomes among white siblings, black siblings, and Hispanic siblings. This assumption allows us to make the inference, for example, that were black siblings exposed to the same average SES as white siblings, the excess suspension gap among black relative to white siblings would be reduced by 64 percent. While our data generally do not reject the null hypothesis of comparable treatment effects, we do find some important

outcomes reported on birth certificates: In addition to birthweight, a sensitive and powerful predictor of newborns' long term health and educational outcomes into adulthood (Black et al., 2007; Aizer and Currie, 2014; Figlio et al., 2014), we also measure Apgar scores, gestational age, congenital anomalies, complications of labor and delivery, abnormal birth conditions, maternal health, and adequacy of prenatal care. In all cases, these at-birth outcomes differ systematically among SES groups: low-SES newborns are delivered in poorer health to less healthy mothers who received less prenatal care and experience more frequent birth complications. Yet, in no case is the brother-sister gap in these outcomes predicted by SES; brothers and sisters appear equally advantaged or disadvantaged by family SES.

${ }^{8}$ While the children observed in our sample are not yet old enough for us to observe adult outcomes such as high school dropout (except for the oldest cohorts) or labor force participation and criminal activity, there is strong reason to suspect that observed differences in disciplinary behaviors across genders and family types will later be manifest in differences in academic and labor market performance. For example, Duckworth and Seligman (2005) find that measures of eighth grade self-discipline are better predictors of subsequent academic performance than are measures of IQ. Similarly, Segal (2013) reports that eight-grade teacher evaluations of children's misbehavior (arguably akin to our school suspension measure) have important predictive power for adult earnings over and above eighth grade test scores. Segal (2013) additionally finds that, holding constant educational attainment, childhood misbehavior is negatively associated with adult earnings at all educational levels, whereas achievement test scores are positively related to earnings only for young men with postsecondary degrees. 
deviations from this benchmark - in particular, greater family SES has a somewhat smaller moderating effect on the sibling gender gap in suspensions among non-whites than among whites, perhaps because schools are more punitive towards minority than non-minority boys. Accounting for this non-parallelism does not substantively change our findings, however, as we discuss and interpret below.

While the SES gradient in the gender gap may stem from family environment per se, it may also reflect the differential effect of neighborhood and school quality - both of which are correlated with family income, education, and marital status - on boys relative to girls. We empirically differentiate among these alternatives by augmenting our main analysis with measures of the non-family environment that siblings experience, including: measures of school quality produced by the Florida Department of Education; estimates of the causal effect of counties of residence on economic mobility produced by Chetty and Hendren (2015); and a saturated set of neighborhood indicators (corresponding to zip codes). In all cases, we allow these environmental quality measures to differentially affect outcomes of boys relative to girls. After accounting for the direct effect of family characteristics, we find that neighborhood quality makes a modest additional contribution to the boy-girl outcome gap. School quality matters more, however: low quality schools, as measured by Florida state reports of student test score gains, are particularly disadvantageous for boys. Nevertheless, accounting non-parametrically for the differential impact of schools and neighborhoods on boys relative to girls reduces the estimated impact of family disadvantage on the sibling gender gap in behavioral outcomes by at most one quarter. ${ }^{9}$

This paper contributes to an active literature examining the emerging gender gap in educational and behavioral outcomes. ${ }^{10}$ Buchmann and DiPrete (2006), Goldin et al. (2006), DiPrete and Jennings (2012), Autor and Wasserman (2013), Bertrand and Pan (2013), DiPrete and Buchmann (2013), Fortin et al. (2015), Chetty et al. (2016b), and Lundberg (2017) explore the evolution of gender differences in behavioral and educational outcomes in the United States and internationally. Several papers explore specific hypotheses for this gender gap. Becker et al. (2010) theorize that gender differences in the psychic costs of education-primarily differences in the distributions of non-cognitive skills - explain the overtaking of men by women in higher education. Papers by Buchmann and DiPrete (2006), DiPrete and Jennings (2012), Baker and Milligan (2013), Bertrand

\footnotetext{
${ }^{9}$ It is still possible that neighborhood factors can explain some of what we are calling family disadvantage effects. Disadvantaged families might occupy micro-neighborhoods within the larger neighborhoods we can measure with available administrative data. There exists considerable evidence from the sociology literature documenting that neighborhoods vary within a zip code - the finest geography we observe in our data. (See Ingoldsby and Shaw (2002); Beyers et al. (2003); Leventhal and Brooks-Gunn (2003); Ramirez-Valles et al. (2002) and Karriker-Jaffe et al. (2009) for examples.) If particularly disadvantaged micro-neighborhoods affect boys more than girls within the same family, then these micro-neighborhoods would still be a pathway through which family disadvantage is operating. That said, we have access to data from one large anonymous county-level school system in Florida that constructs micro-neighborhoods that are on average one-tenth the population of the typical Census block group in the county. In this one county, the between-zip code variation accounts for 74 percent of the overall variation in micro-neighborhood poverty rates in the county, and the between-zip code variation accounts for 60 percent of the overall variation in micro-neighborhood non-parental guardianship rates in the county. We therefore believe that most of the variation in neighborhood quality is reflected in the zip code measure that we can observe statewide.

${ }^{10}$ See Lundberg and Pollak (2007), Cherlin (2009), and Cherlin (2014) for broader discussions of the economics of family structure and its evolution over recent decades.
} 
and Pan (2013), Lundberg (2017), Owens (2016), Prevoo and ter Weel (2014), Karbownik and Myck (2017), Riphahn and Schwientek (2015), and Woessmann (2015) focus on the role of family and schooling environment in generating observed gender gaps in behavioral and educational outcomes. ${ }^{11}$ Bertrand and Pan (2013) offer the most complete extant analysis of the relationship between family background and gender differences in early childhood outcomes. They document that boys raised in single-parent families exhibit twice the rate of behavioral and disciplinary issues as boys raised in two-parent families and are more than twice as likely to be suspended from school by the eighth grade. Considering detailed measures of home environment, school environment, and parent-child interactions, Bertrand and Pan (2013) find only modest evidence that parental and schooling inputs differ systematically between boys and girls across family types. Their analysis suggests, however, that the quality of parental and child-rearing inputs has larger impacts on the behavioral and disciplinary outcomes of boys than it does of girls. Consistent with this line of argument, Fan et al. (2015) provide evidence from Norwegian registry data that mother's employment during children's early years has a differentially adverse effect on the educational attainment of sons relative to daughters. They hypothesize that rising female employment may in part explain the reversal of the male-favorable gap in educational attainment. ${ }^{12}$

Prior research in this vein implicitly draws a contrast between boys and girls born to different mothers to assess the relationship between family disadvantage and the gender gaps in child outcomes. This approach, necessitated by data and sample size constraints, leaves open the possibility that unmeasured differences among families with children of different sexes - or unobserved changes in family structure occurring in childhood - may in part explain the contrast in developmental outcomes. Our approach exploits cross-gender, within-family sibling comparisons (akin to Chetty and Hendren 2015, but adding the gender contrast), to sweep out unmeasured, time-constant family effects that may bias comparisons of children of different genders raised in different families. Additionally, the uniquely detailed Florida data, sourced from birth records, enumerate family structure at birth-married, unmarried with father present, or unmarried with father absent - thus abstracting from any changes in family structure that occur postpartum. ${ }^{13}$ Across all manner of sibling contrasts, we find robust evidence that behavioral and academic outcomes of boys are differentially affected by family circumstances.

A second strand of literature to which we contribute studies the causal effects of environmental and maternal stresses on children's in utero mortality, birthweight, health, cognitive development, and educational and labor market outcomes. Almond and Currie (2011) and Aizer and Currie (2014)

\footnotetext{
${ }^{11}$ There is also a large sociological literature that documents gender differences in outcomes during childhood. See, for example, Sampson et al. (2005) and Farrell et al. (2005).

${ }^{12}$ Baker et al. (2008) document that the introduction of highly subsidized, universally accessible child care in Quebec during the late 1990s increased maternal labor supply significantly and, simultaneously, adversely impacted early childhood developmental outcomes among affected cohorts of children. Follow-up work by Baker and Milligan (2013) found that this childcare expansion generated increased parental time investment in boys relative to girls.

${ }^{13}$ Unmarried fathers are more likely to establish paternity when the child is male (Almond and Rossin-Slater, 2013). In addition, we have conducted an analysis of longitudinal data from a large Florida school district that shows that unmarried fathers are more likely to leave the household by the time a child is in kindergarten if the child is a daughter rather than a son.
} 
review the large literature establishing the causal effect of maternal disadvantage on infant birthweight and infant health, while Almond et al. (2005), Black et al. (2007), and Figlio et al. (2014) document the robust and enduring adverse effect of low birthweight on children's IQ scores, educational attainment, and adult earnings. Several papers confirm the long-standing Trivers-Willard hypothesis (Trivers and Willard, 1973) that in utero stress increases the mortality odds of male relative to female fetuses (Norberg, 2004; Almond and Edlund, 2007). Studies that test for impacts of maternal malnutrition and maternal nutrition supplementation on subsequent academic and labor market outcomes of children who were potentially exposed in utero, find robust, though generally modest, impacts on adult health, skills acquisition, and labor market outcomes (Almond and Mazumder, 2011; Field et al., 2009; Maccini and Yang, 2009; Almond et al., 2014; Hoynes et al., 2016; Greve et al., 2015). These studies do not, however, find consistent differential impacts by gender on post-natal outcomes. Moreover, where differences are detected, they largely suggest that pre-natal disadvantage has a slightly more adverse impact on girls than boys. ${ }^{14}$ Assuming plausibly that pre-natal and post-natal disadvantage are positively correlated, this (modest) pre-natal differential would work against our finding that boys are differentially adversely affected by family disadvantage.

A third strand of literature to which we contribute analyzes the causal effects of neighborhoods on developmental, educational, and labor market outcomes, abstracting from the direct effect of family characteristics that are often tightly correlated with neighborhood attributes (e.g., income, race, and educational attainment). Recent work that pairs experimental (Chetty et al., 2016a) or quasi-experimental (Chetty and Hendren, 2015) research designs with high resolution tax register find that early and prolonged childhood exposure to low or high quality neighborhoods affects labor force participation, earnings, and education in adulthood. Of particular relevance to our work, two quasi-experimental studies that obtain identification from millions of neighborhood moves, Chetty and Hendren (2015) find that boys' outcomes vary more across areas than girls, and that boys' outcomes - particularly employment rates in early adulthood - are differentially sensitive to neighborhood exposure.

Our paper confirms the pattern reported by Chetty and Hendren (2015) and Chetty et al. (2016a) and expands it along multiple dimensions. Most centrally, we demonstrate that although neighborhood environment and family environment are highly correlated, they appear to make substantial independent contributions to the gender gap in behavioral and educational outcomes.

\footnotetext{
${ }^{14}$ Greve et al. (2015) find that fetal exposure to Ramadan has a larger negative impact on the achievement scores of Muslim girls than boys in Denmark. Hoynes et al. (2016) find that improvements in in utero nutrition have a larger positive impact on economic self-sufficiency (an omnibus skills and earnings measure) and overall good health among exposed girls than boys, while impacts for the prevalence of metabolic syndrome show slightly greater benefits for exposed boys than girls. In a developing country context, Maccini and Yang (2009) examine the effect of weather shocks around the time of birth on Indonesian women and men, finding positive effects on health, height, schooling, and household wealth in adulthood among women but not men. Field et al. (2009) find that prenatal iodine supplementation during the first trimester increased completed schooling by as much as half a year, with generally stronger effects for girls than boys. Cullen et al. (2015) review a large body of U.S., international, and time series data on the male/female post-natal mortality gap. In wealthy countries such as the U.S., it is unambiguously the case that poorer post-natal conditions (measured by income, education, or prevalence of poverty) are associated with higher differential male mortality. Their paper does not explore mechanisms.
} 
Accounting parametrically or non-parametrically for the county level community quality differences documented by Chetty and Hendren (2015) and Chetty et al. (2016a), or for zip code level measures of neighborhood quality, we find that the bulk of the within-sibling, SES gradient in the gender gap remains - even while schools and neighborhoods also have independent differential effects by gender. This leads to our broader conclusion that diminished child-rearing environments - whether at the household, school or neighborhood level - appear particularly pernicious for boys.

\section{Data and descriptive statistics}

\section{$1.1 \quad$ Principal data sources}

Data for our main analysis are drawn from two sources: the universe of birth certificates for the state of Florida for years 1992 through 2002, sourced from the Florida Bureau of Vital Statistics; and linked school records from the 1995-96 through the 2012-13 school years from the Florida Department of Education Data Warehouse for children in these birth cohorts who attended the Florida public schools. ${ }^{15}$ The Florida Departments of Education and Health matched birth certificate data to schooling records for the purposes of this project using first and last names, exact date of birth and social security number. Of the 2,047,663 births recorded by the Florida Bureau of Vital Statistics during 1992-2002, 1,652,333 were observed in Florida public school data, representing an 80.7\% match rate. The match rate is almost identical to the percentage of children who are born in Florida, reside there until school-going age, and attend public school, as computed from data from the decennial Census and American Community Survey for years 2000 through 2009. ${ }^{16}$

Florida birth certificates enumerate demographic characteristics of the mother (including education, marital status and information whether birth was paid for by Medicaid), health and demographic characteristics of the the newborn, and demographic characteristics of the father if he appears on the birth certificate. ${ }^{17}$ We use the birth certificate data to create three proxies of family environment: mother's completed education; birth paid by Medicaid, which we use as an indicator of poverty status at the time of birth; and family structure at the time of birth. We use three categories of family structure: parents married at birth (married); unmarried but the father's name appears on the birth certificate (father present); and unmarried and the father's name does not appear on the birth certificate (father absent). ${ }^{18}$ We also construct a single composite SES measure

\footnotetext{
${ }^{15}$ The bulk of our analysis is limited to children born between 1994 and 2002, as we only observe neighborhood measures, proxy for income (Medicaid indicator) and sibship status for children in those birth cohorts. We make use of data from 1992 and 1993 in order to study high school graduation, since our most recent data extract covers outcomes through the high school class of 2012/2013.

${ }^{16}$ Figlio et al. (2013) provide further details on the matching process as well as extensive validity checks on the matching procedure.

${ }^{17}$ In the very small number of cases $(<100$ sibling pairs) where the measured race or ethnicity of the mother on siblings' birth certificates do not match, we assign the race and ethnicity of the first-born child.

${ }^{18}$ For children born to unmarried parents, information about the father appears on the birth certificate only if he claims paternity, so presence/absence refers to the father's paternity status, not his physical presence/absence at delivery. Paternity acknowledgment grants fathers legal rights to their children as well as obligates fathers to pay child support. Prior research has documented that paternity acknowledgment is associated with greater father involvement - measured by visitations and payments of child support - relative to births to unmarried mothers without
} 
based on a principal components analysis of family structure/marital status, Medicaid-funded birth, and maternal education (in years). Details on the construction of this measure are documented in Online Appendix Table O1.

School records include third through eighth grade Florida Comprehensive Assessment Test (FCAT) math and reading scores (which we average together), as well as records of absence rates and suspensions during each academic year. In addition, for some cohorts of children, the Florida Department of Education recorded the results of a universally-administered kindergarten readiness assessment. ${ }^{19}$ Each child in the sample can contribute multiple observations, one per each year observed in each grade. We discuss both birth characteristics and educational outcomes at length below. Following Autor et al. (2016b), we use school-level gain scores calculated by the Florida Department of Education - schools' average contribution to student outcomes - to measure the quality of elementary and middle schools that children attend. For each school, we compute a simple average of the observed gain scores between 2002 and 2013, which we then convert into a percentile rank in the observed gains distribution across Florida schools. ${ }^{20}$ For each student, we construct the cumulative quality of schools attended from grade three through eight, equal to a years-weighted average of the rank quality of all schools attended to that point. To measure the quality of neighborhoods, we employ the Chetty-Hendren (2015) measure of county economic mobility associated with the zip code of the mother's residence at the time of birth as well as the median income in the zip code, computed from the 2000 Census.

\subsection{Sample selection}

Table 1 presents summary statistics for the universe of Florida children born to white non-Hispanic, black non-Hispanic, and Hispanic mothers for the years 1994 through 2002 (column 1), which for compactness, we will refer to as white, black, and Hispanic for the remainder of the paper. ${ }^{21}$ The second column drops the $4 \%$ of records that are missing key variables. The third column includes

paternity acknowledgment (Mincy et al., 2005). Our expectation is that the greatest degree of paternal involvement occurs when the parents are married and the lowest degree of paternal involvement occurs when fathers are not present on the birth certificate.

${ }^{19}$ The Florida Department of Education recorded kindergarten readiness measures for entering kindergarteners in two sets of kindergarten cohorts: those who entered kindergarten in fall 2001 and before, and those who entered kindergarten in fall 2006 or later. In the early round of kindergarten readiness assessments, teachers administered a readiness checklist of academic and behavioral skills designed by the state Department of Education with a dichotomous ready/not-ready measure recorded in state records. In the later round of kindergarten readiness, the state universally implemented the DIBELS assessment aimed at measuring early pre-literacy skills; this is a discrete measure that we dichotomize using the approach described in Figlio et al. (2013) so that the percent identified as kindergarten ready corresponds to the percentage in the later assessment. The birth cohorts between 1994 and 2002 who took the kindergarten readiness assessment, therefore, are those born between 1994 and 1996 and those born between 2000 and 2002.

${ }^{20}$ We average the three gain score measures consistently produced over the entire period: percent making gains in reading, percent making gains in math, and percent of bottom quartile students making gains in reading. These scores are available for download at schoolgrades.fldoe.org.

${ }^{21}$ We exclude the 2.7 percent of births where mothers do not identify as white, black, or Hispanic. We also exclude the 24 percent of births that are to immigrant mothers since these families are too heterogeneous to defy any simple characterization. In Autor et al. (2016a) we additionally explored gender gaps among immigrant families. Gender gaps among children born to immigrant mothers fall in between the black and Hispanic gaps and the proportion of the gap that is explained by the differential effect of family SES on boys is similar to that of the Hispanic population. 
the $81 \%$ of column 2 records that were matched to Florida school records; those not matched to school records have either left the state of Florida or attended private school in the state. Column 4 contains the subset of column 3 records with a valid third-grade test score, while column 5 presents the subset of column 4 records with matched siblings.

Relative to the population of Florida births (column 1), limiting the sample to birth records with complete data (column 2) has almost no effect on birth demographics. Restricting further to births that subsequently appear in Florida public school records (column 3) and eventually obtain a third grade test score (column 4) increases the share of mothers who are black, younger, less educated, and unmarried at the time of childbirth. These compositional changes are consistent with the greater cross-state mobility of high SES adults and higher private school attendance rates of their children (Molloy et al., 2011). While the matched sample represents a more disadvantaged population than the full sample, the gender composition of those matched to school records does not differ appreciably from the full population of births, and there are virtually no differences in birthweight between the full population and the matched sample. ${ }^{22}$ When we further limit the sample to matched sibling births (column 5), we observe relatively fewer white mothers, slightly more college educated mothers, and slightly more births with no paternity established.

Table 2 summarizes key demographic characteristics for our main sample observed either at birth or during K-12 schooling according to the race and ethnicity of the mother. These include mother's education, the Medicaid funding indicator, and paternal status at birth (married; paternity claimed (father present); and no paternity claimed (father absent)), the median income in the zip code of the mother's residence at the time of birth, the Chetty-Hendren (2015) measure of county economic mobility associated with that zip code, and the rated quality of Florida public schools subsequently attended. The pronounced contrasts among race and ethnic groups in each of these measures highlights the degree to which family disadvantage differs systematically across these broad demographic groups. For example, the fraction of children born with no claimed paternity ranges from 7 percentage points among whites to 43 percentage points among blacks. Comparisons of maternal education, Medicaid-funded births, and zip code income reveal similarly stark contrasts, underscoring that comparisons across race and ethnic groups are also implicitly comparisons across education groups, income levels, and family types. To overcome these confounds, we assess the impact of education, income and family structure on children's outcomes by leveraging withinfamily, cross-gender contrasts; these within-family contrasts implicitly hold constant parental race, education, poverty, and family structure (among many other factors).

\subsection{Sibling gender gaps by family and maternal characteristics}

Figure 1 sets the stage for our empirical inquiry by plotting gender contrasts in siblings' educational and behavioral outcomes by family demographics along four dimensions: kindergarten readiness (a behavioral and academic measure); school absence rates (a behavioral measure); combined stan-

\footnotetext{
${ }^{22}$ The slight reduction in the fraction of male births (from $51.3 \%$ to $50.5 \%$ ) as the sample is restricted to more disadvantaged mothers is consistent with the Trivers-Willard (1973) hypothesis.
} 
dardized math and reading scores (an academic measure); and on-time high school graduation rates (a labor market measure). Kindergarten readiness and high school graduation are observed for a subset of cohorts. Appendix Tables A1 and A2 provide the corresponding summary statistics. Absence rates and math/reading scores are observed during grades three through eight for 1994 to 2002 cohorts; kindergarten readiness is observed for cohorts born between 1994 and 1996 and those born between 2000 and 2002; and high school completion is observed for the 1992 and 1993 cohorts, which had reached the age of on-time high school completion by the end of our sample.

Panel A of Figure 1 highlights the cross-race and cross-ethnicity differences in the gender gap in academic and behavioral outcomes. Among children born to white mothers, the boy-girl gap in the absence rate is 0.14 percentage points, the boy-girl gap in middle school math and reading scores is -0.04 standard deviations (SDs), and the boy-girl gap in both kindergarten readiness as well as on-time high school graduation is about -6 percentage points (i.e., girls start kindergarten more ready to start school, and also have higher graduation rates). The gap in each of these outcomes is monotonically widening (becoming less favorable to boys) as we move the focus of comparison from whites to Hispanics to blacks. Among children of black mothers, the boy-girl gaps in absences, math and reading scores, and on-time graduations are, respectively, 0.53 percentage points, -0.14 SDs, and -12.7 percentage points - in each case, two to four times as large as among whites. The boy-girl gap in kindergarten readiness among blacks is -8.4 percentage points, nearly one and a half the size of the boy-girl gap among white children. The gender gap in outcomes among children of Hispanics mothers fall roughly in between those of whites and blacks on these measures.

Panels B through D of Figure 1 plot analogous contrasts by maternal education (high school dropout, high school graduate or some college, four year college degree or higher), family structure at birth (father absent, father present, married), and SES quartile (see Online Appendix O1). ${ }^{23}$ The boy-girl deficits in behavioral and educational outcomes are robustly larger in families with greater disadvantage, whether measured by maternal education, family structure, or the SES composite.

\section{Empirical framework}

Our empirical objective is to isolate the causal effect of family disadvantage on the gender gap in childhood behavioral and educational outcomes. Since family types are not randomly assigned to children, we propose an identification strategy that recognizes the intrinsic correlation between parents and children operating through both environmental and hereditary channels.

Let $Y_{j b} \in\left\{Y_{j b}^{0}, Y_{j b}^{1}\right\}$ and $Y_{j g} \in\left\{Y_{j g}^{0}, Y_{j g}^{1}\right\}$ equal the potential outcomes of gender-discordant siblings, $b$ and $g$, born to mother $j$ whose socioeconomic status at the time of the children's birth is $D_{j} \in\{0,1\}$. For expositional simplicity, we treat $D_{j}$ as discrete (i.e., a family is either disadvantaged or advantaged), and we consider the case where $D_{j}$ is the same for both births, $D_{j}=D_{j b}=D_{j g}$.

\footnotetext{
${ }^{23}$ High school graduations are not plotted by SES and family structure since not all of our component measures of SES are available for the 1992 and 1993 birth cohorts, which are the cohorts for whom we currently observe high school graduation. For these two cohorts, we lack information on Medicaid receipt and cannot differentiate between paternal presence versus paternal absence among births to unmarried mothers.
} 
We relax both assumptions in the estimation. ${ }^{24}$ For each sibling pair $j$, we observe only one set of potential outcomes as a function of family disadvantage, $D_{j}$ :

$$
Y_{j b}=Y_{j b}^{1} \times D_{j}+Y_{j b}^{0} \times\left(1-D_{j}\right) \text { and } Y_{j g}=Y_{j g}^{1} \times D_{j}+Y_{j g}^{0} \times\left(1-D_{j}\right) .
$$

We expect that potential outcomes will differ between brothers and sisters within a family,

$$
E\left[Y_{j b}^{1}\right] \neq E\left[Y_{j g}^{1}\right], E\left[Y_{j b}^{0}\right] \neq E\left[Y_{j g}^{0}\right]
$$

and further, that potential outcomes will not be independent of family disadvantage for either boys or girls,

$$
E\left[Y_{j s}^{1} \mid D_{j}=1\right] \neq E\left[Y_{j s}^{1} \mid D_{j}=0\right], E\left[Y_{j s}^{0} \mid D_{j}=1\right] \neq E\left[Y_{j s}^{0} \mid D_{j}=0\right] \text { for } s \in\{b, g\}
$$

These confounds mean that absent random assignment of disadvantage to households, simple within or between-family contrasts will not provide a valid causal estimate of the effect of family disadvantage on outcomes $Y$ for either boys or girls. To see why, consider the non-experimental contrast between the outcomes of boys born to disadvantaged versus advantaged families. This contrast is

$$
\begin{aligned}
E\left[Y_{j b} \mid D_{j}=1\right]-E\left[Y_{j b} \mid D_{j}=0\right]= & \left\{E\left[Y_{j b}^{1} \mid D_{j}=1\right]-E\left[Y_{j b}^{0} \mid D_{j}=1\right]\right\} \\
& +\left\{E\left[Y_{j b}^{0} \mid D_{j}=1\right]-E\left[Y_{j b}^{0} \mid D_{j}=0\right]\right\},
\end{aligned}
$$

where the first bracketed term on the right-hand side is the average causal effect of family disadvantage on outcome $Y$ for disadvantaged boys, and the second bracketed expression is a bias term, stemming from differences in potential outcomes between boys born to disadvantaged versus advantaged families. Both intuition and data suggest that this bias term will be non-zero (per equation 3): children born to advantaged families are likely to have genetic and health advantages at birth that may yield more favorable outcomes, holding child-rearing circumstances constant. If so, we cannot estimate the causal effect of family disadvantage on children's outcomes simply by contrasting children born to disadvantaged and advantaged families. ${ }^{25}$

To circumvent this identification challenge, we select as our outcome of interest the difference in the gender gap in sibling outcomes, $\hat{Y}_{j}^{1} \equiv Y_{j b}^{1}-Y_{j g}^{1}$ and $\hat{Y}_{j}^{0} \equiv Y_{j b}^{0}-Y_{j g}^{0}$, between advantaged and disadvantaged families. Our hypothesis is that developmental outcomes of boys are more elastic than those of girls to the quality and quantity of family inputs - hence, the same exposure to family advantage or disadvantage affects boys and girls differently. We can identify the causal effect of family disadvantage on the gender gap under the following assumption:

Assumption 1. (Unconfoundedness) $\hat{Y}_{j}^{1}, \hat{Y}_{j}^{0} \perp D_{j}$. The latent gap in childhood outcomes between brothers and sisters is as good as randomly assigned to families.

Under Assumption (1), any observed variation in the gender gap that differs systematically

\footnotetext{
${ }^{24}$ For exposition, we focus on gender-discordant siblings. But our empirical analysis includes all siblings, regardless of gender discordance. These additional observations help to identify the relationships between our outcomes and other attributes that vary across individuals within families, such as age and parity.

${ }^{25} \mathrm{By}$ a similar argument, the contrast between brothers and sisters within a family does not identify a parameter of interest since, within families, we expect potential behavioral and educational outcomes to differ systematically between boys and girls (equation 2).
} 
across family types will reflect the causal effect of family advantage on the gender gap (rather than a reification of the latent gap). ${ }^{26}$ Assumption (1) permits identification of the causal effect of family disadvantage on the gender gap accordingly by contrasting within-family, cross-sibling differences in outcomes across disadvantaged and advantaged families:

$$
\begin{aligned}
E\left[\hat{Y}_{j}^{1} \mid D_{j}=1\right]-E\left[\hat{Y}_{j}^{0} \mid D_{j}=0\right] & =E\left[Y_{j b}^{1}-Y_{j g}^{1} \mid D_{j}=1\right]-E\left[Y_{j b}^{0}-Y_{j g}^{0} \mid D_{j}=0\right] \\
& =E\left[Y_{j b}^{1}-Y_{j g}^{1} \mid D_{j}=1\right]-E\left[Y_{j b}^{0}-Y_{j g}^{0} \mid D_{j}=1\right],
\end{aligned}
$$

where the second equality above follows from Assumption (1). This double-difference eliminates the dependency between family disadvantage and potential outcomes by contrasting brothers and sisters; it further eliminates the dependency between gender and potential outcomes (arising from intrinsic gender differences) by contrasting the sibling gender gap across advantaged and disadvantaged families. Under unconfoundedness, equation (5) provides an unbiased estimate of the causal effect of family disadvantage on boys relative to girls.

Is this unconfoundedness assumption plausible? Assume for example, in violation of our identifying assumption, that family SES differentially affected the fetal development of sons relative to daughters - which could occur if the male fetus is more sensitive than the female fetus to maternal stress levels during pregnancy. In this case, the contrast formed in equation (5) would confound any causal effect of family disadvantage on the gap in outcomes between boys and girls with the differential in utero impact of maternal stress on the subsequent development of children of each sex. Following the fundamental problem of causal inference, this assumption is not directly testable. But we can explore its plausibility by assessing whether gender gaps in neonatal health, measured by birthweight, prenatal care, maternal health, and Apgar scores, differ across families of varying socioeconomic levels. As documented in section 4, we find no evidence that these gaps vary substantially or systematically with family disadvantage. ${ }^{27}$

Equation (5) also highlights an important feature of our identification approach. Imagine hypothetically that we were to estimate this key equation by calculating the double-difference in the boy-girl gap among children from disadvantaged relative to advantaged families without using sibling contrasts:

$$
\begin{aligned}
& \left(E\left[Y_{j b} \mid D_{j}=1\right]-E\left[Y_{j g} \mid D_{j}=1\right]\right)-\left(E\left[Y_{j b} \mid D_{j}=0\right]-E\left[Y_{j g} \mid D_{j}=0\right]\right)= \\
& \quad\left\{E\left[Y_{j b}^{1} \mid D_{j}=1\right]-E\left[Y_{j g}^{1} \mid D_{j}=1\right]\right\}-\left\{E\left[Y_{j b}^{0} \mid D_{j}=1\right]-E\left[Y_{j g}^{0} \mid D_{j}=1\right]\right\} \\
& \quad+\left\{E\left[Y_{j b}^{0} \mid D_{j}=1\right]-E\left[Y_{j b}^{0} \mid D_{j}=0\right]\right\}-\left\{E\left[Y_{j g}^{0} \mid D_{j}=1\right]-E\left[Y_{j g}^{0} \mid D_{j}=0\right]\right\} .
\end{aligned}
$$

The first line following the equal sign in this expression is the causal effect of interest. The second line is a pair of bias terms corresponding to the difference in potential outcomes between boys and girls from disadvantaged versus advantaged families. If potential outcomes are not independent of family disadvantage, as per equation (3), then each of these terms will be non-zero. The composite

\footnotetext{
${ }^{26}$ It is sufficient for our purposes that the latent gender gap is uncorrelated with our measures of family disadvantage. Thus, Assumption (1) is stronger than we require but nevertheless appears plausible, as we document further below.

${ }^{27}$ Furthermore, the multiple studies cited in the Introduction assessing the impact of in utero shocks on post-natal outcomes generally find that adverse impacts are slightly more pronounced for girls than boys, which would work against a finding that post-natal family disadvantage is differentially detrimental to boys.
} 
bias expression will be non-zero if the two bias terms are not of equal magnitudes. In practice, this form of bias may arise if family structure is endogenous to the sex of children, as suggested by Dahl and Moretti (2008), leading to the possibility that the potential outcomes of girls and boys may be differentially correlated with family disadvantage. We address this confound by limiting our analysis to families with two or more children and, further, by sweeping out unobserved family attributes using within-family comparisons. ${ }^{28}$

\section{$2.1 \quad$ Implementation}

We use a simple regression framework to quantify our motivating observation that there is a substantially greater female advantage in behavioral and early academic preparedness among children of black and Hispanic households relative to children of white households. This observed gap serves as a benchmark for assessing the explanatory power of our subsequent models. To obtain this baseline, we estimate the following within-family gender gap regression:

$$
\begin{aligned}
Y_{i j}= & \alpha_{j}+\beta_{1} \operatorname{Boy}_{i}+\beta_{2}\left(\text { Boy }_{i} \times \text { Black }_{j}\right)+\beta_{3}\left(\text { Boy }_{i} \times \text { Hispanic }_{j}\right) \\
& +\mathbf{F}_{j}^{\prime} \psi+\mathbf{X}_{i}^{\prime} \lambda+e_{i j},
\end{aligned}
$$

where $Y_{i j}$ represents an outcome for child $i$ born to mother $j$, Boy $_{i}$ is an indicator variable for whether the child is male, and Black $j$ and Hispanic ${ }_{j}$ are indicators for whether the mother of child $i$ belongs to one of those mutually exclusive race or ethnic categories, with white, non-Hispanic mothers serving as the reference category. The regression model includes family fixed effects $\alpha_{j}$, which sweep out mother-specific variation that is constant across sibling births, such as shared genetics or common elements of the home environment. The vector $\mathbf{F}_{j}$ controls for maternal and family environment characteristics that may vary across births $i$, including mother's education, Medicaid receipt, age, and marital/paternity status. The vector $\mathbf{X}_{i}$ additionally controls for time-invariant child attributes, including birth order and month and year of birth.

In this initial descriptive regression model, the coefficient $\beta_{1}$ measures the brother-sister difference in outcome $Y$ for the reference category of children of white, non-Hispanic mothers. The coefficients $\beta_{2}$ and $\beta_{3}$ correspond to the demographic differentials of interest, indicating how the brother-sister gap varies with the race-ethnicity status of the mother. The main effect of family socioeconomic status (SES) $D_{j}$ is absorbed by a vector of mother fixed effects $\alpha_{j}{ }^{29}$ These SES effects are constrained to be constant across genders in the baseline specification.

In a second step, we apply our proposed identification strategy to estimate the effect of family

\footnotetext{
${ }^{28} \mathrm{~A}$ concern remains that we are introducing selection into our sample by limiting it to mothers who have at least two children. Evidence from Dahl and Moretti (2008) suggests that a first born girl increases women's total fertility, though the effect for the marginal second child is extremely small. We also perform our main analysis using all singletons, however, and find largely comparable results.

${ }^{29}$ Our analysis permits measures of family disadvantage (mother education, Medicaid indicator, father absent/present/married) to vary across births, but all of the results are robust to either restricting the sample to mothers with stable characteristics across births, or to assigning the characteristics of the first birth (maternal education, Medicaid indicator, marital status) to all subsequent births. Our primary models include main effects for disadvantage to account for this variation and thus allow $D_{j}$ to also take an $i$ subscript. We suppress this notation here for simplicity.
} 
disadvantage on the gender gap in academic and behavioral outcomes by augmenting the baseline model to permit the effect of family disadvantage $D_{j}$ to differ by child gender:

$$
\begin{aligned}
Y_{i j}= & \alpha_{j}+\beta_{1}^{\prime} \operatorname{Boy}_{i}+\beta_{2}^{\prime}\left(\operatorname{Boy}_{i} \times \operatorname{Black}_{j}\right)+\beta_{3}^{\prime}\left(\operatorname{Boy}_{i} \times \text { Hispanic }_{j}\right) \\
& +\beta_{4}^{\prime}\left(\operatorname{Boy}_{i} \times D_{j}\right)+\mathbf{F}_{j}^{\prime} \psi+\mathbf{X}_{i}^{\prime} \delta+e_{i j} .
\end{aligned}
$$

Here, $D_{j}$ is a measure of family disadvantage and the coefficient $\beta_{4}^{\prime}$ on interaction term $\left(\operatorname{Boy}_{i} \times D_{j}\right)$ captures the differential responsiveness of boys to family disadvantage. The interpretation of $\beta_{4}^{\prime}$ as the causal effect of family disadvantage on the gender gap in cognitive and behavioral outcomes hinges critically on the unconfoundedness assumption. We assess the plausibility of this assumption in section 4 by estimating Equation (8) for pregnancy health and at-birth child health outcomes.

Through a comparison of the coefficients from the within-family gap model from Equation (7) and the augmented model from Equation (8), we infer what fraction of the race-ethnicity gradient in the gender gap is explained by the differential effect of family disadvantage on boys. Specifically, we compare $\beta_{2}$ to $\beta_{2}^{\prime}$ and $\beta_{3}$ to $\beta_{3}^{\prime}$. Take, for example, the comparison of the black-white gender gap in the within-family gap model relative to the augmented model, as estimated by $\beta_{2}$ and $\beta_{2}^{\prime}$, respectively. If we find that the black-white gender gap declines when we permit family disadvantage to differentially affect boys, i.e. $\beta_{2}^{\prime}$ is smaller in (absolute) magnitude than $\beta_{2}$, we would attribute this to the fact that disadvantage exerts a disproportionate negative effect on boys relative to girls and, critically, is more prevalent among black than white families.

Our main estimates use the population of Florida mothers who give birth to two or more children in the observed years, allowing us to achieve identification of the boy main effect (and interactions) while including family fixed effects. To assess whether this identification strategy is likely to limit the generalizability of the findings, we take two further steps in Appendix Table A3: estimating models that exclude family fixed effects on the siblings sample; and estimating models without family fixed effects on an expanded sample that includes all singleton births. In practice, these three specifications (siblings with family fixed effects, siblings without family fixed effects, and all singleton births without family fixed effects) yield largely comparable results.

Equation (8) imposes the restriction that the impact of disadvantage on the gender gap in outcomes is constant across race and ethnicity groups - that is, the coefficient on $\mathrm{Boy}_{i} \times D_{j}$ does not require a race-ethnicity subscript. If this restriction does not hold, the precise contribution of disadvantage to cross-group variation in the gender gap may be ambiguous for the simple reason that the share of the cross-group gap explained by disadvantage will depend upon which group-specific Boy $_{i} \times D_{j}$ slope is used for the calculation. We test this restriction of constant slopes in section 4.2 and find that it is generally supported for most but not all outcomes. We elaborate upon and interpret this finding below. 


\section{Main results: Gender gaps in behavioral and academic outcomes}

Our main analysis estimates the causal effect of family disadvantage on the gender gap in two behavioral outcomes - absence and suspension rates - and one academic outcome, combined math and reading standardized test scores, all observed in elementary through middle school, as well as for kindergarten readiness. We then assess whether these results for medium-term outcomes carry forward to a directly market-relevant outcome: high school completion.

\subsection{Elementary and middle school behavioral and academic outcomes}

\section{Behavioral outcomes: Absences and suspensions}

The first column in panel A of Table 3 reports estimates of Equation (7) for the gender gap in absence rates, by mother's race-ethnicity. The conditioning variables for this model include mother fixed effects, mother's age, education, Medicaid indicator, and marital status at birth (married, father present, father absent), and child's birth order, birth month, and birth year. The coefficient on the boy main effect, corresponding to the conditional mean difference between white, non-Hispanic boys and their sisters, indicates that boys from this ethnic group have grade three through eight absence rates that average 0.22 percentage points higher than those of their sisters. Confirming the qualitative patterns in Figure 1, the coefficients on the interactions between the boy main effect and each of the race-ethnicity main effects reveal that the boy-girl gap in absence rates is higher by 0.33 and 0.14 percentage points for black and Hispanic siblings, respectively. We refer to these interactions as excess gender gaps, denoting the unexplained additional gender gaps detected among blacks and Hispanics siblings relative to white siblings from families with the same maternal education, Medicaid status, and family structure/marital status.

Column 2 augments this model with interactions between the boy indicator and variables that proxy for family advantage at birth - parental status, poverty, and maternal education, as per Equation (8). Consistent with our primary hypothesis, the interaction terms between the boy dummy and various measures of advantage are uniformly negative, indicating that the brothersister gap in absence rates is smaller in more advantaged families. Relative to children born to absent fathers, the boy-girl gap in absences is 0.20 percentage points lower where the father claimed paternity, and 0.24 percentage points lower where the parents were married at the child's birth. Higher levels of maternal education and family income predict additional reductions in this gap of up to 0.15 percentage points. Noting that these effects are additive, the model implies that the boy-girl gap in school absences is half a percentage point lower among children born to married parents with college-educated mothers whose births were not funded by Medicaid relative to those born to father-absent families with non-high school mothers who utilized Medicaid payments for birth.

Are effects of this magnitude economically consequential? Following our discussion above, a useful benchmark for answering this question is to scale these effects relative to the excess gender gaps among black and Hispanic siblings. If the causal effect of family disadvantage on the gender 
gap is economically consequential and if disadvantage is systematically greater among minorities than whites, then including interactions between gender and disadvantage will reduce these excess gender gaps. Column 2 confirms this conjecture. Simply including interactions between gender and family structure, Medicaid indicator, and maternal education reduces the excess black gender gap by more than half, from 0.33 to 0.13 percentage points, with comparable proportional declines (from a smaller base) among Hispanic siblings. This pattern indicates that the bulk of the black-white excess gender gap is explained (in the sense of our decomposition above) by the disparate effect of family disadvantage on boys relative to girls. If our causal framework above is valid - a subject we return to below - we can infer that half or more of the excess gender gap in absenteeism in black families is due to the differential adverse effect of disadvantage on boys relative to girls rather than factors specific to black families per se. The role that disadvantage plays in the excess gender gaps for Hispanic families is equally non-trivial.

To streamline exposition, column 3 of the table subsumes the interaction terms in the first five rows of column 2 into a single composite SES measure based on a principal components analysis of family structure/marital status, the proxy for poverty, and maternal education (in years). Construction of this measure is documented in Online Appendix Table O1. Similar to the higher-dimensional specification in column 2, the interaction between SES and gender reduces the black excess gender gap in absences from 0.33 to 0.17 . This reduction follows directly from two facts: the SES gap between white and black families and the differential effect of family disadvantage on boys. Figure 2 panel A plots the SES gradient in the gender gap with a bin-scatter of the boy-girl gap in absences against the composite SES index while conditioning on all of the covariates used in the corresponding estimate in Table 3 (column 3 of panel A). This figure underscores the robust SES gradient in the sibling gender gap in absences. ${ }^{30}$

While our preferred estimates focus on siblings and include mother fixed effects, it is useful to assess the degree to which the estimated relationships change depending on the inclusion of fixed effects and the expansion of the sample to include all singleton births. Appendix Table A3 explores these permutations. With and without family fixed effects, and even when expanding the sample to all singleton births, the estimates reinforce the prior conclusions: the boy-girl gap in absence rates is larger among black and Hispanic families than among white families; conditional on race and ethnicity, the boy-girl gap is larger in lower SES families (lower maternal education, birth paid by Medicaid, greater share of absent or unmarried fathers); and inclusion of the composite SES index substantially reduces these excess gender gaps. The similarity of the results from the specifications with and without family fixed effects suggests that within-family contrasts are not central to estimation of the causal effect of family disadvantage on the gender gap in youth outcomes. As discussed above, due to ex ante concerns regarding the endogeneity of family types when contrasting children across genders and families, our preferred specification uses family fixed effects.

We extend this exercise to consider school suspensions in panel B of Table 3. Approximately 12

\footnotetext{
${ }^{30}$ The plot includes point estimates for the larger SES bins only, and also reports the slope of an OLS regression fit to all 94 points. This slope is close to the corresponding estimate in Table 3 , but does not match exactly given the differences in the specifications.
} 
percent of Florida public school children are suspended for at least one day per school year during grades 3 through 8 (Table A1). But suspension rates are twice as high among boys as girls (16.6 versus 8.0 percent), and the gender gap is almost twice as large among blacks as whites (13.1 vs. 7.0 percent). Panel B of Table 3 demonstrates that this pattern is replicated within families: white boys are 7.0 percentage points more likely to be suspended than their sisters, while black boys are 13.4 percentage points more likely to be suspended than their sisters.

The bin-scatter in Figure 2 panel B documents that conditional on race-ethnicity, the brothersister gap in suspensions is far smaller in families where children are born to married parents, where mothers are better educated and family income is higher. Accounting for race and ethnicity, the column 2 estimate of panel B implies that the brother-sister gap in suspensions is more than 10 percentage points lower in the most relative to the least advantaged families. Collapsing our multiple indicators of family disadvantage into the composite SES index in column 3 yields strong evidence of an SES gradient in the gender gap: each standard deviation increase in disadvantage (a reduction in the SES index of 1.57) increases the within-family boy-girl gap in suspensions by 2.2 percentage points. Accounting for the differential effect of disadvantage of boys relative to girls reduces the black excess suspension gap by more than 60 percent.

\section{Academic outcomes: Test scores in grades 3 throughout 8}

We measure academic performance using combined standardized mathematics and reading tests administered annually during elementary and middle school. ${ }^{31}$ Relative to siblings in white families, black and Hispanic boys perform worse than their sisters in mathematics and reading. Distinct from the two outcomes analyzed above (absences and suspensions), we find in panel $\mathrm{C}$ of Table 3 that family disadvantage contributes only modestly to the cross-race and cross-ethnic group variation in the gender gap in these educational measures. The various measures of family advantage generally have the expected sign (reducing relative boy-girl disadvantage in math and reading), but these measures are not consistently statistically significant. When combined into a composite measure, family SES is statistically significant but of modest economic magnitude (also see in the bin-scatter in Figure 2 panel C). Accounting for SES differences explains about 10 percent of the excess black-white gender gap in test scores. The substantially stronger effects for behavioral outcomes are consistent with findings from the Perry Preschool Program, which provided intensive early enrichment to lowincome minority children, leading to improved labor market and demographic outcomes in adulthood. The Perry Program did not have lasting impacts on IQ scores but did augment personality traits associated with labor market success (Heckman and Kautz, 2012).

\footnotetext{
${ }^{31}$ We combine mathematics and reading test scores for conciseness. When performing this analysis separately by subject, we find the same pattern of results, despite the fact that on average boys tend to outperform girls in mathematics and the reverse is true with regard to reading.
} 


\section{Early academic and behavioral outcome: Kindergarten readiness}

The Florida Department of Education recorded kindergarten readiness measures for entering kindergarteners in two sets of kindergarten cohorts - those who entered kindergarten in fall 2001 and before, and those who entered kindergarten in fall 2006 or later. ${ }^{32}$ We use these assessments to construct a dichotomous measure of readiness, based on the approach described in Figlio et al. (2013). Appendix Table A4 reports the estimates of the effect of family disadvantage on the gender gap in kindergarten readiness, with panel $\mathrm{C}$ presenting the estimates from the models including mother fixed effects. A one standard deviation increase in the SES index raises the readiness of boys relative to girls by almost a full percentage point. The inclusion of the interaction of boy and SES reduces the excess black-white disparity in kindergarten readiness among boys by 60 percent, and the adjusted differential is no longer statistically different from zero. Thus, the apparent effect of family disadvantage on the gender gap in schooling outcomes emerges as early as age five.

\section{Robustness}

We have performed numerous extensions that corroborate these findings, many of which are available as Online Appendix tables. To analyze the impact of family structure on the gender gap among siblings that experience arguably comparable family circumstances, we focused on both closely-spaced siblings and on the first two siblings observed in larger families, and obtained closely comparable effects. We also find comparable results when we assign each child born to a given mother the family structure (married, father present, father absent), poverty status, and maternal education observed at the first birth. To further unpack the complex role played by parental structure, we present a set of estimates for behavioral outcomes (i.e., absences and suspensions) in Appendix Table A5 in which we limit the sample to the approximately 36 percent of families with distinct fathers and the same mother. We then subdivide further into cases where family structure differs across births and cases where it does not. ${ }^{33}$ We estimate that marital status and, to a lesser degree, father presence, reduce absences and suspensions for brothers relative to sisters among siblings with distinct fathers born to the same mother, though these contrasts are not statistically significant.

We have also explored how the SES gradient in the gender gap in early outcomes evolves between grades three and eight using successive observations across grades (again, contrasting within families). Both the SES gap and the gender gap in absences, suspensions, and test scores increases year-over-year across grades within sibling pairs - that is, low SES children fare increasingly poorly relative to high SES children, and boys fare increasingly poorly relative to girls. We do not, however, find a consistent triple-interaction between these two forms of divergence. ${ }^{34}$

\footnotetext{
${ }^{32}$ The birth cohorts between 1994 and 2002 who took the kindergarten readiness assessment, therefore, are those born between 1994 and 1996 and those born between 2000 and 2002.

${ }^{33}$ In each instance where no paternity is claimed on a birth certificate, we treat the father as distinct.

${ }^{34}$ Of course, the third-level, within-family comparison makes substantial demands on the data.
} 


\subsection{High school completion}

The cumulative adverse effect of family disadvantage on the boy-girl gap in behavioral and academic outcomes in kindergarten through middle school suggests that disadvantage may also contribute to gender gaps in downstream market outcomes, including educational attainment and earnings. We test this hypothesis by analyzing a key market outcome that is available in our data: high school graduation. ${ }^{35}$ We ask whether family disadvantage affects the gender gap in high school graduation, and whether the impact of family disadvantage on third through eighth grade behavioral outcomes and test scores can account for this relationship. Of necessity, this analysis is limited to the oldest cohorts in our sample, principally those born in 1992 and 1993, for whom on-time graduations are presently available. For these cohorts, we do not observe information on Medicaid payments or paternity status among non-marital births and we additionally cannot link siblings.

Table 4 compares two OLS models fit to our Florida sample in order to assess the relationship between family advantage and the gender gap in high school graduations (summarized in Appendix Table A2): one containing the full set of family, mother, and child controls plus all boy $\times$ raceethnicity dummies; the second augmented with interactions between child gender and family advantage (here, mother's education and her marital status at the time of childbirth). ${ }^{36}$ The first column of panel A shows that the conditional mean on-time high school graduation rate of white boys is 6.0 percentage points below that of white girls, and that there is an additional (excess) gap of 6.7 and 2.2 percentage points for black and Hispanic boys, respectively. Among black and Hispanic students, these very large gender gaps in on-time high school graduation rates - ranging from 8 to 13 percentage points - are about equally accounted for by higher male dropout rates and higher male grade repetition rates (which may culminate in dropout or high school completion). For white students, the gender gap in high school graduation is attributed primarily to grade repetition.

The second column of each panel shows that the boy-girl disadvantage in high school completion is substantially smaller in more advantaged families. Conditional on race-ethnicity, the gender gap in on-time completions is 3.2 percentage points smaller for boys born to married mothers and 3.2 percentage points smaller again for boys with college-educated relative to high school dropout mothers. ${ }^{37}$

Given the substantial differences in the distribution of maternal education and the prevalence of in-wedlock childbearing between whites, blacks, and Hispanics (Table 2), it follows that the pronounced excess boy-girl disadvantage in high school graduations among non-whites is in part explained by the higher prevalence of disadvantage among minorities. A comparison of the boy $\times$

\footnotetext{
${ }^{35}$ While high school diplomas are not allocated by a market mechanism, high school degrees are priced in the labor market (see Autor 2014 for discussion).

${ }^{36}$ We do not apply the SES index to this exercise because we lack information on Medicaid payments and paternity status for the cohorts that have so far reached high school completion age.

${ }^{37}$ These results are consistent with the evidence in Chetty et al. (2016b) that find a differential advantage of growing up in a higher income family for boys' relative to girls' college attendance, employment, and earnings outcomes. In contrast, recent evidence by Brenoe and Lundberg (2017) from Denmark and Lundberg (2017) from the U.S. finds that the differential negative effect of family disadvantage on boys' adolescent outcomes does not persist into adulthood. Our data do not permit us to assess post-high school outcomes.
} 
race/ethnicity dummies in the even and odd-numbered columns confirms this intuition. Accounting for mother's education and marital status at child-birth reduces the black excess boy-girl disadvantage in high school graduations from 6.7 to 4.6 percentage points (30 percent), and reduces the Hispanic excess boy-girl disadvantage from 2.2 to 1.5 percentage points. We also conjecture that family disadvantage contributes to gender differentials in downstream market outcomes, including college-going and earnings, though these outcomes are not visible in our data.

To what degree do the upstream effects of SES on the gender gap in elementary and middle school disciplinary and academic outcomes plausibly account for the SES gradient in the on-time high school graduation gender gap? We cannot provide a complete answer to this question since we cannot exhaustively account or control for all causal pathways. We offer a simple benchmark, however, as follows. We first estimate the predictive relationship between on-time high school graduation observed in grade twelve and behavioral and educational outcomes observed in kindergarten and grades five through eight. ${ }^{38}$ We then apply our estimates of the causal effect of SES on upstream outcomes to the point estimates from this predictive model to obtain an implied effect of family disadvantage on high school graduations operating through these channels. ${ }^{39}$

Table 5 summarizes this exercise. The first panel presents a linear probability regression of on-time high school graduation $\left(H_{i j}\right)$ on our standard set of covariates (child sex, race-ethnicity interacted with child sex, birth order, birth year, and birth month, and mother's education, age and marital status at childbirth), augmented with a vector $\mathbf{T}_{i}$ of elementary and middle school behavioral and educational outcomes. These child-specific outcomes include: absence rates, suspension rates, combined standardized math and reading scores, each averaged over grades five through eight as well as the kindergarten readiness measure:

$$
\begin{aligned}
H_{i j}= & \mathbf{T}_{i}^{\prime} \pi+\beta_{1} \text { Boy }_{i}+\beta_{2}\left(\text { Boy }_{i} \times \text { Black }_{j}\right)+\beta_{3}\left(\text { Boy }_{i} \times \text { Hispanic }_{j}\right) \\
& +\mathbf{F}_{j}^{\prime} \psi+\mathbf{X}_{i}^{\prime} \lambda+e_{i j} .
\end{aligned}
$$

To facilitate comparison across coefficients, we standardize each of the predictive variables in $\mathbf{T}$ to have mean zero and unit variance. The regression coefficients therefore correspond to standardized effect sizes.

Estimates of Equation (9) in Table 5 find a highly significant predictive relationship between early behavioral and educational outcomes and subsequent on-time high school completions. Whether entered into the regression individually (columns 1 through 4) or as a group (column 5), the data unambiguously show that children who have higher absence and suspension rates and lower read-

\footnotetext{
${ }^{38}$ Absences and suspensions are observed starting in the 2002-2003 school year. For this exercise, we therefore utilize grades five through eight since we can observe both cognitive and behavioral measures for the full set of children born in 1992 and 1993, the cohorts for which we observe high school graduation.

${ }^{39}$ Our models for the predictive relationship between K-8 outcomes and subsequent high school graduations should be understood as descriptive rather than causal. We do not claim that any causal effect of family disadvantage on high school outcomes runs entirely through K-8 behavioral and academic outcomes. Due to the data limitations for the high school graduation sample, we re-estimated our main models from Table 3 on grade five through eight behavioral and academic outcomes. These yield coefficients of $-0.15(0.02),-2.39(0.13)$ and $0.01(0.00)$ for absences, suspensions, and test scores, respectively.
} 
ing/math scores during grades three through eight, as well as lower rates of kindergarten readiness, are significantly less likely to complete high school within four years. Notably, the standardized effect sizes of early behavioral measures (absences and suspensions) are larger than the effect sizes of math and reading scores, which are in turn substantially larger than the effect sizes of kindergarten readiness.

To benchmark the economic magnitude of these coefficients relative to those above, we scale them by the estimated impact of SES on each behavioral and educational outcome and report them (in standardized form) in panel B of Table 5. The final panel of Table 5 reports the implied impact of SES on high school graduations scaled by three metrics: a one-standard deviation increment to SES (row 1); the mean white-black SES differential (row 2); and the mean white-Hispanic SES differential (row 3).

There is a large implied impact of family disadvantage on the gender gap in high school graduations operating through early behavioral and educational outcomes. A one-standard deviation reduction in family SES is predicted to raise the boy-girl high school graduation deficit by approximately 1.32 percentage points. Since cross-group differences in SES are substantial, this mechanism also contributes to observed race and ethnic gaps in on-time high school graduations. The mean black-white and Hispanic-white SES differentials of $-1.63 \sigma$ and $-0.59 \sigma$, respectively, can explain 1.37 percentage points of the 6.7 percentage point excess boy-girl deficit in HS graduations among blacks and 0.49 percentage points of the 2.2 percentage point excess boy-girl deficit among Hispanics. These estimated contributions operating through upstream channels are about 60 percent as large as the direct effects of SES on the excess gender gap in high school completions that we estimate in Table 4.

The primary channel through which these effects appear to operate is through behavioral outcomes. Variation in the gender gap in reading/math achievement and kindergarten readiness makes a negligible contribution to the gender gap in HS graduations, jointly accounting for only 8 percent of the total explained by the fifth through eighth grade measures (versus 92 percent explained by absences and suspensions). A plausible interpretation of this finding is that, at least for boys, it is behavioral rather than formal skills deficits that inhibit high school completion, as posited by Heckman and Kautz (2012). Indeed, of the four measures considered, suspensions play the largest role in explaining the boy-girl deficit in high school completions (panel C). Notably, when we estimate models akin to panel A of Table 5 for high school dropout and five-plus years of high school attendance, we find that three-quarters of the estimated impact of behavioral measures on on-time graduation operates through differences in the likelihood of dropout. 


\section{Testing the identifying assumptions}

\subsection{Unconfoundedness}

\section{Earliest health outcomes: Neonatal health}

Interpretation of the above estimates as the causal effect of family disadvantage on the gender gap in children's outcomes hinges on the assumption that the latent gender gap in sibling outcomes is independent of family disadvantage. We provide a falsification test by analyzing the relationship between family disadvantage and the gender gap in the strongest available measure of neonatal health: birthweight. A large medical and economic literature summarized earlier finds birthweight to be robustly predictive of subsequent health, cognitive development, and labor market outcomes. In our sample, there are substantial birthweight differences across our three main demographic groups, as documented in Appendix Table A6. At birth, white children weigh an average of 265 grams (approximately 8.4 percent) more than black children, and about 100 grams more than Hispanic children. There are also substantial differences across these demographic groups in a number of other measures of birth outcomes.

Table 6 estimates Equations (7) and (8) for birthweight and a range of additional neonatal outcomes, including abnormal conditions of the newborn, maternal health, and adequacy of prenatal care, to assess whether the sibling gender gap in neonatal outcomes varies systematically with family disadvantage. If boys conceived by disadvantaged mothers are disproportionately less healthy than girls conceived by disadvantaged mothers, this could be reflected in birthweight and abnormal conditions. Alternatively, if maternal healthcare utilization or health are affected by (or correlated with) the gender of the fetus - perhaps due to son preference, as in Dahl and Moretti (2008) - our measures of prenatal care and maternal health might detect such a relationship.

For each of the birth outcomes, we report three specifications. The first estimates mean birthweight (or other birth outcome) differences between boys and girls, overall and by race-ethnicity, conditional on mother fixed effects. In the case of birthweight, the coefficient on the boy main effect indicates that white newborn boys weigh on average 124 grams more than their white newborn sisters. Despite the substantially lower average birthweight of black boys and girls, the black boy-girl birthweight gap within families is essentially identical to that of whites, just 6 grams less than that observed for whites. We also find very modest mean differences in the cross-sibling gender-racial gap in birthweight among Hispanic births relative to white births.

The second column of each panel tests for a relationship between family disadvantage and the gender gap in birth outcomes by adding a set of interactions between child sex, mother's education, proxy for poverty, and mother's marital status at childbirth. ${ }^{40}$ The boy-girl difference in birthweight is trivially (and not statistically significantly) larger - less than 2 grams - for births where the mother has at least a high school education, and is completely unrelated to family structure. An

\footnotetext{
${ }^{40}$ These variables are only minimally correlated with newborns' gender, and hence their main effects (though not their gender interactions) have essentially no impact on the estimated gender gaps in birth outcomes reported in the first column of each panel.
} 
economically and statistically insignificant relationship between measures of family advantage and gender is generally observed across all of the other birth outcomes. The third column of each panel subsumes these five interaction terms into our single composite SES measure described above. We again estimate a small and statistically insignificant relationship between family advantage and the gender gap in birthweight: a one standard deviation increase in the SES index (an increment of 1.57) predicts less than a two gram rise in the boy-girl differential in birthweight, an order of magnitude that is of negligible educational and health relevance. ${ }^{41}$ We also find no relationship between family SES and the gender gap in the remaining three health outcomes considered in Table 6: abnormal conditions at birth; maternal health problems; and prenatal care adequacy.

Online Appendix Figure O1 summarizes these patterns by presenting scatter plots of the relationship between family SES and the gender gap in neonatal health. Across multiple outcome measures, the relationship between family advantage and the gender gap in infant health is of trivial economic magnitude and is never statistically significant in within-family models. While neonatal outcomes such as the abnormal conditions at birth, prenatal care adequacy, and maternal health indicators are not as sensitive or reliable as birthweight as measures of neonatal health, these multiple outcomes nonetheless paint a consistent picture: there is no evidence that the gender gap in infant health at birth is correlated with family advantage.

We extend the analysis to a broader range of at-birth health outcomes in Online Appendix Table O2, including the clinical estimate of gestation in weeks; the five-minute Apgar score, which is a composite index of neonatal vital sign indicators collected in the minutes following delivery; the presence of congenital anomalies; and complications of labor and delivery. In Online Appendix Table O3, we further present estimates for the natural logarithm of birthweight and an index constructed from all of the birth outcomes. ${ }^{42}$ Across all outcomes, we find no evidence of a socioeconomic gradient in the gender gap in at-birth health. Notably, when we estimate the same birthweight models omitting family fixed effects (Online Appendix Table O4), the coefficients on interactions between SES measures and gender are in some cases statistically significantly different from zero, though in all cases of similar economic magnitude to those estimated using within family contrasts. These results suggest that the ex ante concerns regarding the endogeneity of family types to child gender - the rationale for the family fixed effect research design — does not appear to be consequential in practice.

As a further validation test, we summarize in Online Appendix Table O5 a set of augmented estimates for the relationship between SES and the sibling gender gap in behavioral and educational outcomes that control for the log of birthweight and its interaction with gender (in addition to all prior covariates). If there is any residual relationship between family disadvantage, infant birthweight and the gender gap in subsequent behavioral or educational outcomes, these augmented estimates

\footnotetext{
${ }^{41}$ Figlio et al. (2014) estimate that a $1,000 \mathrm{~g}$ increase in birthweight is associated with a 0.19 standard deviation increase in test scores in grades three through eight. The two gram differential we estimate in Table 6 is 0.2 percent as large, implying a hypothetical impact on test scores on the order of two ten-thousandths of a standard deviation.

${ }^{42}$ The natural logarithm of birthweight parameterization could matter since boys weigh more than girls on average within every demographic subgroup. Construction of each of these outcome variables is detailed in the corresponding table notes.
} 
should account for that relationship. Consistent with expectations, children with higher birthweight attain higher math and reading scores during third through eighth grades, though they also have higher suspension rates. Inclusion of infant birthweight has no discernible impact on the estimated SES gradient in the gender gap in behavioral and educational outcomes. ${ }^{43}$

\section{Medium-term health and behavioral outcomes: Physical versus cognitive/behavioral disabilities}

We obtain additional evidence regarding the evolution of the SES gradient in the gender gap by examining disability, as recorded by the Florida Department of Education. Although disabilities are typically detected many years post-birth, one can view these outcomes as providing a further diagnostic for the unconfoundedness assumption. We distinguish between cognitive/behavioral disabilities and physical disabilities. We hypothesize that physical disabilities are in many cases congenital or otherwise reflect underlying health differences. Cognitive/behavioral disabilities, by contrast, are likely to reflect learning and behavioral issues that, similar to absenteeism and suspensions, suggest the child is not thriving in school. Indeed, children often receive a cognitive/behavioral disability diagnosis during the assessment process for an Individualized Education Program (IEP). ${ }^{44}$

As reported in Appendix Table A6, 11 percent of children in our matched siblings sample have a physical disability and 13 percent have a cognitive/behavioral disability. ${ }^{45}$ Within families, boys are substantially more likely to be classified as physically or cognitively/behaviorally disabled than are their sisters. These gaps also differ across race and ethnic groups. The boy-girl gap in cognitive/behavioral disability is 50 percent larger among white than black siblings: 10.3 percentage versus 6.9 percentage points. Conversely, the boy-girl gap in physical disability is slightly smaller among blacks than white siblings: 4.9 versus 6.3 percentage points. ${ }^{46}$

Table 7 presents family fixed effects models for the incidence of cognitive/behavioral disabilities (panel A) and physical disabilities (panel B). Panel A finds a strong negative relationship between maternal education and non-Medicaid births and the female-favorable gap in cognitive and behav-

\footnotetext{
${ }^{43}$ We have also estimated models that control for a wider variety of birth outcome measures and their interactions with infant gender, and these additions leave our results fundamentally unchanged. Models with second and third level interactions between low birthweight (a dummy variable), SES, and gender find no consistent pattern of effects in sibling fixed effects models. While low birthweight is generally predictive of less advantageous behavioral and academic outcomes, it does not have a strong or consistent interaction with either SES, gender, or SES $\times$ gender.

${ }^{44}$ Cognitive and behavioral disabilities include language impaired; intellectual disability (subdivided in the early years of the data into educable mentally handicapped, trainable mentally handicapped, and profoundly mentally handicapped); developmental delay; specific learning disability; emotionally handicapped; severely emotionally disturbed; and autism spectrum disorders. Physical disabilities include orthopedically impaired; speech impaired; deaf or hard of hearing; visually impaired; hospital/homebound; dual-sensory impaired; traumatic brain injury; and established conditions identified by age two. Because "established conditions" could reflect either physical or cognitive conditions, we investigate whether our estimated relationships are sensitive to our categorization of established conditions as physical versus cognitive/behavioral. The results are robust to these different categorizations.

${ }^{45}$ Children can potentially have both physical and cognitive/behavioral disabilities. We assign each child with a disability to the "primary exceptionality" (physical vs. cognitive/behavioral) first observed (temporally) in their school record. In practice, this breakdown is nearly identical to using the last observed major category of disability.

${ }^{46}$ This physical disability differential is driven almost entirely by speech impairments. High-SES families appear to be more likely to identify and seek treatment for speech impairments, which are either more prevalent or more often treated in boys.
} 
ioral disabilities. This is also seen in the interaction between the boy dummy and the composite SES index (column 3). A one standard deviation increase in the SES index predicts a 1.1 percentage point reduction (t-ratio of 7.12) in the excess probability that a boy is classified as cognitively or behaviorally disabled. Accounting for SES reduces the excess gender gap in cognitive/behavioral disabilities between blacks and whites from 4.0 to 2.0 percentage points - a 50 percent reduction. Conversely, there is small and insignificant SES gradient in the gender gap in physical disability (panel B). The large and pronounced SES gradient in the gender gap in cognitive and behavioral disabilities, with no corresponding SES gradient in the gender gap in physical disabilities, supports the inference that post-natal environmental factors drive the SES gradient in the gender gap in educational and behavioral outcomes.

\subsection{Oaxaca restrictions}

Our econometric framework imposes the restriction that the differential impact of SES on boys' and girls' behavioral and educational outcomes is constant across race-ethnicity groups, as noted in section 2.1. If the impact of SES on the gender gap differed substantially by demographic group, this would complicate interpretation of an SES "effect" on the cross race-ethnicity gender gap.

We test this restriction by estimating an augmented version of equation (8) that includes all second and third-level interactions between gender, SES, and race-ethnicity:

$$
\begin{aligned}
Y_{i j}= & \alpha_{j}+\beta_{1}{\mathrm{Boy}_{i}}_{i}+\beta_{2}\left(\operatorname{Boy}_{i} \times D_{j}\right)+\beta_{3}\left(\operatorname{Boy}_{i} \times \operatorname{Race}_{j}\right)+\beta_{4}\left(\operatorname{Race}_{j} \times D_{j}\right) \\
& +\beta_{5}\left(\operatorname{Boy}_{i} \times \operatorname{Race}_{j} \times D_{j}\right)+\mathbf{F}_{j}^{\prime} \psi+\mathbf{X}_{i}^{\prime} \delta+e_{i j},
\end{aligned}
$$

where $D_{j}$ is the SES (disadvantage) measure and we suppress notation of main effects of raceethnicity and disadvantage. ${ }^{47}$ The assumption that SES affects minority and non-minority boys equally implies that $\beta_{5} \simeq 0$ in the equation above. Online Appendix Tables O6 and O7 present these augmented specifications.

Focusing first on school absences in Table O6, we find no evidence of cross-race-ethnicity variation in the SES gradient in the gender gap. A Wald test for cross-race-ethnicity heterogeneity in the SES gradient in the gender gap fails to reject the null at $p=0.74$. For combined reading $/ \mathrm{math}$ scores, we also do not detect much heterogeneity. Finally, for suspensions, there is statistically significant heterogeneity in slopes. The negative coefficient on Boy $\times$ SES in column 2 of panel B implies that a one standard deviation increase in SES reduces the suspension rate of white boys relative to their female siblings by 2.48 percentage points. The positive third-level interaction of 0.86 among boy, black, and SES in this model indicates that SES has a smaller beneficial effect $(-1.62=-2.48+0.86)$ on the gender suspension gap among black siblings relative to white siblings. We find a similar pattern for Hispanics. While these cross-group discrepancies in slopes do not change the qualitative pattern of findings, they nevertheless suggest that part of the protective effect of SES in reducing suspensions among white males is not present for minority males. A plausible interpretation of this

\footnotetext{
${ }^{47}$ Regression specifications include main effects for all variables that can differ across siblings, including family disadvantage measures (since, e.g., marital status may change between births).
} 
pattern, though not one that we are able to explore in our data, is that public schools suspension policies are differentially punitive towards non-white males.

Table O7 applies our test of the Oaxaca restrictions to on-time high school graduation, high school grade repetition, and high school dropout. Because we do not have all components of the SES variable for the high school age cohorts in our sample, we instead include a full set of main effects and second and third-level interactions for marital status and mother's education (a total of six third-level interactions among disadvantage, boy, and race/ethnicity). For on-time high school graduation, we cannot reject the null of no heterogeneity in the family advantage gradient in the gender gap $(p \geq 0.75)$. Among those not completing high school on time, we find some evidence that Hispanic boys in married families are differentially likely to repeat a grade rather than drop out of high school. ${ }^{48}$

\section{Exploring mechanisms: Schools and neighborhoods}

Family disadvantage may amplify the female favorable gap in childhood outcomes not because boys are more affected by family environment per se but because the neighborhoods and schools in which disadvantaged children are raised are particularly adverse for boys. Boys may be more vulnerable to the risks of violence and gang activity found in low-SES neighborhoods and schools, or boys may be treated more harshly by authority figures in these settings, perhaps facing greater disciplinary and criminal sanctions from teachers and police. We formally test whether family advantage operates primarily through these channels rather than directly through family environment per se. While school and neighborhood appear less important for explaining the gender gap than the direct effect of family environment itself, the results in this section lend broad support to the hypothesis that early outcomes of boys - particularly, behavioral and disciplinary outcomes - are differentially impacted by disadvantage, whether manifested in family disadvantage, neighborhood quality, or school quality.

For this analysis, we augment our data with measures of school and neighborhood quality. As described in section 1, we construct a measure of the quality of elementary and middle schools from the school-level gain scores calculated by the Florida Department of Education, reflecting schools' average contribution to student outcomes. Using these school level gain measures, we calculate for each student a years-weighted average of the rank quality of all schools attended from grade three to eight. We use two sets of variables to proxy for neighborhood quality: the median income of the zip code of residence observed at birth; and a measure of the causal effects of place of residence on economic mobility by Florida county from Chetty and Hendren (2015). The Chetty-Hendren mobility measure corresponds to the estimated percentage gain (or loss) in income at age 26 from spending one more year of childhood in each county in the U.S. We extract the causal exposure effects as percentage gains (or losses) in income at age 26 relative to the national mean for parents at the 25 th and 75 th percentile of the national household income distribution. We then average the two values to obtain one treatment effect for each county. Due to linearity in ranks this measure is

\footnotetext{
${ }^{48}$ Murnane (2013) observes that black and Hispanic students are more likely than whites to complete high school in five-plus years. Thus, race gaps in eventual high school completion are smaller than race gaps in on-time graduation.
} 
the same as the treatment effect on the median person. ${ }^{49}$

Table 8 a presents estimates for absences and suspensions. Columns 1 and 2 replicate our baseline mother fixed effects specification for the gender gap in school absences, while subsequent columns augment this specification with school and neighborhood controls, in each case interacted with gender. ${ }^{50}$ Columns 3 and 4 show that the gender gap in absences is lower in higher income zip codes and areas with higher economic mobility, but these relationships are not statistically significant. The brother-sister gap in absences is smaller, however, for children who attend higher quality Florida public schools relative to those attending lower quality schools (column 5). Moving from the 25th to the 75th percentile in school quality is predicted to reduce the gender gap in absenteeism by 0.0025 percentage points. The sixth column includes all three school and neighborhood measures simultaneously. School quality remains robustly predictive of the gender gap in absences and the economic mobility coefficient increases and becomes marginally significant. ${ }^{51}$

We use two metrics to interpret the magnitude of these relationships: how much of the SES gradient in that gap do they explain; and how much of the race-ethnicity gender gap in absences do they explain? The first question can be answered by comparing the coefficients on the Boy $\times$ SES interaction term across columns of Table $8 \mathrm{a}$ when including versus excluding the neighborhood and school quality interaction terms. The coefficient on Boy $\times$ SES of -0.07 in the column 2 baseline specification falls in magnitude to -0.06 in the final specification that accounts for both school and neighborhood quality. Thus, only 24 percent $(1-0.056 / 0.074)$ of the effect of SES on the gender gap in absences is accounted for by measures of school quality and neighborhood. The remainder is implicitly accounted for by family level effects that operate across siblings within schools and neighborhoods. Of course, this decomposition provides a lower bound on the explanatory power of school and neighborhood since more complete measures of school and neighborhood quality could potentially explain more. We address this issue non-parametrically in Appendix Table O8, summarized below.

The answer to the second question - what share of the race-ethnicity gender gap is explained by family, school, and neighborhood - is summarized in Figure 3. As reported in Table 8a, the regression adjusted excess gender gap in school absences among blacks relative to whites is 0.31 percentage points. Controlling for the differential impact of family advantage on boys explains 46 percent of this gap. Adding neighborhood income explains an additional 4 percentage points (50 percent in total), while controlling school quality and neighborhood economic mobility increases this explanatory power to 59 percent. Of course, school and neighborhood controls have substantially

\footnotetext{
${ }^{49}$ We thank Jeremy Majerovitz for expert assistance with the Chetty-Hendren data. We use data from their Online Data Table 2 (available at http://equality-of-opportunity.org/index.php/data): Preferred Estimates of Causal Place Effects by County.

${ }^{50}$ Samples (and hence point estimates) differ very slightly from our main estimates in Table 3 due to the fact that school quality measures are missing for the subset of schools that are new or have small numbers of students who contribute scores for student gain measures.

${ }^{51}$ Because neighborhood mobility (based on county) and neighborhood income (based on zip code) differ relatively rarely between siblings, the main effects for these variables are only weakly identified and hence are not included in the table. Main effects for school quality are, however, always large and significant with the expected sign (reducing absences and suspensions, increasing test scores).
} 
greater incremental explanatory power for the excess gender gap in absences when SES is excluded from the model: controlling for these factors alone, absent the gender-SES interaction explains 36 percent of the excess black gender gap in absences versus 46 percent for SES alone (column 7 of Table 8a). In summary, 78 percent of the explained impact of family advantage on the excess gender gap in absences appears to operate between siblings within schools and neighborhoods; the combination of family SES, school and neighborhoods can jointly explain 59 percent of the black excess gender gap in absences. The high correlation between the two sets of variables means that either set can proximately account for a substantial share of the explained excess gap. That said, family SES on its own explains more of the excess gender gap than do the neighborhood/school measures and the inclusion of family SES in the neighborhoods/schools specification substantially improves the extent to which the excess gap can be explained.

Panel B of Table 8a implements this exercise for grade three through eight suspensions. In contrast to the results for absence rates, here we find that neighborhood income is a significant predictor of the boy-girl gap in suspensions, with the female-favorable gap smaller in wealthier neighborhoods. A neighborhood's economic mobility again is not statistically significant, though is of sizable magnitude and it becomes significant in the specification that controls for all three measures (column 6). As with absences, school quality makes a substantial contribution, with suspension rates of boys reduced relative to girls in higher quality schools. Notably, inclusion of all three neighborhood and school quality measures only minimally affects the family-level impact of SES on the gender gap: the SES $\times$ gender interaction term falls by approximately one fifth when conditioning on these detailed measures (thus 80 percent of the explained impact of family advantage on the excess gender gap in suspensions appears to operate within schools and neighborhoods). As visually depicted in panel B of Figure 3, family disadvantage alone accounts for 64 percent of the excess gender gap among black relative to white siblings, with school and neighborhood quality accounting for an incremental 15 percentage points. ${ }^{52}$ The final column of Table 8a indicates that when the gender-SES interaction is excluded from the statistical model, schools and neighborhoods alone can explain 44 percent of the excess gender gap in suspensions.

Table $8 \mathrm{~b}$ presents the corresponding analysis for combined math and reading scores. Relative to the behavioral outcomes, these academic indicators are less central to our analysis since they have comparatively modest relationships to high school completion, grade repetition, and dropout (and have only a modest SES gender gradient, as shown above). Qualitatively, we find a similar pattern of results: greater neighborhood economic mobility and higher school quality significantly reduce the boy-girl disadvantage in early academic performance, though for these outcomes we do not find a consistently significant effect of neighborhood income. Accounting for neighborhood and school quality attenuates the relationship between SES and the gender gap in math and reading and in some specifications the coefficient is statistically insignificant. However, none of these measures (individually or in combination) accounts for even a fifth of the excess gender gap in academic outcomes among black relative to white children.

\footnotetext{
${ }^{52}$ Our models tend to over-explain the modest boy-girl gaps in suspensions among Hispanics.
} 
As a final robustness test, we estimate a set of companion models for absences, suspensions, and combined math and reading scores that are saturated with a full set of zip code $\times$ boy and school $\times$ boy interactions. This extension allows the impact of neighborhoods and schools on the gender gap to vary non-parametrically up to the level of granularity available in the data. These non-parametric estimates are reported in Online Appendix Table O8. Comparing across columns of this table documents the robustness of our findings for the contribution of family disadvantage to the gender gap in behavioral outcomes. Relative to the Table 8a models that control directly for neighborhood and school quality, adding non-parametric school and neighborhood controls has almost no discernible effect on the estimated impact of family disadvantage on the gender gap in absences and suspensions - again confirming the centrality of family environment in determining the gender gap in behavioral outcomes. ${ }^{53}$ For combined reading/math scores, the attenuation is larger than in the parametric approach (about 66 percent), and SES is no longer a significant predictor of the gender gap in the models with gender interactions. Family disadvantage appears, however, to account for only a modest component of the gender gap in test scores, as noted above, and test scores in turn play only a modest role in the gender gap in high school graduations.

\section{Conclusions}

This paper investigates whether family disadvantage exerts a differential effect on the educational outcomes of boys relative to girls. Utilizing a unique data set of Florida births from 1992 to 2002 linked to schooling records, and an empirical design that employs within-family brother-sister comparisons, we find that family disadvantage disproportionately negatively affects the behavioral and academic outcomes of school-age boys relative to girls. The differential effect of family disadvantage on the outcomes of boys relative to girls is already evident by the time of kindergarten entry, is further manifested in behavioral and educational gaps in elementary and middle-school performance, and crystalizes into sharp differences in high school graduations by age 18. These SES gradients are especially strong for behavioral outcomes measured during the third through eighth grades, and though more modest for combined math and reading test scores, the gradient persists through high school graduation. Our results imply that a sizable portion of the documented minority-white difference in educational and behavioral gender gaps is attributable to higher degrees of family disadvantage among minority families.

The causal effect of family disadvantage on the gender gap may accrue through two primary channels. One is that the skills development of boys and girls respond differently to the same stimuli. An alternative, non-mutually exclusive, explanation is that parental investments in boys versus girls differ systematically according to family disadvantage. For example, parents in low-SES

\footnotetext{
${ }^{53}$ Controlling non-parametrically for the differential effect of schools and neighborhoods on boys relative to girls attenuates by 18 and 26 percent, respectively, the SES gradient in the gender gap in absences and suspensions; this is almost indistinguishable from the 24 percent and 19 percent attenuation in this gradient when controlling parametrically for neighborhood and school quality in Table 8a. The similarity of the results between the parametric and non-parametric specifications also suggests that our parametric school and neighborhood quality measures are reasonable proxies for school and neighborhood disadvantage.
} 
households, which are disproportionately female-headed, may spend relatively more time mentoring and interacting with daughters than sons (Lundberg et al., 2007; Baker and Milligan, 2013; Bertrand and Pan, 2013; Gayle et al., 2014), or, similarly, parents in high-SES households may make larger compensatory investments in sons than daughters. ${ }^{54}$ Our data do not allow us to evaluate the relative importance of these causal channels, though the evidence in Bertrand and Pan (2013) does not provide strong support for the differential investment hypothesis. We view this as a worthy topic for further research.

While our paper is deliberately agnostic about the specific channels through which post-natal exposure to family disadvantage generates the observed gender gap in outcomes, we are able to rigorously test and, for the most part, reject two natural competing explanations for our main findings. One explanation for the SES gradient in the gender gap is a "fetal origins" hypothesis, in which the SES gradient in potential outcomes is imparted prior to birth. Across a large number of measures of neonatal health - birthweight, infant and maternal health, and numerous indicators of prenatal care and medical complications before and during delivery - we detect no evidence that the SES gradient in the gender gap in outcomes is already present at birth. These results strongly suggest that there is no latent gender gap in potential outcomes that varies with SES, and allows us to infer that the divergent behavioral and cognitive development of boys relative to girls in low-SES versus high-SES families reflects the causal effect of the post-natal environment on child development.

The second explanation for the SES gradient in the gender gap is an environmental factors hypothesis. We document that neighborhood quality makes a small contribution to the SES gradient in the gender gap, while school quality matters more - low quality schools are particularly disadvantageous for boys. Nevertheless, accounting non-parametrically for the differential impact of schools and neighborhoods on boys relative to girls reduces the estimated impact of family disadvantage on the sibling gender gap in behavioral outcomes by less than a quarter. These results imply that family disadvantage makes both a substantial direct contribution to the gender gap as well as an indirect contribution through schools and neighborhoods. Though not observable in our data, we suspect that these early differences in behavioral and educational outcomes continue into adulthood, as boys and girls exit the compulsory school system and matriculate into employment, higher education, and potentially parenthood.

\footnotetext{
${ }^{54}$ We have examined this hypothesis using parental time use data from the American Time Use Survey as well as data from the Florida State Department of Education on whether parents send children to pre-school, an indicator of early childhood investment. With regard to parental time use, we find little support for differential investment in boys versus girls that varies systematically with SES. For the likelihood of sending a child to pre-kindergarten programs, we find that boys are more likely to attend pre-kindergarten programs, and particularly so in relatively advantaged families.
} 


\section{References}

Aizer, Anna and Janet Currie, "The intergenerational transmission of inequality: Maternal disadvantage and health at birth," Science, 2014, 344 (6186), 856-861.

Almond, D and L Edlund, "Trivers-Willard at Birth and One year: Evidence from US Natality Data 1983-2001," Proceedings of the Royal Society B: Biological Sciences, 2007, 274 (1624), 24912496.

Almond, Douglas and Bhashkar Mazumder, "Health Capital and the Prenatal Environment: The Effect of Ramadan Observance During Pregnancy," American Economic Journal: Applied Economics, 2011, 3 (4), 56-85.

- and Janet Currie, "Killing Me Softly: The Fetal Origins Hypothesis," Journal of Economic Perspectives, 2011, 25 (3), 153-172.

- and Maya Rossin-Slater, "Paternity Acknowledgment in 2 Million Birth Records from Michigan," PloS ONE, 2013, 8 (7).

_ , Bhashkar Mazumder, and Reyn van Ewijk, "In Utero Ramadan Exposure and Children's Academic Performance," The Economic Journal, 2014.

_, Kenneth Y Chay, and David S Lee, "The Costs of Low Birth Weight," The Quarterly Journal of Economics, 2005, pp. 1031-1083.

Autor, David and Melanie Wasserman, "Wayward Sons: The Emerging Gender Gap in Education and Labor Markets," Technical Report, Third Way, Washington, DC 2013.

_, David Figlio, Krzysztof Karbownik, Jeffrey Roth, and Melanie Wasserman, "Family Disadvantage and the Gender Gap in Behavioral and Educational Outcomes," NBER Working Paper \#22267, 2016.

Autor, David H, "Skills, Education, and the Rise of Earnings Inequality Among the "Other 99 Percent"," Science, 2014, 344 (6186), 843-851.

_ , David N Figlio, Krzysztof Karbownik, Jeffrey Roth, and Melanie Wasserman, "School Quality and the Gender Gap in Educational Achievement," American Economic Review Papers and Proceedings, 2016.

Baker, Michael and Kevin Milligan, "Boy-Girl Differences in Parental Time Investments: Evidence from Three Countries," NBER Working Paper No. 18893, 2013.

_ , Jonathan Gruber, and Kevin Milligan, "Universal Child Care, Maternal Labor Supply, and Family Well-Being," Journal of Political Economy, 2008, 116 (4), 709-745.

Becker, Gary S., William H. J. Hubbard, and Kevin M. Murphy, "Explaining the Worldwide Boom in Higher Education of Women," Journal of Human Capital, 2010, 4 (3), 203-241.

Bertrand, Marianne and Jessica Pan, "The Trouble with Boys: Social Influences and the Gender Gap in Disruptive Behavior," American Economic Journal: Applied Economics, 2013, 5 (1), 32-64. 
Beyers, Jennifer M, John E Bates, Gregory S Pettit, and Kenneth A Dodge, "Neighborhood Structure, Parenting Processes, and the Development of Youths' Externalizing Behaviors: A Multilevel Analysis," American Journal of Community Psychology, 2003, 31 (1-2), 35-53.

Black, Sandra E., Paul T. Devereux, and Kjell G. Salvanes, "From the Cradle to the Labor Market? The Effect of Birth Weight on Adult Outcomes," Quarterly Journal of Economics, 2007, $122(1), 409-439$.

Brenoe, Anne Ardila and Shelly Lundberg, "Gender gaps in the effects of childhood family environment: Do they persist into adulthood?," European Economic Review, 2017, 0, 1-21.

Buchmann, C. and T. a. DiPrete, "The Growing Female Advantage in College Completion: The Role of Family Background and Academic Achievement," American Sociological Review, 2006, 71 (4), 515-541.

Cherlin, Andrew, The Marriage-Go-Round: The State of Marriage and the Family in America Today, New York: Knopf, 2009.

Cherlin, Andrew J, Labor's Love Lost: The Rise and Fall of the Working-Class Family in America, New York: Russell Sage Foundation, 2014.

Chetty, Raj and Nathan Hendren, "The Impacts of Neighborhoods on Intergenerational Mobility: Childhood Exposure Effects and County-Level Estimates," 2015.

_, Nathaniel Hendren, and Lawrence F Katz, "The Effects of Exposure to Better Neighborhoods on Children: New Evidence from the Moving to Opportunity Experiment," American Economic Review, 2016, 106 (4), 855-902.

_ , _, Frina Lin, Jeremy Majerovitz, and Benjamin Scuderi, "Childhood Environment and Gender Gaps in Adulthood," American Economic Review Papers and Proceedings, 2016.

Cullen, Mark R, Michael Baiocchi, Karen Eggleston, Pooja Loftus, and Victor Fuchs, "The Weaker Sex? Vulnerable Men, Resilient Women, and Variations in Sex Differences in Mortality since 1900," NBER Working Paper \#21114, 2015, (April).

Dahl, Gordon B. and Enrico Moretti, "The Demand for Sons," Review of Economic Studies, 2008, 75 (4), 1085-1120.

DiPrete, Thomas A. and Claudia Buchmann, The Rise of Women, New York, NY: Russell Sage Foundation, 2013.

DiPrete, Thomas and Jennifer L Jennings, "Social and Behavioral Skills and the Gender Gap in Early Educational Achievement," Social Science Research, 2012, 41 (1), 1-15.

Duckworth, Angela L and Martin E P Seligman, "Self-discipline outdoes IQ in predicting academic performance of adolescents.," Psychological science, 2005, 16 (12), 939-44.

Fan, Xiaodong, Hanming Fang, and Simen Markussen, "Mothers' Employment and Children's Educational Gender Gap," NBER Working Paper \#21183, 2015, (May).

Farrell, Albert D., Terri N. Sullivan, Layla E. Esposito, Aleta L. Meyer, and Robert F. Valois, "A latent growth curve analysis of the structure of aggression, drug use, and delinquent 
behaviors and their interrelations over time in urban and rural adolescents," Journal of Research on Adolescence, 2005, 15 (2), 179-204.

Field, Erica, Omar Robles, and Maximo Torero, "Iodine Deficiency and Schooling Attainment in Tanzania," American Economic Journal: Applied Economics, 2009, 1 (4), 140-169.

Figlio, David, Jonathan Guryan, Krzysztof Karbownik, and Jeffrey Roth, "The Effects of Poor Neonatal Health on Children's Cognitive Development," American Economic Review, 2014, 104 (12), 3921-3955.

Figlio, David N, Jonathan Guryan, Krzysztof Karbownik, and Jeffrey Roth, "The Effects of Poor Neonatal Health on Children's Cognitive Development," 2013.

Fortin, Nicole M, Philip Oreopoulos, and Shelley Phipps, "Leaving Boys Behind: Gender Disparities in High Academic Achievement," Journal of Human Resources, 2015, 50 (3).

Gayle, George-Levi, Limor Golan, and Mehmet A. Soytas, "What Accounts for the Racial Gap in Time Allocation and Intergenerational Transmission of Human Capital?," Washington University in St. Louis Working Paper, 2014, (October).

Goldin, Claudia, Lawrence F Katz, and Ilyana Kuziemko, "The Homecoming of American College Women: The Reversal of the College Gender Gap," 2006.

Greve, Jane, Marie Louise Schultz-nielsen, Jane Greve, and Marie Louise Schultznielsen, "Fetal Malnutrition And Academic Success: Evidence From Muslim Immigrants In Denmark," NBER Working Paper No. 21545, 2015.

Heckman, James J. and Tim Kautz, "Hard evidence on soft skills," Labour Economics, 2012, 19 (4), 451-464.

Hoynes, Hilary, Diane Whitmore Schanzenbach, and Douglas Almond, "Long Run Impacts of Childhood Access to the Safety Net," American Economic Review, 2016, 106 (4), 903-934.

Ingoldsby, E M and D S Shaw, "Neighborhood contextual factors and ealry-starting antisocial pathways," Clinical Child and Family Psychology Review, 2002, 5 (1), 21-55.

Karbownik, Krzysztof and Michal Myck, "Who Gets to Look Nice and Who Gets to Play? Effects of Child Gender on Household Expenditure," Review of Economics of the Household, 2017, 15 (3), 925-944.

Karriker-Jaffe, Katherine J., Vangie A. Foshee, Susan T. Ennett, and Chirayath Suchindran, "Sex differences in the effects of neighborhood socioeconomic disadvantage and social organization on rural adolescents' aggression trajectories," American Journal of Community Psychology, 2009, 43 (3-4), 189-203.

Leventhal, T and J Brooks-Gunn, "Moving to Opportunity: An experimental study of neighborhood effects on mental health," American Journal of Public Health, 2003, 93 (9), 1576-1582.

Lundberg, Shelly, "Father Absence and the Educational Gender Gap," IZA Discussion Paper No. $10814,2017$.

_ and Robert A Pollak, "The American Family and Family Economics," Journal of Economic 
Perspectives, 2007, 21 (2), 3-26.

_, Sabrina Wulff Pabilonia, and Jennifer Ward-Batts, "Time Allocation of Parents and Investments in Sons and Daughters," Unpublished paper, 2007.

Maccini, Sharon and Dean Yang, "Under the Weather: Health, Schooling, and Economic Consequences of Early-Life Rainfall," American Economic Review, 2009, 99 (3), 1006-1026.

Mincy, Ronald, Irwin Garfinkel, and Lenna Nepomnyaschy, "In-hospital paternity establishment and father involvement in fragile families," Journal of Marriage and Family, 2005, 67 (3), 611-626.

Molloy, Raven, Christopher L Smith, and Abigail Wozniak, "Internal Migration in the United States," Journal of Economic Perspectives, 2011, 25 (3), 173-196.

Murnane, Richard J, "U.S. High School Graduation Rates: Patterns and Explanations," Journal of Economic Literature, jun 2013, 51 (2), 370-422.

Norberg, Karen, "Partnership Status and the Human Sex Ratio at Birth," Proceedings of the Royal Society B: Biological Sciences, nov 2004, 271 (1555), 2403-2410.

OECD, Education at a Glance 2013 Education at a Glance, OECD Publishing, 2013.

Owens, Jayanti, "Early Childhood Behavior Problems and the Gender Gap in Educational Attainment in the United States," Sociology of Education, 2016, 3 (89), 236-258.

Prevoo, Tyas and Bas ter Weel, "The Effect of Family Disruption on Children's Personality Development: Evidence from British Longitudinal Data," IZA DP No. 8217, 2014, (December).

Ramirez-Valles, J, M A Zimmerman, and L Juarez, "Gender differences of neighborhood and social control process: A study of the timing of first intercourse among low-achieving, urban, African American youth," Youth and Society, 2002, 33 (3), 418-441.

Riphahn, Regina $\mathbf{T}$ and Caroline Schwientek, "What Drives the Reversal of the Gender Education Gap? Evidence from Germany," Applied Economics, 2015, 6846 (October), 1-28.

Sampson, Robert J., Jeffrey D. Morenoff, and Stephen Raudenbush, "Social anatomy of racial and ethnic disparities in violence," American Journal of Public Health, 2005, 95 (2), $224-232$.

Segal, Carmit, "Misbehavior, Education, and Labor Market Outcomes," Journal of the European Economic Association, aug 2013, 11 (4), 743-779.

Trivers, Rorbert L and Dan E Willard, "Natural Selection of Parental Ability to Vary the Sex Ratio of Offspring," Science, 1973, 179 (4068), 90-92.

U.S. National Center for Education Statistics, "Digest of Education Statistics 2013," Technical Report, Washington, DC 2013.

Woessmann, Ludger, "Single-Parent Families and Student Achievement: An International Perspective," Ifo Institute at the University of Munich, 2015, (January). 


\section{Figures and Tables}

Figure 1: Boy-Girl Gaps in Absences, Math Scores, On-Time High School Completion and Kindergarten Readiness by Family Characteristics

A. By Race-Ethnicity

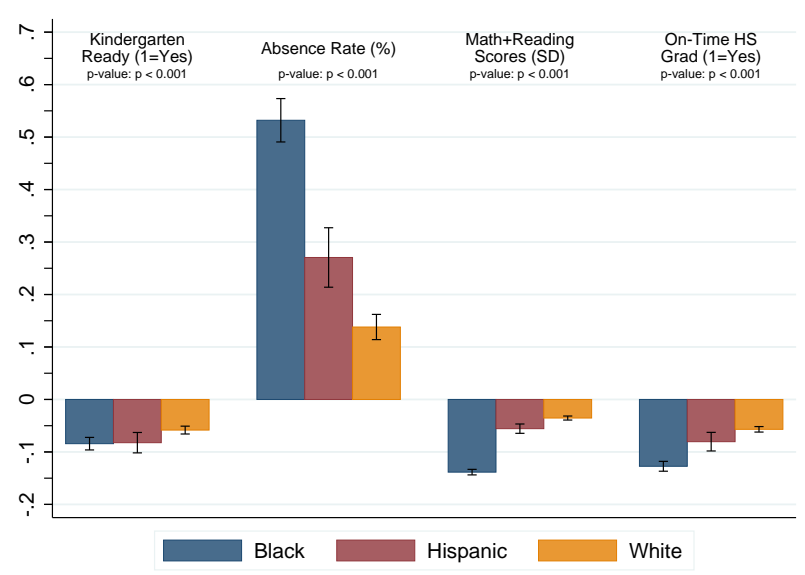

C. By Marital Status at Birth

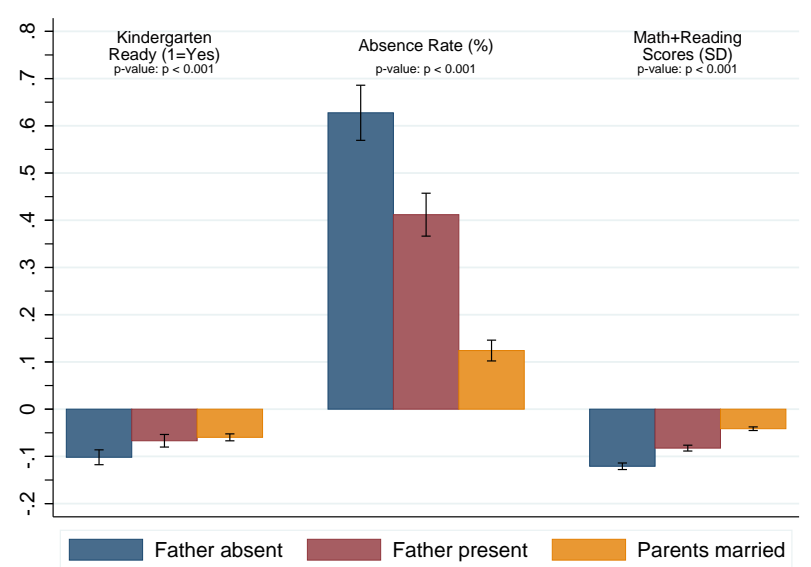

B. By Mother's Education

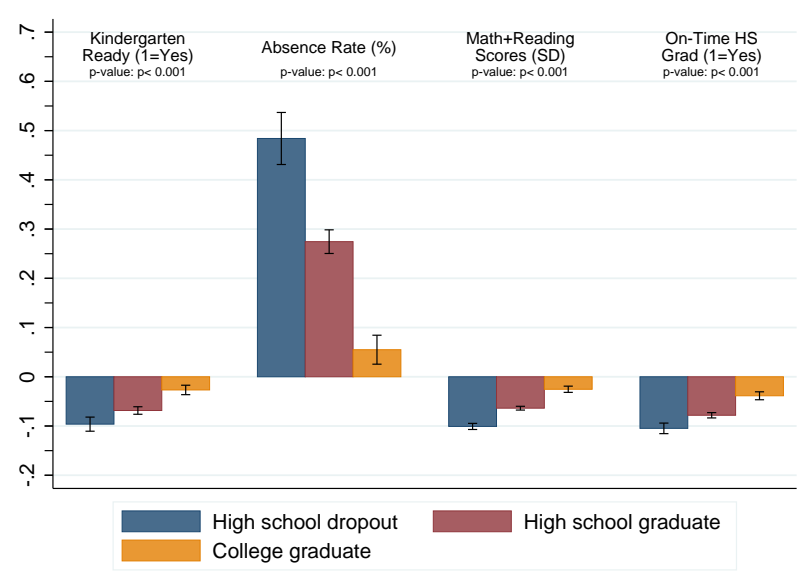

D. By SES Quartile

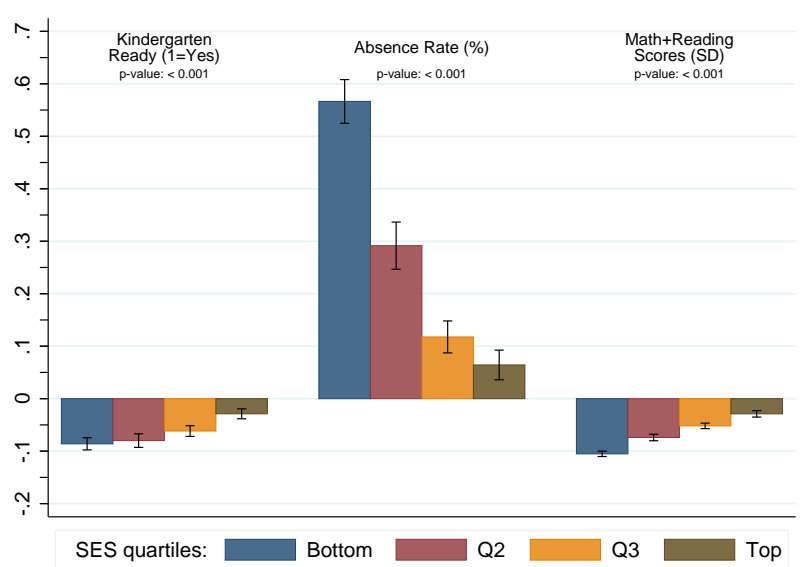

Note: This figure plots mean kindergarten readiness rates, absence rates, averaged FCAT math and reading scores, and ontime high school completion rates, by gender and family demographics. Absence rates and FCAT math and reading scores are computed from the pooled sample of non-twin siblings spanning grades three through eight. On-time high school completion indicates a high school diploma within four years of entering and is computed from the pooled sample of non-twin singletons who were observed in Florida public schools until at least ninth grade. Data are limited to the 1992 and 1993 birth cohorts, the only students old enough to be observed in the high school outcomes data. Kindergarten readiness rates are computed from the pooled sample of non-twin siblings born in cohorts 1994 to 1996 and 2000 to 2002. The SES measure is constructed as the first component of a principal components analysis of years of maternal education, non-Medicaid birth indicator, and marital status/family structure (married, father present, father absent) at birth. 95\% confidence intervals are represented by whiskers on each bar. 
Figure 2: Boy-Girl Gap in Behavioral and Academic Outcomes by Family SES at Birth

A. Absence Rate (\%)

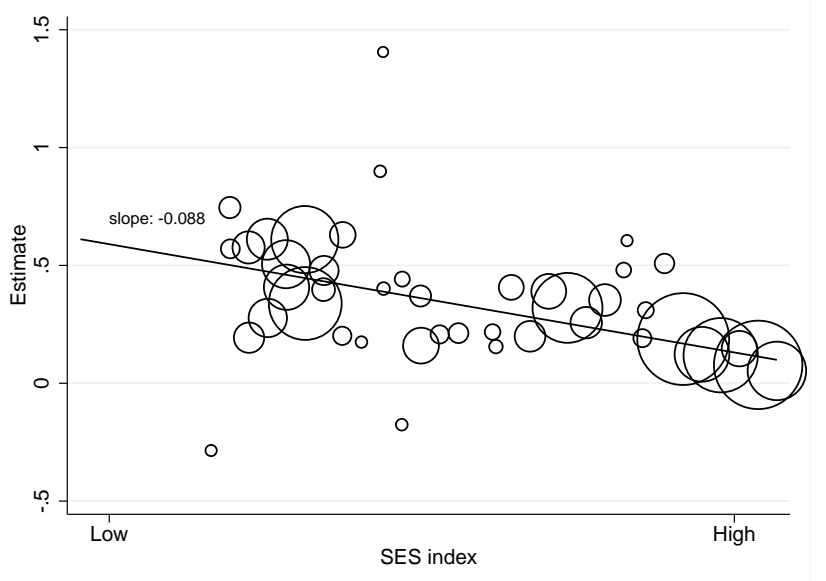

B. Suspension Rate (\%)

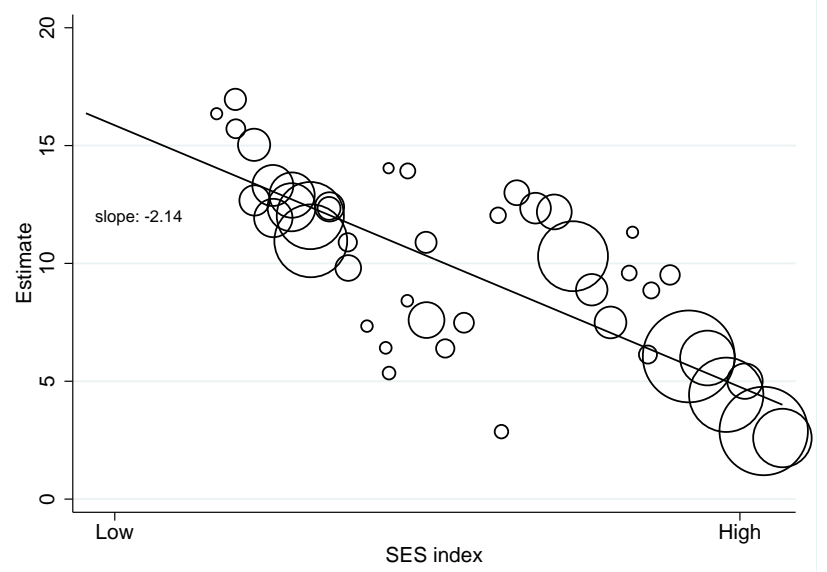

C. Math and Reading Scores

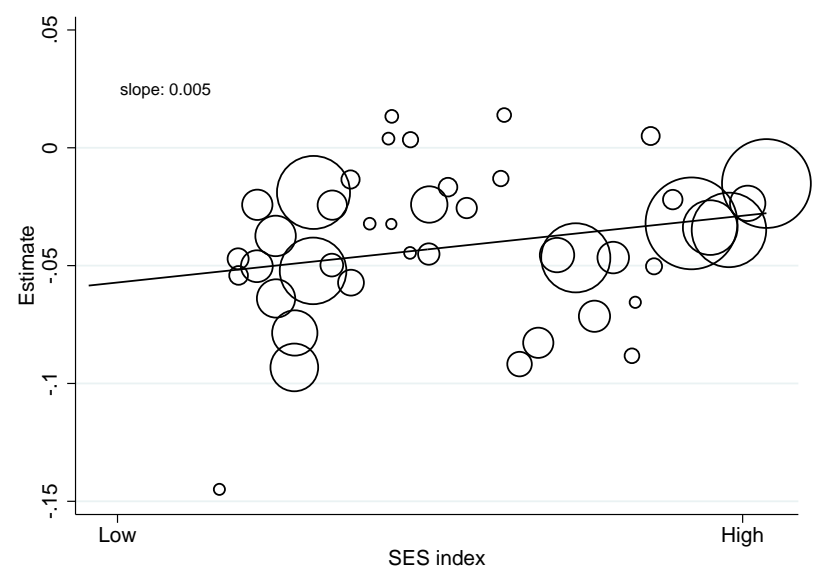

Note: This figure plots regression-adjusted mean absence rates, suspension rates, and FCAT math and reading scores against the mean values of the SES index, for 94 bins of the SES index. Graphs suppress bins with very small sample sizes for expositional clarity. Lines come from OLS regressions fitted through all bins and weighted by bin size. The sample is non-twin siblings born 1994-2002. The regression controls include child gender, year and month of birth, maternal age at birth, birth order within family/sibling composition, the main effect of the SES index, and the race-ethnicity of the mother and their interactions with child gender. The SES measure is constructed as the first component of a principal components analysis of years of maternal education, non-Medicaid birth indicator and marital status/family structure (married, father present, father absent) at birth. 
Figure 3: Sibling Gender Gaps in Behavioral and Academic Outcomes: Observed and Explained

A. Absence Rate $(\%)$

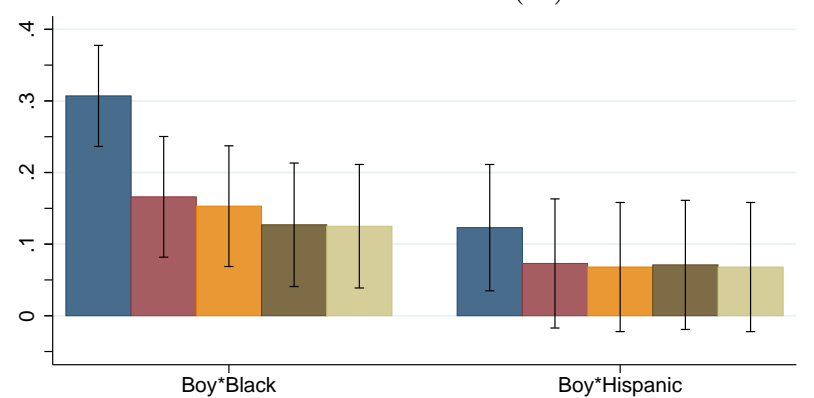

B. Suspension Rate (\%)

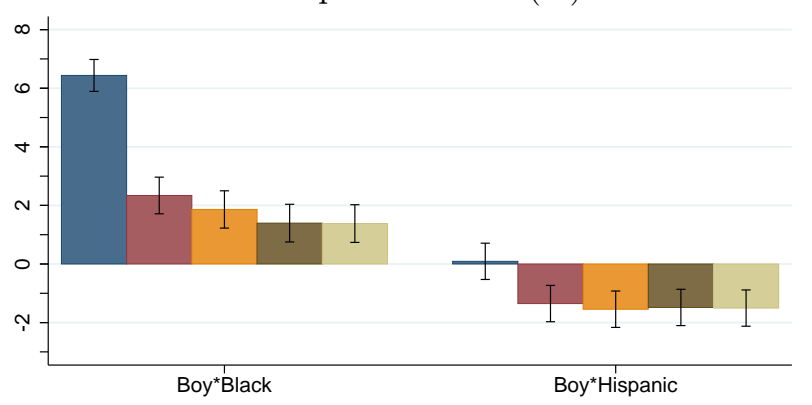

C. Math and Reading Scores

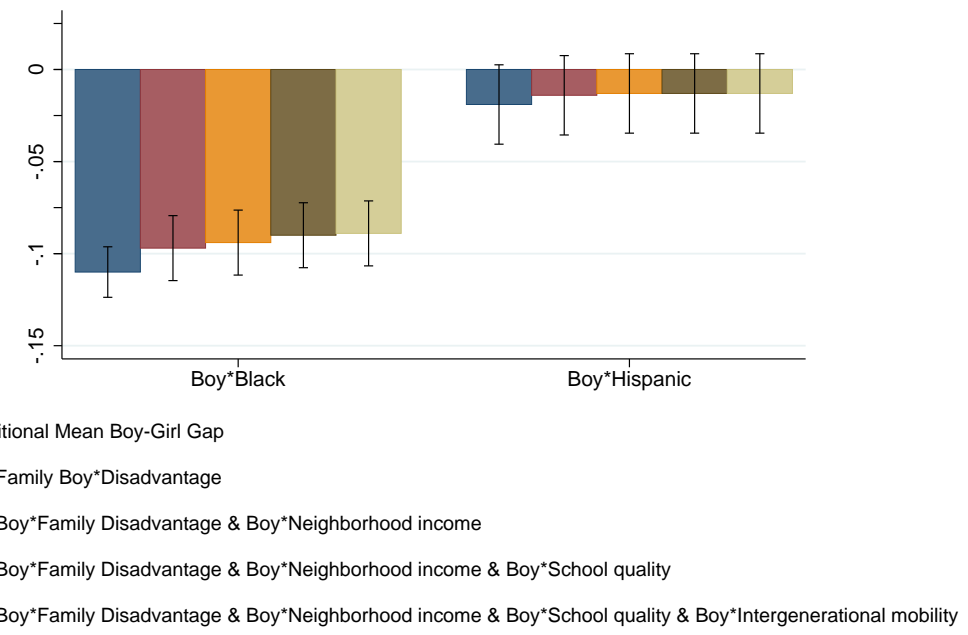

Note: This figure plots the regression-adjusted race-ethnicity gender gap in absence rates, suspension rates, FCAT math and reading scores from sibling fixed effects models in Tables $8 \mathrm{a}$ and $8 \mathrm{~b} .95 \%$ confidence intervals are represented by whiskers on each bar. 
Table 1: Sample Selection: Matched Florida Birth and Public School Records

\begin{tabular}{lccccc}
\hline & $\begin{array}{c}\text { White, black } \\
\text { and Hispanic } \\
\text { Births }\end{array}$ & $\begin{array}{c}\text { With } \\
\text { Complete } \\
\text { Data }\end{array}$ & $\begin{array}{c}\text { Matched to } \\
\text { Florida School } \\
\text { Records }\end{array}$ & $\begin{array}{c}\text { Matched to } \\
\text { 3rd Grade } \\
\text { Test Score }\end{array}$ & $\begin{array}{c}\text { Sibling Sample } \\
\text { wrd Grade } \\
\text { Test Score }\end{array}$ \\
\cline { 2 - 5 } & $(1)$ & $(3)$ & $(4)$ & $(5)$ \\
White non-Hispanic & 67.7 & 67.6 & 65.1 & 64.0 & 59.2 \\
Black non-Hispanic & 21.7 & 21.7 & 24.1 & 25.1 & 29.5 \\
Hispanic & 10.6 & 10.7 & 10.8 & 10.9 & 11.4 \\
High school dropout & 18.7 & 18.6 & 20.4 & 21.0 & 22.7 \\
High school graduate & 60.1 & 60.3 & 61.8 & 62.3 & 59.4 \\
College graduate & 20.9 & 21.1 & 17.8 & 16.7 & 17.9 \\
Age 21 or below & 24.1 & 24.0 & 26.1 & 26.8 & 27.9 \\
Age between 22 and 29 & 41.9 & 41.9 & 42.0 & 42.0 & 44.8 \\
Age between 30 and 35 & 24.9 & 25.0 & 23.4 & 23.0 & 21.5 \\
Age 36 or above & 9.1 & 9.1 & 8.5 & 8.2 & 5.8 \\
Non-married, father absent & 14.4 & 14.3 & 15.7 & 16.2 & 17.7 \\
Non-married, father present & 21.9 & 22.0 & 23.8 & 24.6 & 22.9 \\
Married at time of birth & 63.5 & 63.7 & 60.5 & 59.2 & 59.4 \\
Medicaid-funded birth & 49.9 & 51.3 & 51.0 & 50.5 & 50.8 \\
Boy & 3,337 & 3,337 & 3,324 & 3,322 & 3,325 \\
Birth weight (grams) & $1,209,870$ & $1,157,930$ & 935,993 & 770,384 & 301,709 \\
N & 51.3 & 51.3 & 51.0 & 50.5 & 50.8 \\
\hline
\end{tabular}

Note: This table reports summary statistics for the Florida statewide data. The first column is the full sample of Florida births 1994-2002, excluding immigrants; the second column drops the $4 \%$ of records that are missing key variables; the third column contains the $81 \%$ of column 2 records that were matched to Florida school records; the fourth column is the subset of column 3 for children who remained in Florida public schools through third grade and had at least one test score; and the fifth column is the subset of column 4 in the matched sibling sample - children in families with two or more children born 1994-2002. All demographic characteristics are derived from the birth certificate. White, black, and Hispanic are mutually exclusive categories. 
Table 2: Descriptive Statistics: Selected Parent and Child Characteristics, by Race and Ethnicity

\begin{tabular}{|c|c|c|c|c|}
\hline & $\begin{array}{l}\text { All } \\
(1)\end{array}$ & $\begin{array}{c}\text { White Non- } \\
\text { Hispanic } \\
\text { Native } \\
(2) \\
\end{array}$ & $\begin{array}{c}\text { Black Non- } \\
\text { Hispanic } \\
\text { Native } \\
(3) \\
\end{array}$ & $\begin{array}{c}\text { Hispanic } \\
\text { Native } \\
(4)\end{array}$ \\
\hline Unmarried: Father absent & 17.7 & 6.5 & 42.5 & 12.0 \\
\hline Unmarried: Father present & 22.9 & 16.4 & 34.6 & 26.4 \\
\hline Married & 59.4 & 77.1 & 22.9 & 61.7 \\
\hline Mother HS dropout & 22.7 & 15.8 & 34.6 & 28.0 \\
\hline Mother HS grad & 59.4 & 59.3 & 60.5 & 57.2 \\
\hline Mother college grad & 17.9 & 24.9 & 5.0 & 14.8 \\
\hline Non-medicaid birth & 50.1 & 66.0 & 19.6 & 46.4 \\
\hline Median zip code income & $\begin{array}{c}44,989 \\
(13,723)\end{array}$ & $\begin{array}{c}49,182 \\
(13,373)\end{array}$ & $\begin{array}{c}36,761 \\
(10,411)\end{array}$ & $\begin{array}{c}44,492 \\
(13,325)\end{array}$ \\
\hline $\mathrm{N}$ & 301,709 & 178,517 & 88,894 & 34,298 \\
\hline $\begin{array}{l}\text { Chetty/Hendren CZ mobility } \\
\text { measure }\end{array}$ & $\begin{array}{l}-0.27 \\
(0.19)\end{array}$ & $\begin{array}{l}-0.27 \\
(0.19)\end{array}$ & $\begin{array}{l}-0.26 \\
(0.19)\end{array}$ & $\begin{array}{l}-0.29 \\
(0.18)\end{array}$ \\
\hline $\mathrm{N}$ & 301,680 & 178,491 & 88,892 & 34,297 \\
\hline School quality & $\begin{array}{c}51.1 \\
(15.3)\end{array}$ & $\begin{array}{c}55.5 \\
(14.9)\end{array}$ & $\begin{array}{c}41.8 \\
(12.3)\end{array}$ & $\begin{array}{c}52.9 \\
(14.0)\end{array}$ \\
\hline $\mathrm{N}$ & 283,635 & 166,856 & 85,057 & 31,722 \\
\hline
\end{tabular}

Note: This table reports summary statistics for the sample of non-twin siblings born 1994-2002, by race and ethnicity of the mother. Standard deviations for continuous measures are given in parentheses. The sample is reduced for the Chetty/Hendren $\mathrm{CZ}$ mobility and the school quality variables due to the lack of availability of these measures for a subset of Florida counties and schools. 


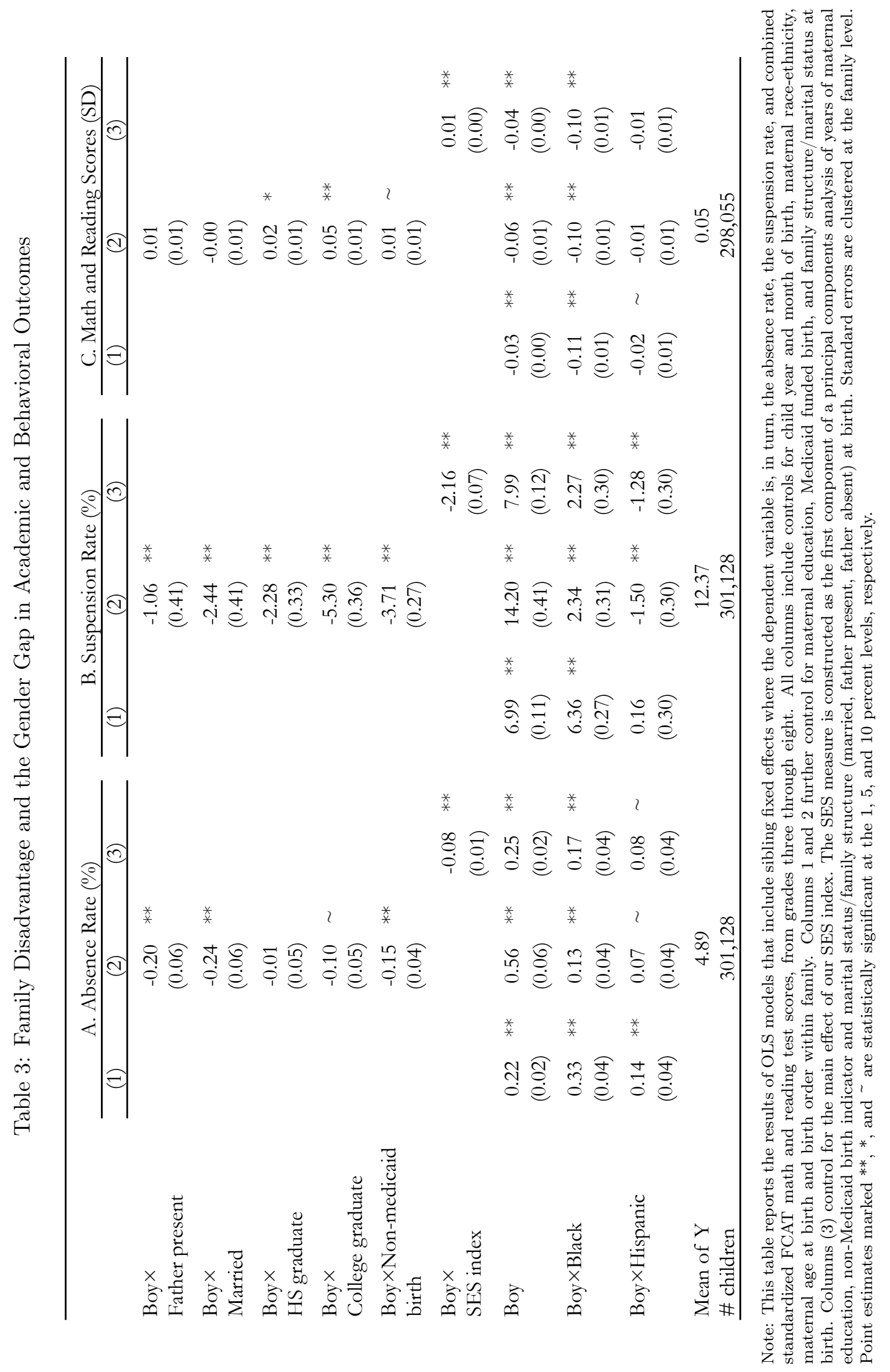


Table 4: Family Disadvantage and the Gender Gap in High School Graduation

\begin{tabular}{|c|c|c|c|c|c|c|c|c|c|c|c|c|}
\hline \multirow[b]{3}{*}{ Boy $\times$} & \multicolumn{4}{|c|}{ A. On-time HS grad } & \multicolumn{4}{|c|}{ B. $5+$ years of $\mathrm{HS}$} & \multicolumn{4}{|c|}{ C. HS dropout } \\
\hline & $(1)$ & & $(2)$ & & $(1)$ & & $(2)$ & & $(1)$ & & $(2)$ & \\
\hline & & & $\begin{array}{c}3.22 \\
(0.59)\end{array}$ & ** & & & $\begin{array}{l}-1.22 \\
(0.45)\end{array}$ & ** & & & $\begin{array}{l}-2.01 \\
(0.50)\end{array}$ & ** \\
\hline Boy $x$ & & & 0.63 & & & & -0.44 & & & & -0.19 & \\
\hline HS graduate & & & $(0.64)$ & & & & $(0.51)$ & & & & $(0.57)$ & \\
\hline $\begin{array}{l}\text { Boy } \times \\
\text { College graduate }\end{array}$ & & & $\begin{array}{c}3.17 \\
(0.76)\end{array}$ & $* *$ & & & $\begin{array}{l}-2.30 \\
(0.57)\end{array}$ & ** & & & $\begin{array}{l}-0.88 \\
(0.66)\end{array}$ & \\
\hline Boy & $\begin{array}{l}-6.04 \\
(0.25)\end{array}$ & ** & $\begin{array}{l}-9.61 \\
(0.66)\end{array}$ & ** & $\begin{array}{l}3.92 \\
(0.18)\end{array}$ & ** & $\begin{array}{c}5.60 \\
(0.53)\end{array}$ & $* *$ & $\begin{array}{c}2.12 \\
(0.22)\end{array}$ & $* *$ & $\begin{array}{l}4.00 \\
(0.60)\end{array}$ & ** \\
\hline Boy $\times$ Black & $\begin{array}{l}-6.65 \\
(0.53)\end{array}$ & $* *$ & $\begin{array}{l}-4.56 \\
(0.60)\end{array}$ & ** & $\begin{array}{c}2.94 \\
(0.43)\end{array}$ & ** & $\begin{array}{c}2.01 \\
(0.48)\end{array}$ & ** & $\begin{array}{c}3.71 \\
(0.43)\end{array}$ & ** & $\begin{array}{c}2.55 \\
(0.50)\end{array}$ & ** \\
\hline Boy $\times$ Hispanic & $\begin{array}{l}-2.17 \\
(0.91)\end{array}$ & * & $\begin{array}{l}-1.46 \\
(0.91)\end{array}$ & & $\begin{array}{c}0.37 \\
(0.69)\end{array}$ & & $\begin{array}{c}0.01 \\
(0.69)\end{array}$ & & $\begin{array}{c}1.81 \\
(0.76)\end{array}$ & * & $\begin{array}{c}1.45 \\
(0.77)\end{array}$ & $\sim$ \\
\hline $\begin{array}{l}\text { Mean of Y } \\
\text { \# children }\end{array}$ & & $\begin{array}{r}70.4 \\
61,53 \\
\end{array}$ & & & & $\begin{array}{l}12.8 \\
61,53\end{array}$ & & & & $\begin{array}{r}16.8 \\
161,5\end{array}$ & & \\
\hline
\end{tabular}

Note: This table reports the results of OLS models where the dependent variable is, in turn, on-time graduation, continuation in high school, and dropout, from the sample of non-twin singletons who were observed in Florida public schools until at least ninth grade. Data are limited to the 1992 and 1993 birth cohorts, the only students old enough to be observed in the high school outcomes data. On-time high school completion takes on a value of one hundred if a student obtains a high school diploma within four years of entering, and is zero otherwise. $5+$ years of high school takes on a value of one hundred if the student is enrolled in high school more than four years after entry but has not yet dropped out, and is zero otherwise. High school dropout takes on a value of one hundred if a student does not earn a high school diploma and is no longer enrolled in high school $5+$ years after entry, and is zero otherwise. All columns include controls for child year and month of birth as well as maternal age at birth, birth order, maternal education, marital status at birth, and maternal race-ethnicity. Robust standard errors are in parentheses. Point estimates marked $* *, *$, and $\sim$ are statistically significant at the 1,5 , and 10 percent levels, respectively. 
Table 5: The Relationship Between Elementary and Middle School Behavioral and Academic Measures and On-Time High School Completion

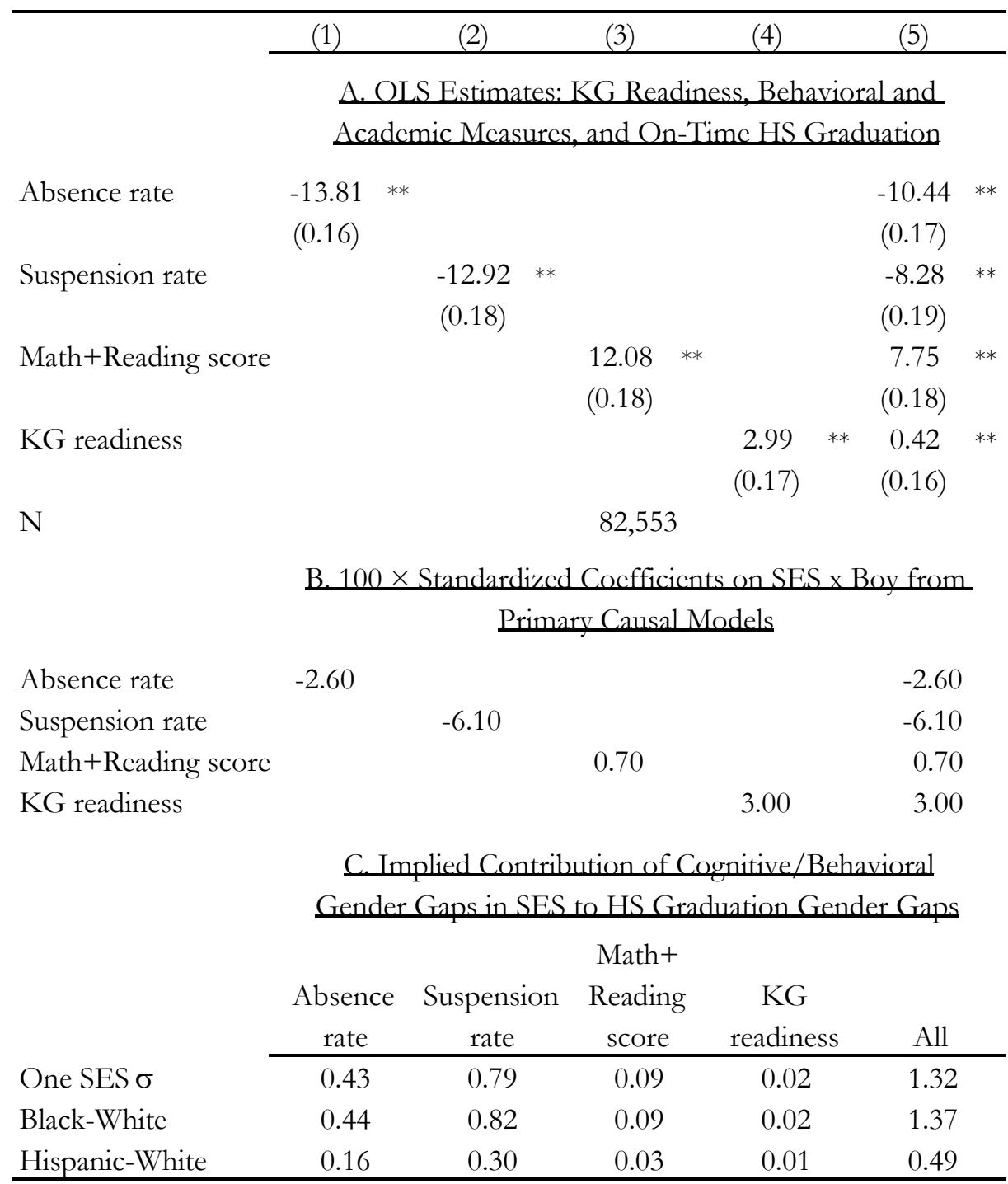

Note: Panel A of this table reports the results from regression of on-time high school graduation on absence rates, suspension rates, averaged reading and math scores, and kindergarten readiness, respectively, each standardized with mean zero and unit variance. All regressions also include controls for gender, race, ethnicity, interactions between racial-ethnic categories and gender, marital status at birth, maternal education, maternal age at birth, child year/month of birth and number of births. Panel B reports the coefficients on the interaction term Boy $\times$ SES in a standardized form based on the models estimated in Table 3 and Appendix Table A4. Due to data limitations necessitating the use of grades five to eight in Panel A, we re-estimate our models from Table 3 using only grades five through eight for the purpose of this exercise. Panel C reports the implied contribution of the estimated SES gradient in the gender gap on the gender gap in high school graduation, by multiplying the coefficients from panels A and B, and scaling the result by the standard deviation in SES, black/white SES gap, and Hispanic/white SES gap. 


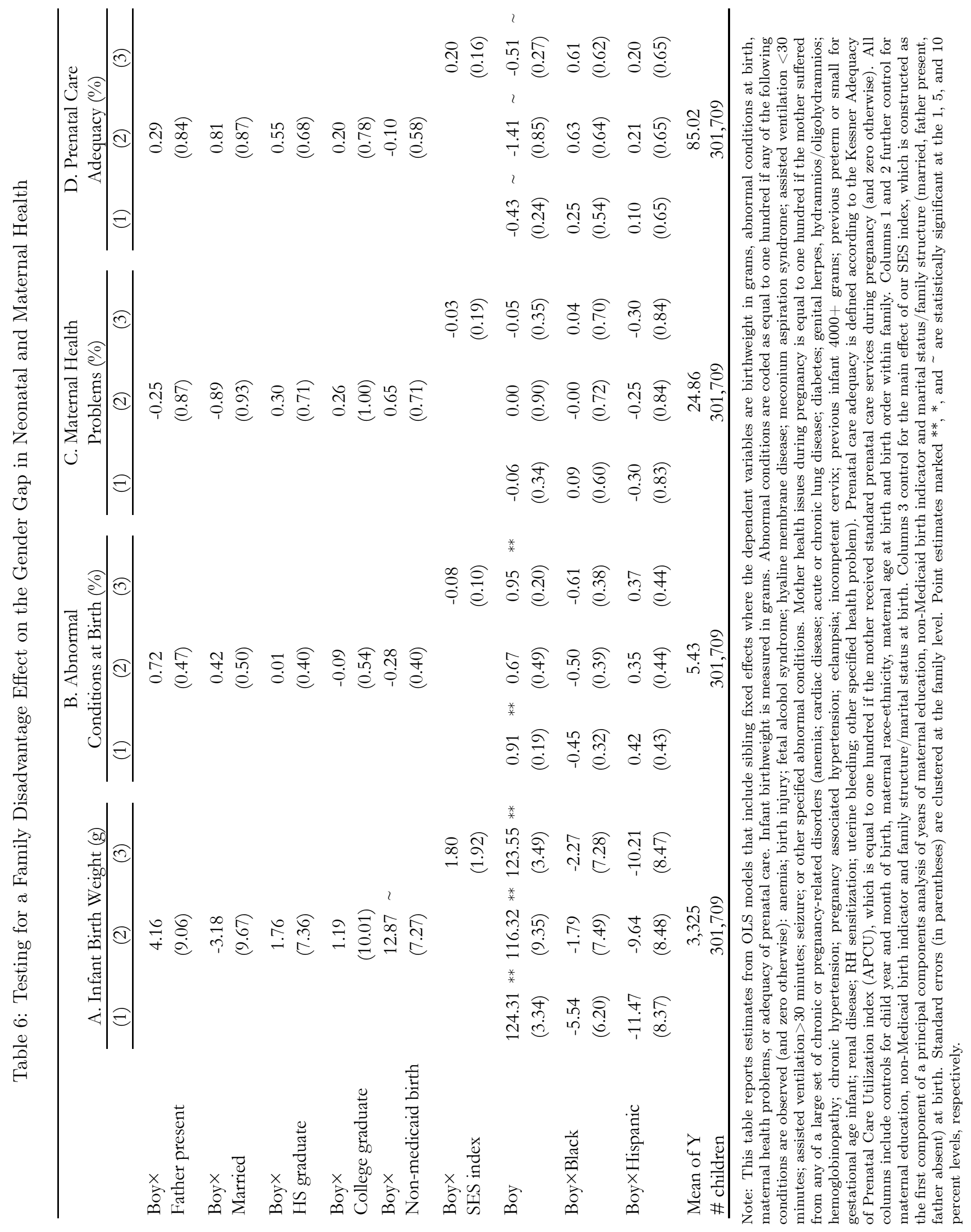


Table 7: Family Disadvantage and the Gender Gap in Physical and Cognitive/Behavioral Disabilities

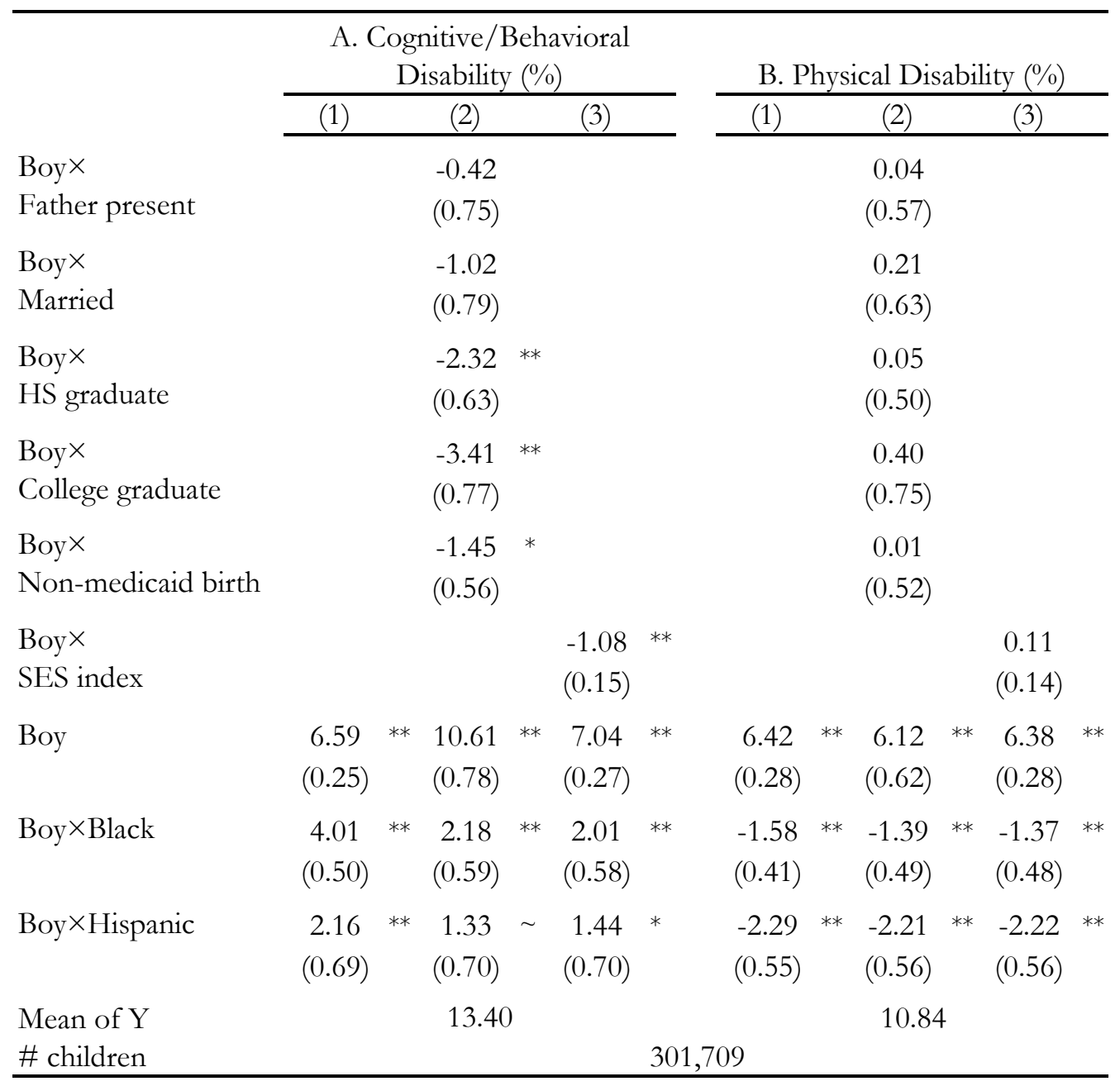

Note: This table reports estimates from OLS models that include sibling fixed effects where the dependent variables are the incidence of cognitive/behavioral disabilities and physical disabilities. Cognitive/behavioral disability takes on a value of one hundred if the child has one of the following conditions (and is zero otherwise): language impaired; intellectual disability subdivided in the early years of the data into educable mentally handicapped, trainable mentally handicapped, and profoundly mentally handicapped; developmental delay; specific learning disability; emotionally handicapped; severely emotionally disturbed; or autism spectrum disorders. Physical disability takes on a value of one hundred if the child has one of the following conditions (and is zero otherwise): orthopedically impaired; speech impaired; deaf or hard of hearing; visually impaired; hospital/homebound; dual-sensory impaired; traumatic brain injury; or established conditions. All columns include controls for child year and month of birth, maternal race-ethnicity, maternal age at birth and birth order within family. Columns 1 and 2 further control for maternal education, non-Medicaid birth indicator and family structure/marital status at birth. Column 3 controls for the main effect of our SES index, which is constructed as the first component of a principal components analysis of years of maternal education, non-Medicaid birth indicator and marital status/family structure (married, father present, father absent) at birth. Standard errors are clustered at the family level. Point estimates marked $*^{*}, *$, and $\sim$ are statistically significant at the 1,5 , and 10 percent levels, respectively. 
Table 8a: Determinants of the Gender Gap in Behavioral Outcomes: Neighborhood Income, School Quality and Economic Mobility

\begin{tabular}{|c|c|c|c|c|c|c|c|c|c|c|c|c|c|c|}
\hline \multirow{3}{*}{$\begin{array}{l}\text { Boy } \times \\
\text { SES index }\end{array}$} & $(1)$ & & $(2)$ & & (3) & & $(4)$ & & (5) & & $(6)$ & & $(7)$ & \\
\hline & \multicolumn{14}{|c|}{ A. Absence Rate (\%) } \\
\hline & & & $\begin{array}{l}-0.074 \\
(0.011)\end{array}$ & $* *$ & $\begin{array}{l}-0.070 \\
(0.012)\end{array}$ & $* *$ & $\begin{array}{l}-0.075 \\
(0.011)\end{array}$ & $* *$ & $\begin{array}{l}-0.056 \\
(0.012)\end{array}$ & $* *$ & $\begin{array}{l}-0.056 \\
(0.012)\end{array}$ & $* *$ & & \\
\hline $\begin{array}{l}\text { Boy } \times \text { Income in } \\
10000 \text { USD }\end{array}$ & & & & & $\begin{array}{l}-0.016 \\
(0.011)\end{array}$ & & & & & & $\begin{array}{l}-0.001 \\
(0.012)\end{array}$ & & $\begin{array}{l}-0.013 \\
(0.011)\end{array}$ & \\
\hline $\begin{array}{l}\text { Boy } \times \\
\text { Mobility }\end{array}$ & & & & & & & $\begin{array}{l}-0.104 \\
(0.080)\end{array}$ & & & & $\begin{array}{l}-0.140 \\
(0.081)\end{array}$ & $\sim$ & $\begin{array}{l}-0.147 \\
(0.081)\end{array}$ & $\sim$ \\
\hline $\begin{array}{l}\text { Boy } \times \\
\text { School Quality }\end{array}$ & & & & & & & & & $\begin{array}{l}-0.005 \\
(0.001)\end{array}$ & $* *$ & $\begin{array}{l}-0.005 \\
(0.001)\end{array}$ & $* *$ & $\begin{array}{l}-0.007 \\
(0.001)\end{array}$ & ** \\
\hline Boy & $\begin{array}{c}0.203 \\
(0.018)\end{array}$ & $* *$ & $\begin{array}{c}0.238 \\
(0.020)\end{array}$ & $* *$ & $\begin{array}{c}0.315 \\
(0.057)\end{array}$ & $* *$ & $\begin{array}{c}0.209 \\
(0.030)\end{array}$ & $* *$ & $\begin{array}{c}0.520 \\
(0.061)\end{array}$ & $* *$ & $\begin{array}{c}0.494 \\
(0.072)\end{array}$ & $* *$ & $\begin{array}{c}0.604 \\
(0.072)\end{array}$ & ** \\
\hline Boy $\times$ Black & $\begin{array}{c}0.307 \\
(0.036)\end{array}$ & $* *$ & $\begin{array}{c}0.166 \\
(0.043)\end{array}$ & $* *$ & $\begin{array}{c}0.153 \\
(0.043)\end{array}$ & $* *$ & $\begin{array}{c}0.166 \\
(0.043)\end{array}$ & $* *$ & $\begin{array}{c}0.126 \\
(0.043)\end{array}$ & $* *$ & $\begin{array}{c}0.125 \\
(0.044)\end{array}$ & $* *$ & $\begin{array}{c}0.197 \\
(0.040)\end{array}$ & $* *$ \\
\hline $\begin{array}{l}\text { Boy } \times \text { Hispanic } \\
\text { Mean of Y } \\
\# \text { children }\end{array}$ & $\begin{array}{c}0.123 \\
(0.045)\end{array}$ & $* *$ & $\begin{array}{c}0.073 \\
(0.046)\end{array}$ & & $\begin{array}{c}0.068 \\
(0.046)\end{array}$ & & $\begin{array}{r}0.071 \\
(0.046) \\
4.83 \\
280,9\end{array}$ & & $\begin{array}{c}0.071 \\
(0.046)\end{array}$ & & $\begin{array}{c}0.068 \\
(0.046)\end{array}$ & & $\begin{array}{c}0.096 \\
(0.045)\end{array}$ & $*$ \\
\hline $\begin{array}{l}\text { Mean of Y } \\
\# \text { children }\end{array}$ & \multicolumn{14}{|c|}{ B. Suspension Rate $(\%)$} \\
\hline $\begin{array}{l}\text { Boy } \times \\
\text { SES index }\end{array}$ & & & $\begin{array}{l}-2.15 \\
(0.08)\end{array}$ & $* *$ & $\begin{array}{l}-1.98 \\
(0.08)\end{array}$ & $* *$ & $\begin{array}{l}-2.15 \\
(0.08)\end{array}$ & $* *$ & $\begin{array}{l}-1.79 \\
(0.08)\end{array}$ & $* *$ & $\begin{array}{l}-1.74 \\
(0.08)\end{array}$ & $* *$ & & \\
\hline $\begin{array}{l}\text { Boy } \times \text { Income in } \\
10000 \text { USD }\end{array}$ & & & & & $\begin{array}{l}-0.62 \\
(0.08)\end{array}$ & $* *$ & & & & & $\begin{array}{l}-0.32 \\
(0.08)\end{array}$ & $* *$ & $\begin{array}{l}-0.70 \\
(0.08)\end{array}$ & ** \\
\hline $\begin{array}{l}\text { Boy } \times \\
\text { Mobility }\end{array}$ & & & & & & & $\begin{array}{l}-0.09 \\
(0.58)\end{array}$ & & & & $\begin{array}{l}-1.03 \\
(0.59)\end{array}$ & $\sim$ & $\begin{array}{l}-1.25 \\
(0.60)\end{array}$ & $*$ \\
\hline $\begin{array}{l}\text { Boy } \times \\
\text { School Quality }\end{array}$ & & & & & & & & & $\begin{array}{l}-0.10 \\
(0.01)\end{array}$ & $* *$ & $\begin{array}{l}-0.10 \\
(0.01)\end{array}$ & $* *$ & $\begin{array}{l}-0.14 \\
(0.01)\end{array}$ & ** \\
\hline Boy & $\begin{array}{c}6.91 \\
(0.11)\end{array}$ & $* *$ & $\begin{array}{c}7.90 \\
(0.13)\end{array}$ & $* *$ & $\begin{array}{l}10.88 \\
(0.40)\end{array}$ & $* *$ & $\begin{array}{l}7.88 \\
(0.21)\end{array}$ & $* *$ & $\begin{array}{l}13.48 \\
(0.42)\end{array}$ & $* *$ & $\begin{array}{l}14.33 \\
(0.50)\end{array}$ & $* *$ & $\begin{array}{l}17.74 \\
(0.49)\end{array}$ & ** \\
\hline Boy $\times$ Black & $\begin{array}{c}6.44 \\
(0.28)\end{array}$ & $* *$ & $\begin{array}{c}2.34 \\
(0.32)\end{array}$ & $* *$ & $\begin{array}{c}1.86 \\
(0.33)\end{array}$ & $* *$ & $\begin{array}{c}2.34 \\
(0.32)\end{array}$ & $* *$ & $\begin{array}{c}1.56 \\
(0.32)\end{array}$ & $* *$ & $\begin{array}{c}1.38 \\
(0.33)\end{array}$ & $* *$ & $\begin{array}{c}3.59 \\
(0.31)\end{array}$ & ** \\
\hline Boy $\times$ Hispanic & $\begin{array}{c}0.09 \\
(0.32)\end{array}$ & & $\begin{array}{l}-1.35 \\
(0.32)\end{array}$ & $* *$ & $\begin{array}{l}-1.54 \\
(0.32)\end{array}$ & $* *$ & $\begin{array}{l}-1.35 \\
(0.32)\end{array}$ & $* *$ & $\begin{array}{l}-1.39 \\
(0.32)\end{array}$ & $* *$ & $\begin{array}{l}-1.51 \\
(0.32)\end{array}$ & $* *$ & $\begin{array}{l}-0.65 \\
(0.31)\end{array}$ & $*$ \\
\hline $\begin{array}{l}\text { Mean of Y } \\
\text { \# children }\end{array}$ & & & & & & & $\begin{array}{r}12.2 \\
280,9\end{array}$ & & & & & & & \\
\hline
\end{tabular}

Note: See note to Table $8 \mathrm{~b}$. 
Table 8b: Determinants of the Gender Gap in Academic Outcomes: Neighborhood Income, School Quality and Economic Mobility

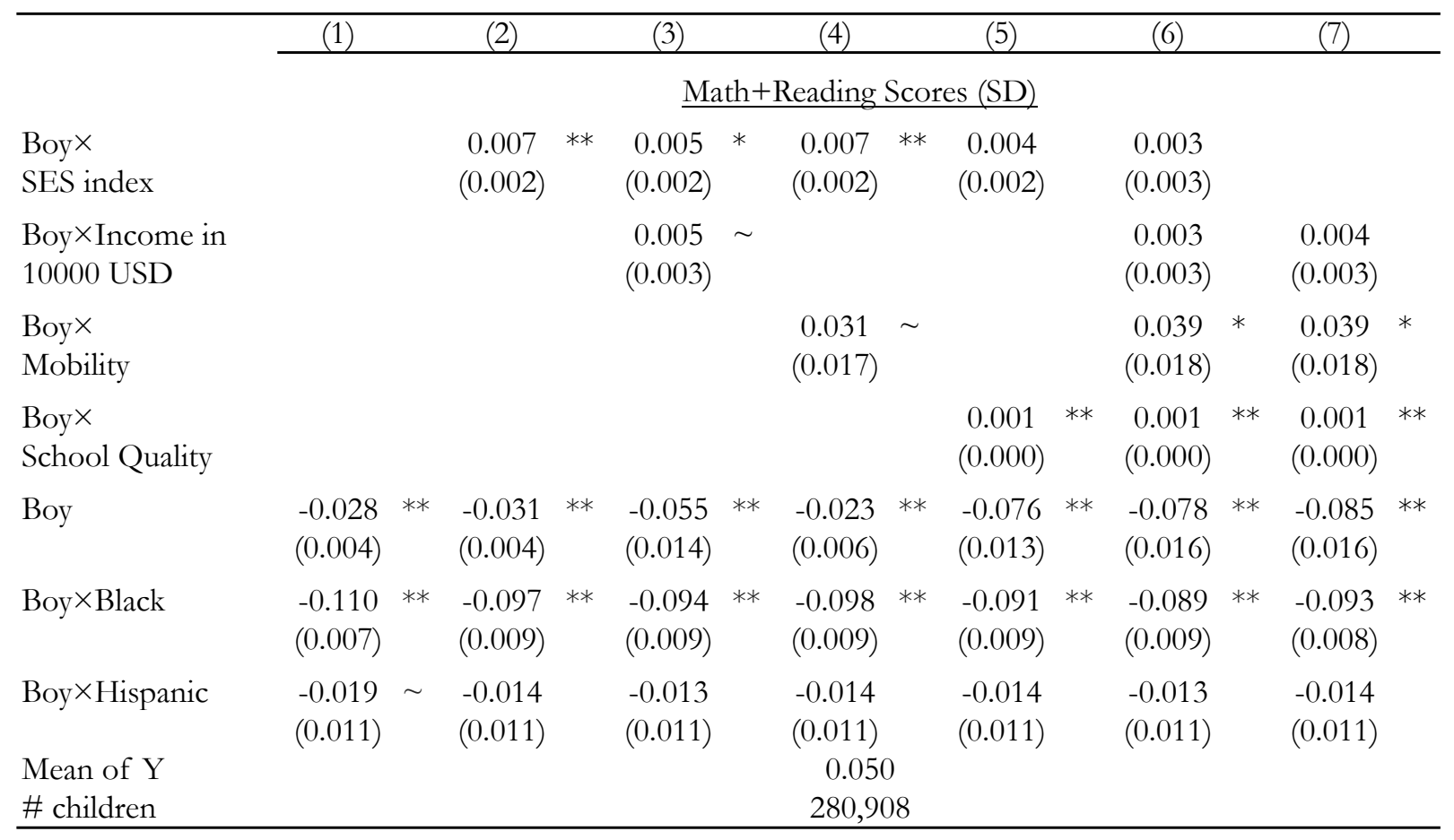

Note: These tables presents results from OLS models that include sibling fixed effects where the dependent variables are the absence rate, suspension rate, or combined standardized FCAT math and reading test scores, from grades three through eight. All columns include controls for child year and month of birth, maternal race-ethnicity, maternal age at birth, and birth order within family, the SES index, income of the zip code of residence at the time of birth, the Chetty-Hendren mobility measure, and the school quality measure. Column 2 additionally includes the interaction of boy and the SES index. Column 3 further includes the interaction of boy and income of the zip code of residence at the time of birth. Column 4 includes the interaction of boy and the Chetty-Hendren mobility measure. Column 5 includes the interaction of boy and school quality. Column 6 includes the interactions of all four measures with boy simultaneously. Column 7 replicates column 6 but excludes interaction between boy and SES index. The sample excludes families for whom zip code or school quality are not known. Standard errors are clustered at the family level. Point estimates marked ${ }^{* *},{ }^{*}$, and $\sim$ are statistically significant at the 1,5 , and 10 percent levels, respectively. 


\section{Appendix Tables}

Table A1: Descriptive Statistics: Behavioral and Academic Outcomes in Grades 3 - 8

\begin{tabular}{|c|c|c|c|c|}
\hline & $\begin{array}{l}\text { All } \\
(1)\end{array}$ & $\begin{array}{c}\text { White Non- } \\
\text { Hispanic } \\
(2) \\
\end{array}$ & $\begin{array}{c}\text { Black Non- } \\
\text { Hispanic } \\
(3) \\
\end{array}$ & $\begin{array}{c}\text { Hispanic } \\
\text { (4) }\end{array}$ \\
\hline & \multicolumn{4}{|c|}{$\underline{\text { A. Means }}$} \\
\hline $\begin{array}{l}\text { Kindergarten } \\
\text { ready }(\%)\end{array}$ & $\begin{array}{l}83.05 \\
(37.52) \\
55,419\end{array}$ & $\begin{array}{c}87.18 \\
(33.43) \\
30,329\end{array}$ & $\begin{array}{c}77.26 \\
(41.92) \\
18,787\end{array}$ & $\begin{array}{c}80.47 \\
(39.65) \\
6,303\end{array}$ \\
\hline $\begin{array}{l}\text { Absence } \\
\text { rate }(\%)\end{array}$ & $\begin{array}{c}4.89 \\
(5.30) \\
1,099,317\end{array}$ & $\begin{array}{c}4.68 \\
(4.96) \\
654,896\end{array}$ & $\begin{array}{c}5.28 \\
(5.99) \\
323,400\end{array}$ & $\begin{array}{c}4.93 \\
(5.04) \\
121,021\end{array}$ \\
\hline $\begin{array}{l}\text { Suspension } \\
\text { rate }(\%)\end{array}$ & $\begin{array}{c}12.37 \\
(32.92) \\
1,099,317\end{array}$ & $\begin{array}{c}7.30 \\
(26.01) \\
654,896\end{array}$ & $\begin{array}{c}23.86 \\
(42.62) \\
323,400\end{array}$ & $\begin{array}{c}9.11 \\
(28.78) \\
121,021\end{array}$ \\
\hline \multirow[t]{2}{*}{$\begin{array}{l}\text { Math+Reading } \\
\text { score (SD) }\end{array}$} & $\begin{array}{c}0.05 \\
(0.92) \\
1,274,816\end{array}$ & $\begin{array}{c}0.32 \\
(0.86) \\
758,127\end{array}$ & $\begin{array}{c}-0.49 \\
(0.83) \\
374,255\end{array}$ & $\begin{array}{c}-0.01 \\
(0.86) \\
142,434\end{array}$ \\
\hline & \multicolumn{4}{|c|}{ B. Boy-Girl Differences } \\
\hline $\begin{array}{l}\text { Kindergarten } \\
\text { ready }(\%)\end{array}$ & $\begin{array}{c}-6.90 \\
(0.32) \\
55,419\end{array}$ & $\begin{array}{c}-5.83 \\
(0.38) \\
30,329\end{array}$ & $\begin{array}{c}-8.42 \\
(0.61) \\
18,787\end{array}$ & $\begin{array}{l}-8.24 \\
(0.99) \\
6,303\end{array}$ \\
\hline $\begin{array}{l}\text { Absence } \\
\text { rate }(\%)\end{array}$ & $\begin{array}{c}0.26 \\
(0.01) \\
1,099,317\end{array}$ & $\begin{array}{c}0.14 \\
(0.01) \\
654,896\end{array}$ & $\begin{array}{c}0.53 \\
(0.02) \\
323,400\end{array}$ & $\begin{array}{c}0.27 \\
(0.03) \\
121,021\end{array}$ \\
\hline $\begin{array}{l}\text { Suspension } \\
\text { rate }(\%)\end{array}$ & $\begin{array}{c}8.60 \\
(0.06) \\
1,099,317\end{array}$ & $\begin{array}{c}6.97 \\
(0.06) \\
654,896\end{array}$ & $\begin{array}{c}13.14 \\
(0.15) \\
323,400\end{array}$ & $\begin{array}{c}7.38 \\
(0.16) \\
121,021\end{array}$ \\
\hline $\begin{array}{l}\text { Math+Reading } \\
\text { score (SD) }\end{array}$ & $\begin{array}{c}-0.06 \\
(0.00) \\
1,274,816\end{array}$ & $\begin{array}{c}-0.04 \\
(0.00) \\
758,127\end{array}$ & $\begin{array}{c}-0.14 \\
(0.00) \\
374,255\end{array}$ & $\begin{array}{c}-0.06 \\
(0.00) \\
142,434\end{array}$ \\
\hline
\end{tabular}

Note: This table reports mean absence rates (multiplied by 100), ever suspended rates (multiplied by 100), and standardized Florida Comprehensive Assessment Test (FCAT) math and reading scores, by race-ethnicity category, from the pooled sample of non-twin siblings, spanning grades three through eight, with each child contributing up to one observation per grade observed in each year. Absence and suspension rates as well as test scores are for birth cohorts 1994-2002. It additionally reports kindergarten readiness rates (multiplied by 100), computed from the pooled sample of non-twin siblings born in cohorts 1994 to 1996 and 2000 to 2002. Standard deviations are reported in parentheses. Numbers of observations are recorded beneath each standard deviation. 
Table A2: High School Completion Rates (1992 and 1993 Birth Cohorts)

\begin{tabular}{|c|c|c|c|c|}
\hline & $\begin{array}{l}\text { All } \\
(1) \\
\end{array}$ & $\begin{array}{c}\text { White Non- } \\
\text { Hispanic } \\
(2) \\
\end{array}$ & $\begin{array}{c}\text { Black Non- } \\
\text { Hispanic } \\
\text { (3) }\end{array}$ & $\begin{array}{c}\text { Hispanic } \\
(4)\end{array}$ \\
\hline & \multicolumn{4}{|c|}{ A. Means $(\%)$} \\
\hline On-time graduate & 70.42 & 72.70 & 64.63 & 68.00 \\
\hline $5+$ years & 12.75 & 10.39 & 19.15 & 13.78 \\
\hline \multirow[t]{2}{*}{ Dropout } & 16.83 & 16.91 & 16.22 & 18.22 \\
\hline & \multicolumn{4}{|c|}{ B. Boy-Girl Differences } \\
\hline On-time graduate & $\begin{array}{l}-7.43 \\
(0.23)\end{array}$ & $\begin{array}{l}-5.69 \\
(0.27)\end{array}$ & $\begin{array}{c}-12.74 \\
(0.48)\end{array}$ & $\begin{array}{l}-8.04 \\
(0.90)\end{array}$ \\
\hline $5+$ years & $\begin{array}{c}4.40 \\
(0.17)\end{array}$ & $\begin{array}{c}3.78 \\
(0.18)\end{array}$ & $\begin{array}{c}6.83 \\
(0.39)\end{array}$ & $\begin{array}{c}4.20 \\
(0.67)\end{array}$ \\
\hline Dropout & $\begin{array}{c}3.02 \\
(0.19)\end{array}$ & $\begin{array}{c}1.91 \\
(0.22)\end{array}$ & $\begin{array}{c}5.91 \\
(0.37)\end{array}$ & $\begin{array}{c}3.85 \\
(0.75)\end{array}$ \\
\hline \# students & 161,537 & 111,454 & 39,517 & 10,566 \\
\hline
\end{tabular}

Note: This table reports on-time high graduation rates, continuation in high school rates, and high school dropout rates, by race-ethnicity category, from the sample of non-twin singletons who were observed in Florida public schools until at least ninth grade. All rates and boy-girl differences are multiplied by 100. On-time high school completion indicates a high school diploma within four years of entering. $5+$ years of high school indicates that student is enrolled in high school more than four years after entry but had not yet dropped out. High school dropout indicates that an individual does not earn a high school diploma and is no longer enrolled in high school $5+$ years after entry. Standard deviations for male-female contrasts are reported in parentheses in panel B. 


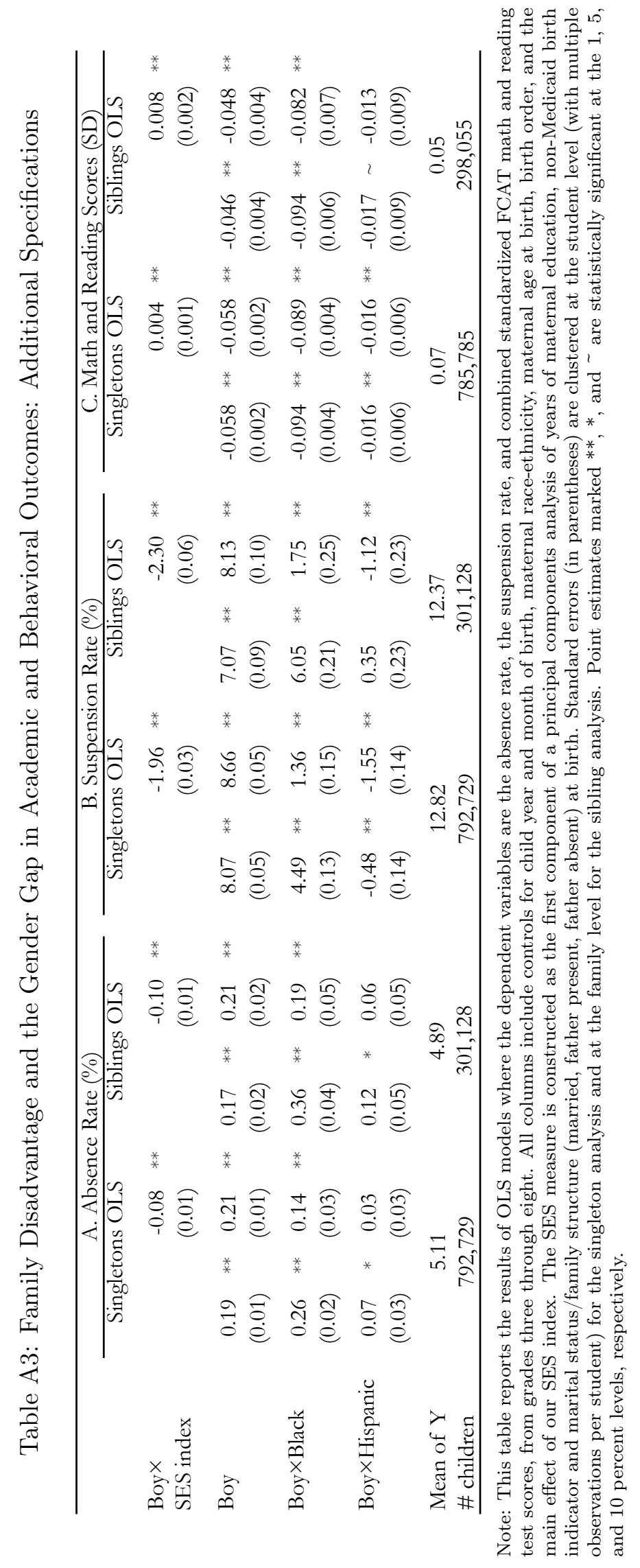


Table A4: Family Disadvantage and the Gender Gap in Kindergarten Readiness

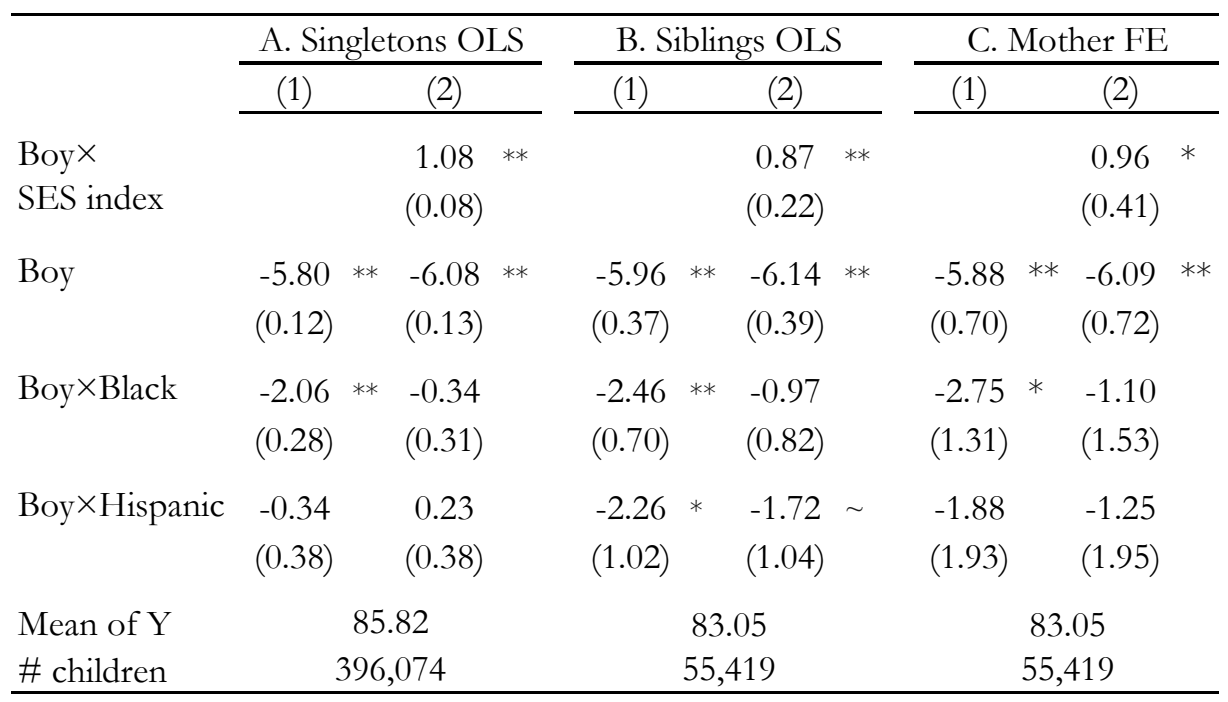

Note: This table reports the results of OLS models with and without sibling fixed effects where the dependent variable is the kindergarten readiness, which takes on a value of one hundred if the child is determined to be ready for kindergarten, and zero otherwise. All columns include controls for child year and month of birth, maternal race-ethnicity, maternal age at birth, birth order within family or sibling composition, and the main effect of our SES index. The SES measure is constructed as the first component of a principal components analysis of years of maternal education, non-Medicaid birth indicator and marital status/family structure (married, father present, father absent) at birth. In panel A, we use robust standard errors. In panels $\mathrm{B}$ and $\mathrm{C}$, standard errors are clustered at the family level. Point estimates marked **, *, and $\sim$ are statistically significant at the 1,5 , and 10 percent levels, respectively. 
Table A5: The Sibling Gender Gap in Behavioral Outcomes in Complex Families: Distinct Fathers with Same or Different Marital Status at Birth

\begin{tabular}{|c|c|c|c|c|c|c|c|c|c|c|c|c|}
\hline & \multicolumn{6}{|c|}{ A. Absence Rate $(\%)$} & \multicolumn{6}{|c|}{ B. Suspension Rate $(\%)$} \\
\hline & $\begin{array}{c}\text { All } \\
\text { Marital } \\
\text { Statuses } \\
(1) \\
\end{array}$ & & $\begin{array}{c}\text { Same } \\
\text { Marital } \\
\text { Status } \\
(2) \\
\end{array}$ & & $\begin{array}{c}\text { Different } \\
\text { Marital } \\
\text { Status } \\
\text { (3) } \\
\end{array}$ & & $\begin{array}{c}\text { All } \\
\text { Marital } \\
\text { Statuses } \\
\quad(1) \\
\end{array}$ & & $\begin{array}{c}\text { Same } \\
\text { Marital } \\
\text { Status } \\
(2) \\
\end{array}$ & & $\begin{array}{c}\text { Differen } \\
\text { Marital } \\
\text { Status } \\
\text { (3) } \\
\end{array}$ & \\
\hline $\begin{array}{l}\text { Boy } \times \\
\text { Father present }\end{array}$ & $\begin{array}{l}-0.16 \\
(0.07)\end{array}$ & * & $\begin{array}{l}-0.39 \\
(0.12)\end{array}$ & $* *$ & $\begin{array}{l}-0.04 \\
(0.08)\end{array}$ & & $\begin{array}{l}-0.64 \\
(0.47)\end{array}$ & & $\begin{array}{l}-1.77 \\
(0.87)\end{array}$ & * & $\begin{array}{l}-0.16 \\
(0.57)\end{array}$ & \\
\hline $\begin{array}{l}\text { Boy } \times \\
\text { Married }\end{array}$ & $\begin{array}{l}-0.21 \\
(0.09)\end{array}$ & $*$ & $\begin{array}{l}-0.35 \\
(0.15)\end{array}$ & $*$ & $\begin{array}{l}-0.13 \\
(0.11)\end{array}$ & & $\begin{array}{l}-2.32 \\
(0.59)\end{array}$ & $* *$ & $\begin{array}{l}-4.52 \\
(1.07)\end{array}$ & $* *$ & $\begin{array}{l}-1.12 \\
(0.73)\end{array}$ & \\
\hline $\begin{array}{l}\text { Boy } \times \\
\text { HS graduate }\end{array}$ & $\begin{array}{l}-0.01 \\
(0.06)\end{array}$ & & $\begin{array}{l}-0.03 \\
(0.11)\end{array}$ & & $\begin{array}{c}0.01 \\
(0.08)\end{array}$ & & $\begin{array}{l}-1.98 \\
(0.45)\end{array}$ & $* *$ & $\begin{array}{l}-1.09 \\
(0.75)\end{array}$ & & $\begin{array}{l}-2.40 \\
(0.56)\end{array}$ & $* *$ \\
\hline $\begin{array}{l}\text { Boy } \times \\
\text { College graduate }\end{array}$ & $\begin{array}{l}-0.06 \\
(0.13)\end{array}$ & & $\begin{array}{l}-0.18 \\
(0.18)\end{array}$ & & $\begin{array}{c}0.20 \\
(0.21)\end{array}$ & & $\begin{array}{l}-5.25 \\
(0.91)\end{array}$ & $* *$ & $\begin{array}{l}-4.03 \\
(1.19)\end{array}$ & $* *$ & $\begin{array}{l}-4.81 \\
(1.61)\end{array}$ & ** \\
\hline $\begin{array}{l}\text { Boy } \times \text { Non- } \\
\text { medicaid birth }\end{array}$ & $\begin{array}{l}-0.17 \\
(0.07)\end{array}$ & $*$ & $\begin{array}{l}-0.13 \\
(0.12)\end{array}$ & & $\begin{array}{l}-0.17 \\
(0.10)\end{array}$ & $\sim$ & $\begin{array}{l}-3.05 \\
(0.52)\end{array}$ & $* *$ & $\begin{array}{l}-2.85 \\
(0.85)\end{array}$ & $* *$ & $\begin{array}{l}-2.80 \\
(0.68)\end{array}$ & $* *$ \\
\hline Boy & $\begin{array}{c}0.57 \\
(0.08)\end{array}$ & $* *$ & $\begin{array}{c}0.70 \\
(0.13)\end{array}$ & $* *$ & $\begin{array}{c}0.49 \\
(0.10)\end{array}$ & $* *$ & $\begin{array}{l}14.84 \\
(0.51)\end{array}$ & $* *$ & $\begin{array}{l}14.69 \\
(0.90)\end{array}$ & $* *$ & $\begin{array}{l}14.94 \\
(0.64)\end{array}$ & $* *$ \\
\hline Boy $\times$ Black & $\begin{array}{c}0.13 \\
(0.07)\end{array}$ & $\sim$ & $\begin{array}{c}0.08 \\
(0.12)\end{array}$ & & $\begin{array}{c}0.12 \\
(0.09)\end{array}$ & & $\begin{array}{c}1.21 \\
(0.47)\end{array}$ & $* *$ & $\begin{array}{c}1.21 \\
(0.85)\end{array}$ & & $\begin{array}{c}0.96 \\
(0.57)\end{array}$ & $\sim$ \\
\hline Boy $\times$ Hispanic & $\begin{array}{c}0.02 \\
(0.10)\end{array}$ & & $\begin{array}{c}0.05 \\
(0.16)\end{array}$ & & $\begin{array}{c}0.01 \\
(0.13)\end{array}$ & & $\begin{array}{l}-2.16 \\
(0.66)\end{array}$ & $* *$ & $\begin{array}{l}-1.58 \\
(1.06)\end{array}$ & & $\begin{array}{l}-2.54 \\
(0.84)\end{array}$ & $* *$ \\
\hline $\begin{array}{l}\text { Mean of Y } \\
\text { \# Families }\end{array}$ & $\begin{array}{r}5.83 \\
49,467 \\
\end{array}$ & & $\begin{array}{c}5.88 \\
21,331 \\
\end{array}$ & & $\begin{array}{c}5.81 \\
28,136\end{array}$ & & $\begin{array}{c}21.05 \\
49,467\end{array}$ & & $\begin{array}{c}21.34 \\
21,331\end{array}$ & & $\begin{array}{c}20.86 \\
28,136 \\
\end{array}$ & \\
\hline
\end{tabular}

Note: This table presents the results of OLS models with sibling fixed effects in which the sample includes only siblings born to distinct fathers with the same mother. Births for which no paternity is claimed are coded as having a distinct father. The sample in column 1 includes siblings with concordant and discordant marital statuses at birth. The sample in column 2 uses siblings with concordant marital statuses at birth, while column 3 uses siblings with discordant marital statuses. In all cases, marital status indicates the mother's marital status at the time of birth. Standard errors (in parentheses) are clustered at the family level. Point estimates marked **, ${ }^{*}$, and are statistically significant at the 1, 5, and 10 percent levels, respectively. 
Table A6: Descriptive Statistics: Neonatal and Medium-Term Health Outcomes

\begin{tabular}{|c|c|c|c|c|}
\hline & $\begin{array}{l}\text { All } \\
(1) \\
\end{array}$ & $\begin{array}{c}\text { White Non- } \\
\text { Hispanic } \\
(2) \\
\end{array}$ & $\begin{array}{c}\text { Black Non- } \\
\text { Hispanic } \\
(3) \\
\end{array}$ & $\begin{array}{c}\text { Hispanic } \\
(4) \\
\end{array}$ \\
\hline & \multicolumn{4}{|c|}{ A. Means } \\
\hline Infant birth weight (g) & 3325 & 3414 & 3149 & 3319 \\
\hline Apgar 5 score & 8.97 & 8.98 & 8.93 & 8.97 \\
\hline Adequate prenatal care (\%) & 85.02 & 90.36 & 73.67 & 86.62 \\
\hline Maternal health issues (\%) & 24.86 & 24.12 & 27.81 & 21.09 \\
\hline Abnormal conditions $(\%)$ & 5.43 & 5.63 & 5.23 & 4.85 \\
\hline Congenital anomalies (\%) & 0.67 & 0.67 & 0.74 & 0.54 \\
\hline Complications of delivery (\%) & 27.51 & 27.50 & 27.98 & 26.35 \\
\hline Weeks of gestation & 38.77 & 38.91 & 38.49 & 38.76 \\
\hline Cognitive/Behavioral disability (\%) & 13.40 & 11.05 & 17.71 & 14.48 \\
\hline \multirow[t]{2}{*}{ Physical disability (\%) } & 10.84 & 13.36 & 7.25 & 7.01 \\
\hline & \multicolumn{4}{|c|}{ B. Boy-Girl Differences } \\
\hline Infant birth weight (g) & $\begin{array}{l}122 \\
(2)\end{array}$ & $\begin{array}{c}119 \\
(2)\end{array}$ & $\begin{array}{l}123 \\
(4)\end{array}$ & $\begin{array}{l}106 \\
(6)\end{array}$ \\
\hline Apgar 5 score & $\begin{array}{l}-0.01 \\
(0.00)\end{array}$ & $\begin{array}{l}-0.01 \\
(0.00)\end{array}$ & $\begin{array}{l}-0.01 \\
(0.00)\end{array}$ & $\begin{array}{l}-0.01 \\
(0.01)\end{array}$ \\
\hline Adequate prenatal care $(\%)$ & $\begin{array}{c}-0.02 \\
(0.13)\end{array}$ & $\begin{array}{l}-0.30 \\
(0.14)\end{array}$ & $\begin{array}{l}-0.05 \\
(0.30)\end{array}$ & $\begin{array}{l}-0.37 \\
(0.37)\end{array}$ \\
\hline Maternal health issues (\%) & $\begin{array}{c}-0.02 \\
(0.16)\end{array}$ & $\begin{array}{l}-0.04 \\
(0.20)\end{array}$ & $\begin{array}{c}0.28 \\
(0.30)\end{array}$ & $\begin{array}{l}-0.21 \\
(0.44)\end{array}$ \\
\hline Abnormal conditions $(\%)$ & $\begin{array}{c}0.78 \\
(0.08)\end{array}$ & $\begin{array}{c}0.94 \\
(0.11)\end{array}$ & $\begin{array}{c}0.37 \\
(0.15)\end{array}$ & $\begin{array}{c}0.98 \\
(0.23)\end{array}$ \\
\hline Congenital anomalies (\%) & $\begin{array}{c}0.12 \\
(0.03)\end{array}$ & $\begin{array}{c}0.15 \\
(0.04)\end{array}$ & $\begin{array}{c}0.02 \\
(0.06)\end{array}$ & $\begin{array}{c}0.23 \\
(0.08)\end{array}$ \\
\hline Complications of delivery (\%) & $\begin{array}{c}0.90 \\
(0.16)\end{array}$ & $\begin{array}{c}0.66 \\
(0.21)\end{array}$ & $\begin{array}{c}1.07 \\
(0.30)\end{array}$ & $\begin{array}{c}1.83 \\
(0.48)\end{array}$ \\
\hline Weeks of gestation & $\begin{array}{l}-0.03 \\
(0.01)\end{array}$ & $\begin{array}{l}-0.07 \\
(0.01)\end{array}$ & $\begin{array}{c}0.04 \\
(0.02)\end{array}$ & $\begin{array}{l}-0.05 \\
(0.02)\end{array}$ \\
\hline Cognitive/Behavioral disability (\%) & $\begin{array}{c}8.03 \\
(0.12)\end{array}$ & $\begin{array}{c}6.94 \\
(0.15)\end{array}$ & $\begin{array}{l}10.32 \\
(0.25)\end{array}$ & $\begin{array}{c}8.46 \\
(0.38)\end{array}$ \\
\hline Physical disability (\%) & $\begin{array}{c}5.65 \\
(0.11)\end{array}$ & $\begin{array}{c}6.28 \\
(0.16)\end{array}$ & $\begin{array}{c}4.87 \\
(0.17)\end{array}$ & $\begin{array}{c}3.75 \\
(0.27)\end{array}$ \\
\hline
\end{tabular}


Note: This table presents summary statistics for children's at-birth and medium-run health outcomes. Prenatal care adequacy is defined according to the Kessner Adequacy of Prenatal Care Utilization index (APCU), which is equal to one hundred if the mother received standard prenatal care services during pregnancy (and zero otherwise). Maternal health issues during pregnancy is equal to one hundred if the mother suffered from any of a large set of chronic or pregnancy-related disorders during pregnancy or delivery: anemia; cardiac disease; acute or chronic lung disease; diabetes; genital herpes, hydramnios/oligohydramnios; hemoglobinopathy; chronic hypertension; pregnancy associated hypertension; eclampsia; incompetent cervix; previous infant 4000 + grams; previous preterm or small for gestational age infant; renal disease; RH sensitization; uterine bleeding; other specified health problem. Abnormal conditions are coded as equal to one hundred if any of the following conditions are observed (and zero otherwise): anemia; birth injury; fetal alcohol syndrome; hyaline membrane disease; meconium aspiration syndrome; assisted ventilation $<30$ minutes; assisted ventilation $>30$ minutes; seizure; or other specified abnormal conditions. Congenital anomalies are coded as equal to one hundred if any of the following conditions are observed: anencephalus; spina bifida/meninocele; hydrocephalus; microcephalus; other central nervous system anomalies; heart malformations; other circulatory/respiratory anomalies; rectal atresia/stenosis; trachea esophageal fistula/esophageal atresia; omphalocele/gastroschisis; other gastrointestinal anomalies; malformed genitalia; renal agenisis; other urogenital anomalies; cleft lip/palate; polydactyly/syndactyly/adactyly; club foot; diaphragmatic hernia; other musculoskeletal/integumental anomalies; Downs Syndrome; other chromosomal anomalies; or other specified congenital anomalies. Complications of labor and delivery are coded as equal to one hundred if any of the following conditions are observed: febrile; moderate/heavy meconium; premature rupture of membranes; abruptio placenta; placenta previa; other excessive bleeding; seizures during labor; precipitous labor; prolonged labor; dysfunctional labor; breech/malpresentation; cephalopelvic disproportion; cord prolapse; anesthetic complications; fetal distress; or other specified complication. Cognitive and behavioral disabilities include language impaired; intellectual disability (subdivided in the early years of the data into educable mentally handicapped, trainable mentally handicapped, and profoundly mentally handicapped); developmental delay; specific learning disability; emotionally handicapped; severely emotionally disturbed; and autism spectrum disorders. Physical disabilities include orthopedically impaired; speech impaired; deaf or hard of hearing; visually impaired; hospital/homebound; dual-sensory impaired; traumatic brain injury; and established conditions identified by age two. Numbers of observations for infant birthweight and disabilities: 301,709 for all; 178,517 for white non-Hispanic; 88,894 for black non-Hispanic and 34,298 for Hispanic mother. Sample sizes vary slightly (by less that $0.1 \%$ ) for the other birth outcomes. 


\section{For Online Publication: Online Appendix}

Figure O1: Boy-Girl Gaps in Infant birthweight, Abnormal Conditions at Birth, Maternal Health Problems, and Prenatal Care Adequacy, by SES

A. Infant Birthweight

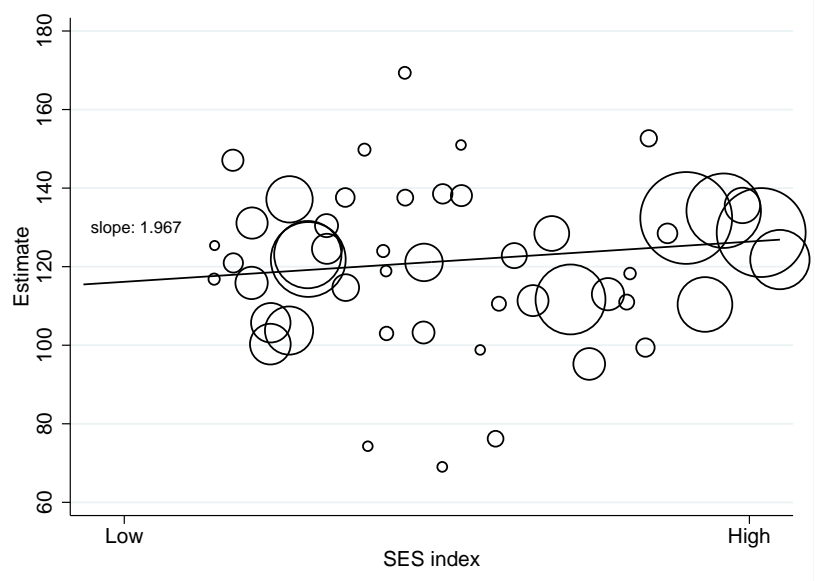

C. Maternal Health Issues in Pregnancy

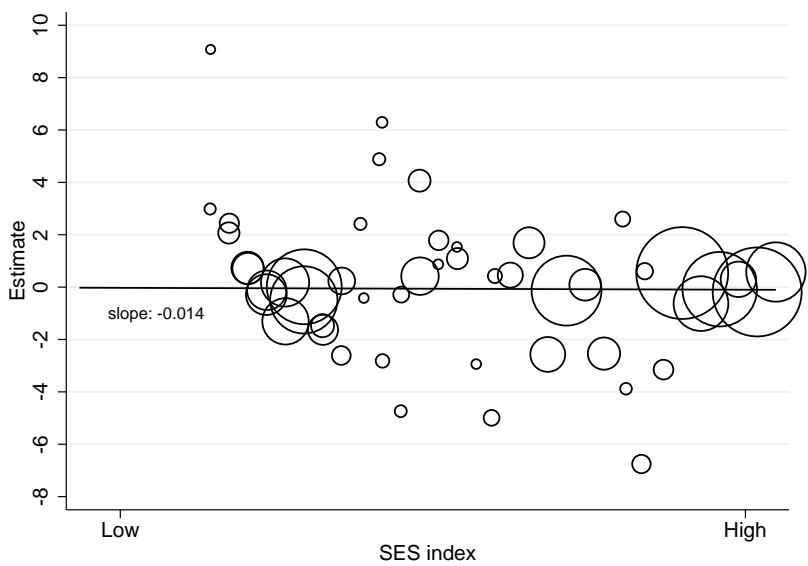

B. Abnormal Conditions at Birth

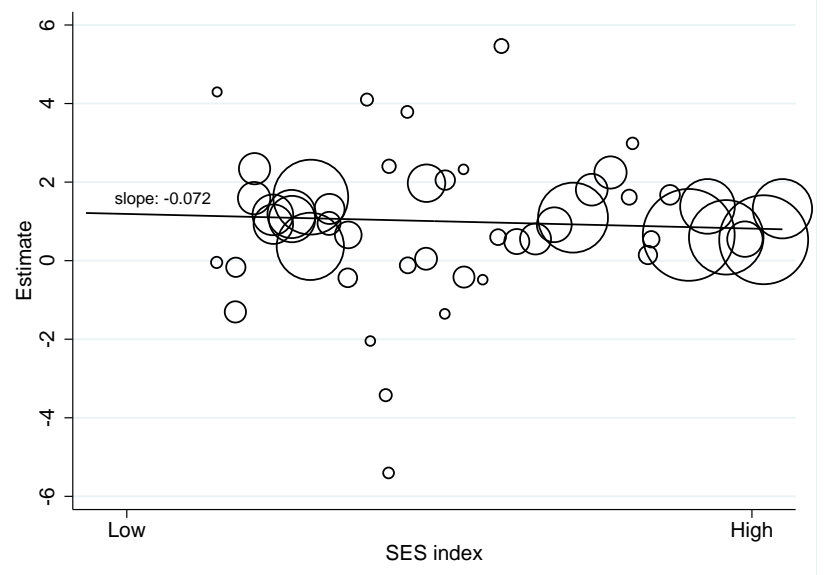

D. Prenatal Care Adequacy

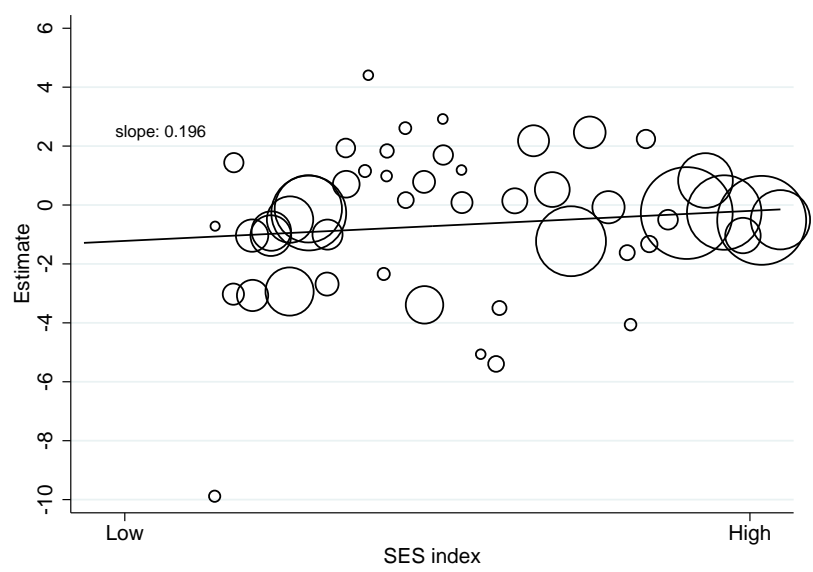

Note: This figure plots the regression-adjusted male-female gap against the mean value of the SES index, for 95 bins of the SES index. Graphs suppress bins of less than 360 children for expositional clarity. Lines come from OLS regressions fitted through all bins and weighted by bin size. The SES measure is constructed as the first component of a principal components analysis of years of maternal education, non-Medicaid birth indicator and marital status/family structure (married, father present, father absent) at birth. The sample is non-twin siblings born 1994-2002. Infant birthweight is in grams. Abnormal conditions are coded as equal to one hundred if any of the following conditions are observed: anemia; birth injury; fetal alcohol syndrome; hyaline membrane disease; meconium aspiration syndrome; assisted ventilation $<30$ minutes; assisted ventilation $>30$ minutes; seizure; or other specified abnormal conditions. Maternal health issues during pregnancy is equal to one hundred if the mother suffered from any of a large set of chronic or pregnancy-related disorders (anemia; cardiac disease; acute or chronic lung disease; diabetes; genital herpes, hydramnios/oligohydramnios; hemoglobinopathy; chronic hypertension; pregnancy-associated hypertension; eclampsia; incompetent cervix; previous infant $4000+$ grams; previous preterm or small for gestational age infant; renal disease; RH sensitization; uterine bleeding; other specified health problem). Prenatal care adequacy is defined according to the Kessner Adequacy of Prenatal Care Utilization index (APCU), which is equal to one hundred if the mother received standard prenatal care services during pregnancy (and zero otherwise). 
Table O1: Construction of Principal Components SES Index for Family Disadvantage

\begin{tabular}{|c|c|c|}
\hline & $\begin{array}{c}\text { First } \\
\text { component }\end{array}$ & $\begin{array}{c}\text { Second } \\
\text { component }\end{array}$ \\
\hline Mother's education & 0.41 & 0.14 \\
\hline Married & 0.58 & -0.10 \\
\hline Father present & -0.40 & 0.70 \\
\hline Father absent & -0.33 & -0.69 \\
\hline Non-medicaid birth & 0.48 & 0.10 \\
\hline Eigenvalue & 2.46 & 1.22 \\
\hline \multicolumn{3}{|c|}{ Summary statistics for the first component } \\
\hline Mean & \multicolumn{2}{|c|}{0.00} \\
\hline SD & \multicolumn{2}{|c|}{$(1.57)$} \\
\hline Mean White & \multicolumn{2}{|c|}{0.42} \\
\hline SD White & \multicolumn{2}{|c|}{$(1.43)$} \\
\hline Mean Black & \multicolumn{2}{|c|}{-1.21} \\
\hline SD Black & \multicolumn{2}{|c|}{$(1.37)$} \\
\hline Mean Hispanic & \multicolumn{2}{|c|}{-0.17} \\
\hline SD Hispanics & \multicolumn{2}{|c|}{$(1.58)$} \\
\hline
\end{tabular}

Note: This table reports the results of a principal components analysis of mother's education (in years), non-Medicaid birth indicator and marital status/family structure at birth (married, unmarried-father present, unmarried-father absent). The eigenvectors associated with the first and second components are reported, as well as their associated eigenvalues. The bottom panel reports summary statistics of the SES index, defined as the first component of the principal components analysis, for the overall sample of siblings as well as the white, black and Hispanic subsamples. 


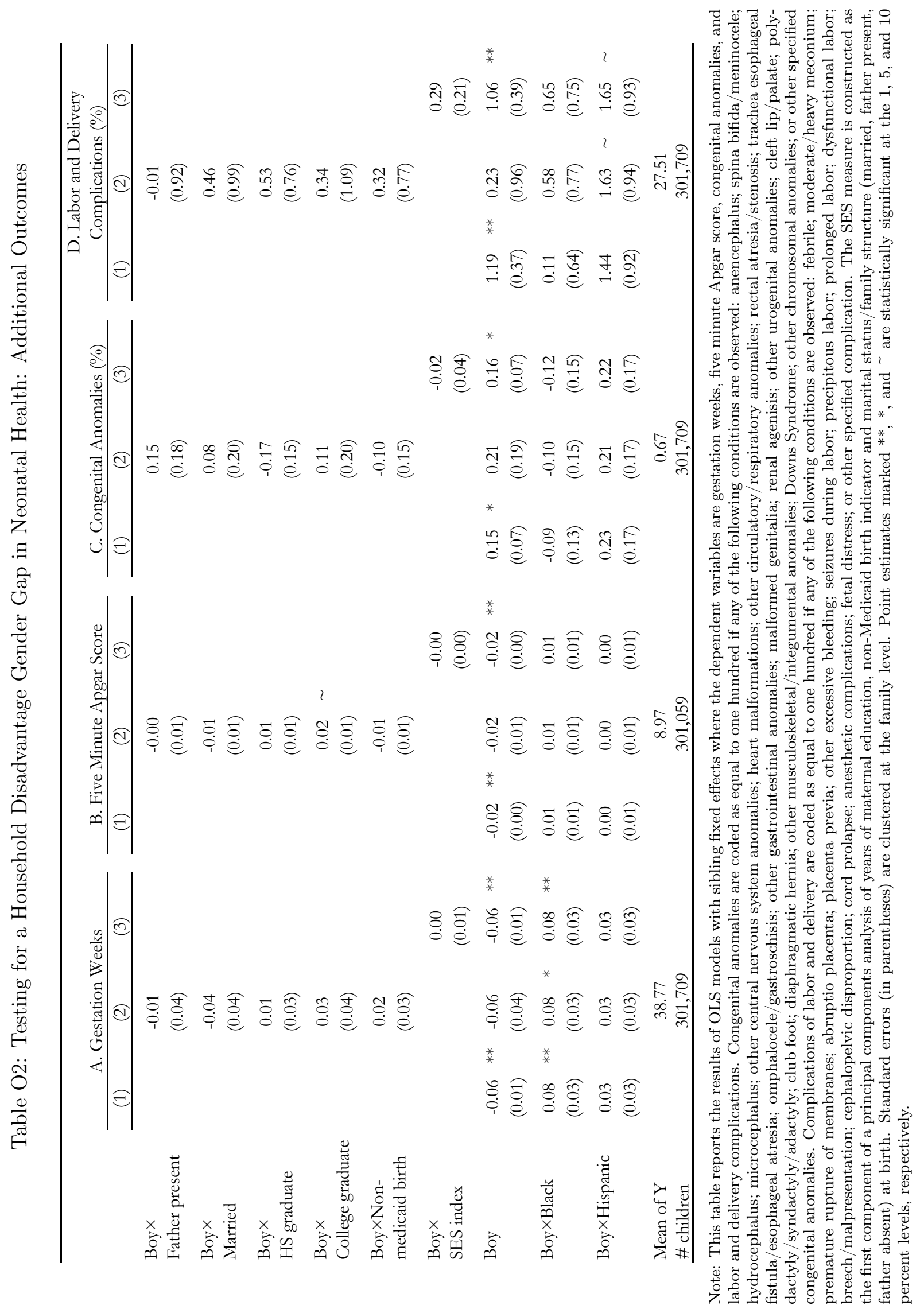


Table O3: Testing for a Household Disadvantage Gender Gap in Neonatal Health: Log Birthweight and Composite Index

\begin{tabular}{|c|c|c|c|c|c|c|c|c|c|c|c|}
\hline & & A. L & og Birth & $\mathrm{Wei}$ & ight & & & $3 . \mathrm{B}$ & irth Index & $\mathrm{x}(\mathrm{PCA})$ & \\
\hline & $(1)$ & & (2) & & (3) & & $(1)$ & & $(2)$ & (3) & \\
\hline Boy $\times$ & & & 0.00 & & & & & & -0.02 & & \\
\hline Father present & & & $(0.00)$ & & & & & & $(0.03)$ & & \\
\hline Boy $x$ & & & -0.00 & & & & & & -0.03 & & \\
\hline Married & & & $(0.00)$ & & & & & & $(0.03)$ & & \\
\hline Boy $\times$ & & & 0.00 & & & & & & 0.02 & & \\
\hline HS graduate & & & $(0.00)$ & & & & & & $(0.02)$ & & \\
\hline Boy $\times$ & & & 0.00 & & & & & & 0.03 & & \\
\hline College graduate & & & $(0.00)$ & & & & & & $(0.03)$ & & \\
\hline $\begin{array}{l}\text { Boy } \times \text { Non- } \\
\text { medicaid birth }\end{array}$ & & & $\begin{array}{c}0.00 \\
(0.00)\end{array}$ & & & & & & $\begin{array}{c}0.01 \\
(0.02)\end{array}$ & & \\
\hline Boy $x$ & & & & & 0.00 & & & & & 0.00 & \\
\hline SES index & & & & & $(0.00)$ & & & & & $(0.01)$ & \\
\hline Boy & $\begin{array}{c}0.04 \\
(0.00)\end{array}$ & $* *$ & $\begin{array}{c}0.03 \\
(0.00)\end{array}$ & $* *$ & $\begin{array}{c}0.04 \\
(0.00)\end{array}$ & $* *$ & $\begin{array}{c}0.02 \\
(0.01)\end{array}$ & * & $\begin{array}{c}0.02 \\
(0.03)\end{array}$ & $\begin{array}{c}0.02 \\
(0.01)\end{array}$ & * \\
\hline Boy $\times$ Black & $\begin{array}{c}0.00 \\
(0.00)\end{array}$ & & $\begin{array}{c}0.00 \\
(0.00)\end{array}$ & & $\begin{array}{c}0.00 \\
(0.00)\end{array}$ & & $\begin{array}{l}0.05 \\
(0.02)\end{array}$ & $*$ & $\begin{array}{c}0.05 * \\
(0.02)\end{array}$ & $\begin{array}{ll}* & 0.05 \\
& (0.02)\end{array}$ & * \\
\hline Boy $\times$ Hispanic & $\begin{array}{l}-0.00 \\
(0.00)\end{array}$ & & $\begin{array}{l}-0.00 \\
(0.00)\end{array}$ & & $\begin{array}{l}-0.00 \\
(0.00)\end{array}$ & & $\begin{array}{l}-0.01 \\
(0.02)\end{array}$ & & $\begin{array}{l}-0.01 \\
(0.02)\end{array}$ & $\begin{array}{l}-0.01 \\
(0.02)\end{array}$ & \\
\hline $\begin{array}{l}\text { Mean of Y } \\
\text { \# children }\end{array}$ & & & $\begin{array}{r}8.09 \\
301,709 \\
\end{array}$ & & & & & & $\begin{array}{r}-0.02 \\
300,984 \\
\end{array}$ & & \\
\hline
\end{tabular}

Note: This table reports the results of OLS models with sibling fixed effects where the dependent variable is the log birthweight, or a birth index coming from a principal component analysis of all birth outcomes in Table 6 and Appendix Table O2 as well as one minute Apgar scores. The SES measure is constructed as the first component of a principal components analysis of years of maternal education, non-Medicaid birth indicator and marital status/family structure (married, father present, father absent) at birth. Standard errors (in parentheses) are clustered at the family level. Point estimates marked ${ }^{* *},{ }^{*}$, and ${ }^{\sim}$ are statistically significant at the 1,5 , and 10 percent levels, respectively. 
Table O4: Testing for a Household Disadvantage Gender Gap in Neonatal Health: OLS Singletons and Siblings Sample

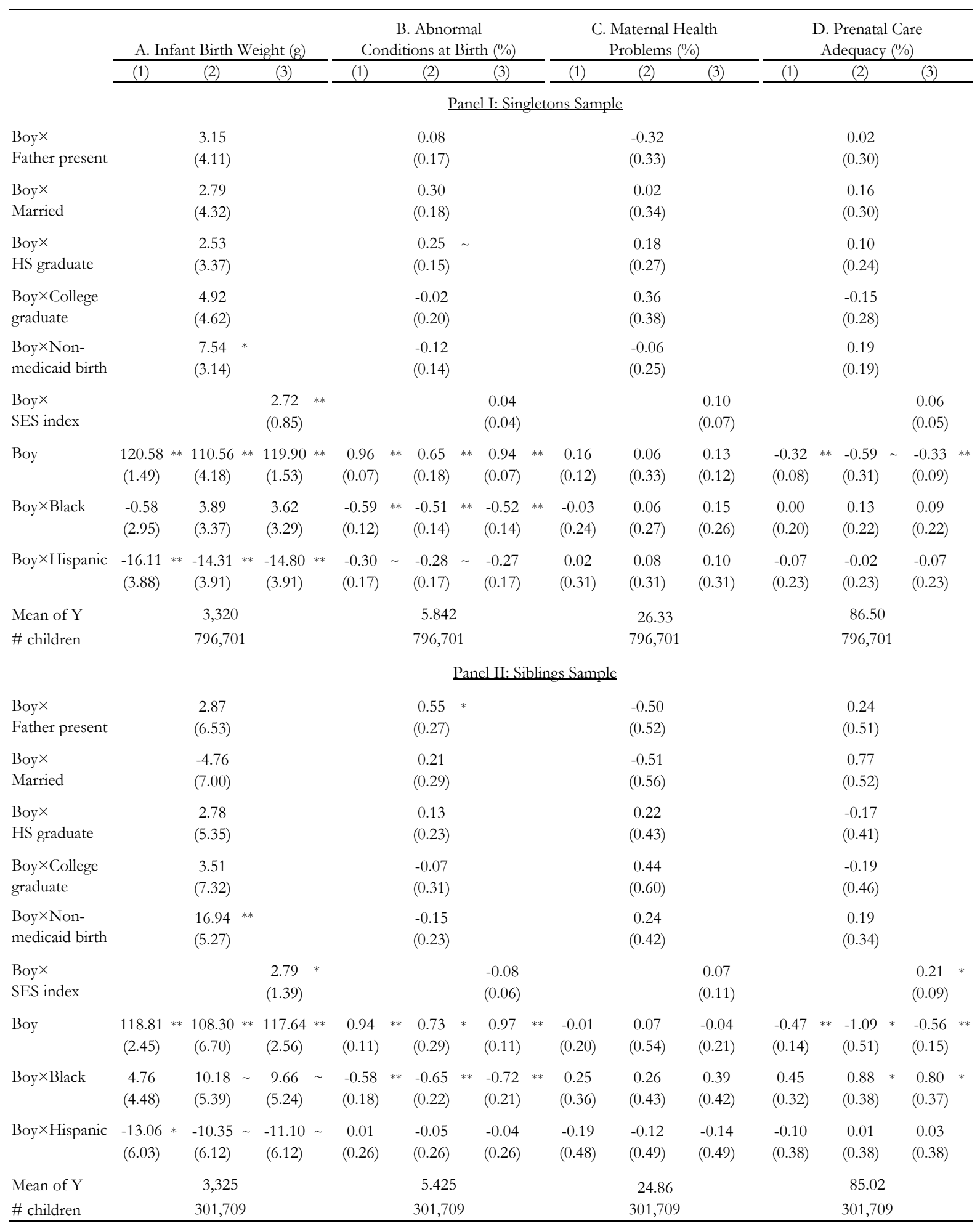

Note: This table reports estimates from OLS models where the dependent variables are birthweight in grams, abnormal conditions at birth, maternal health problems, or adequacy of prenatal care. See note to Table 6 for the definition of the dependent variables. Panel I uses the full sample of singleton births matched to Florida educational outcomes, while panel II uses the sibling sample. Standard errors are in parentheses, with robust standard errors utilized for the singleton analysis and standard errors clustered at the family level utilized for the sibling analysis. Point estimates marked ${ }^{* *},{ }^{*}$, and ${ }^{\sim}$ are statistically significant at the 1,5 , and 10 percent levels, respectively. 
Table O5: Main Estimates for Grade 3 through 8 Outcomes Augmented with Log Birthweight

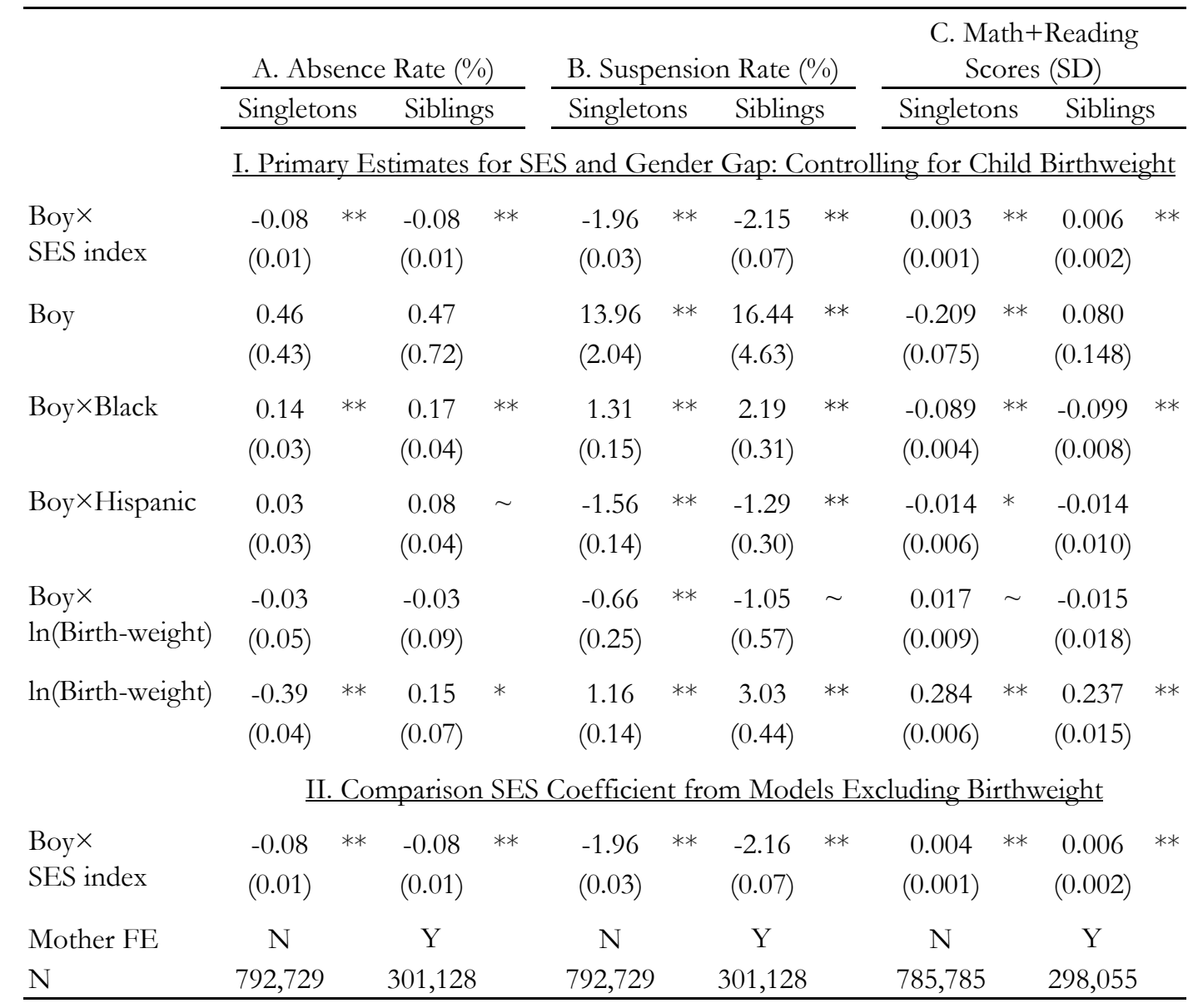

Note: Panel I of this table presents results from OLS regressions on the sample of singleton births, grades three through eight, and results from sibling fixed effect models for the sample of siblings, grades three through eight. The dependent variables are absence rates, suspension rates, and FCAT math and reading scores, as previously defined. All columns include controls for child year and month of birth, maternal age at birth, birth order, and the main effect of the SES index. The singleton specifications additionally include main effects for mother race-ethnicity. Panel II reports the coefficient on the interaction term Boy $\times$ SES from Table 3 and Appendix Table A3, from the corresponding singleton or sibling fixed effects models. Standard errors are clustered at the student level in the singleton specifications and the family level in the siblings specifications. Point estimates marked ${ }^{* *}, *$, and $\sim$ are statistically significant at the 1,5 , and 10 percent levels, respectively. 
Table O6: Testing for Heterogeneous Effects of Family Disadvantage on the Gender Gap in Behavioral and Academic Outcomes among Race Groups

\begin{tabular}{|c|c|c|c|c|c|c|c|c|c|c|c|c|}
\hline \multirow[b]{3}{*}{$\begin{array}{l}\text { Boy } \times \\
\text { SES×Black (A1) }\end{array}$} & \multicolumn{4}{|c|}{$\begin{array}{l}\text { A. Absence } \\
\text { Rate }(\%)\end{array}$} & \multicolumn{4}{|c|}{$\begin{array}{l}\text { B. Suspension } \\
\text { Rate }(\%)\end{array}$} & \multicolumn{4}{|c|}{$\begin{array}{l}\text { C. Math+Reading } \\
\text { Scores (SD) }\end{array}$} \\
\hline & $(1)$ & & $(2)$ & & $(1)$ & & $(2)$ & & $(1)$ & & $(2)$ & \\
\hline & & & $\begin{array}{l}-0.01 \\
(0.02)\end{array}$ & & & & $\begin{array}{l}0.86^{* * *} \\
(0.19)\end{array}$ & & & & $\begin{array}{l}-0.01 * \\
(0.01)\end{array}$ & \\
\hline $\begin{array}{l}\text { Boy } \times \\
\text { SES } \times \text { Hispanic (A2) }\end{array}$ & & & $\begin{array}{c}0.01 \\
(0.03)\end{array}$ & & & & $\begin{array}{l}0.72^{* * *} \\
(0.20)\end{array}$ & & & & $\begin{array}{c}0.00 \\
(0.01)\end{array}$ & \\
\hline $\begin{array}{l}\text { Boy } \times \\
\text { SES index }\end{array}$ & $\begin{array}{l}-0.08 \\
(0.01)\end{array}$ & $* *$ & $\begin{array}{l}-0.08 \\
(0.01)\end{array}$ & $* *$ & $\begin{array}{l}-2.16 \\
(0.07)\end{array}$ & $* *$ & $\begin{array}{l}-2.48 \\
(0.09)\end{array}$ & $* *$ & $\begin{array}{c}0.01 \\
(0.00)\end{array}$ & $* *$ & $\begin{array}{c}0.01 \\
(0.00)\end{array}$ & $* *$ \\
\hline Boy $\times$ Black & $\begin{array}{c}0.17 \\
(0.04)\end{array}$ & $* *$ & $\begin{array}{l}0.15 \\
(0.04)\end{array}$ & $* *$ & $\begin{array}{c}2.27 \\
(0.30)\end{array}$ & $* *$ & $\begin{array}{c}2.89 \\
(0.33)\end{array}$ & $* *$ & $\begin{array}{c}-0.1 \\
(0.01)\end{array}$ & $* *$ & $\begin{array}{l}-0.11 \\
(0.01)\end{array}$ & ** \\
\hline Boy $\times$ Hispanic & $\begin{array}{c}0.08 \\
(0.04)\end{array}$ & $\sim$ & $\begin{array}{l}0.08 \\
(0.04)\end{array}$ & * & $\begin{array}{l}-1.28 \\
(0.30)\end{array}$ & $* *$ & $\begin{array}{l}-1.34 \\
(0.29)\end{array}$ & $* *$ & $\begin{array}{l}-0.02 \\
(0.01)\end{array}$ & & $\begin{array}{l}-0.01 \\
(0.01)\end{array}$ & \\
\hline Boy & $\begin{array}{c}0.25 \\
(0.02)\end{array}$ & $* *$ & $\begin{array}{l}0.25 \\
(0.02)\end{array}$ & $* *$ & $\begin{array}{c}7.99 \\
(0.12)\end{array}$ & $* *$ & $\begin{array}{c}8.14 \\
(0.13)\end{array}$ & $* *$ & $\begin{array}{l}-0.03 \\
(0.00)\end{array}$ & $* *$ & $\begin{array}{l}-0.04 \\
(0.00)\end{array}$ & k* \\
\hline $\begin{array}{l}\mathrm{H}_{0}(\mathrm{~A} 1=\mathrm{A} 2=0) \\
\# \text { children }\end{array}$ & & 301, & $\begin{array}{l}0.74 \\
128 \\
\end{array}$ & & & 301, & $\begin{array}{r}0.00 \\
128 \\
\end{array}$ & & & 298, & $\begin{array}{l}0.16 \\
055 \\
\end{array}$ & \\
\hline
\end{tabular}

Note: This table presents results from OLS models with sibling fixed effects in which the dependent variables are absence rates, suspension rates, and FCAT math and reading scores, as previously defined. All columns include controls for child year and month of birth, maternal age at birth, birth order within family, and the main effect of the SES index. Standard errors are clustered at the family level. P-values associated with the Wald tests of coefficient equality are reported at the bottom of the table. Point estimates marked ${ }^{* *},{ }^{*}$, and $\sim$ are statistically significant at the 1,5 , and 10 percent levels, respectively. 
Table O7: Testing for Heterogeneous Effects of Family Disadvantage on the Gender Gap in High School Outcomes among Race Groups

\begin{tabular}{|c|c|c|c|c|}
\hline & $\begin{array}{c}\text { A. On-Time HS } \\
\text { Grad }(\%) \\
\end{array}$ & $\begin{array}{c}\text { B. } 5+\text { Years } \\
\text { High School }(\%)\end{array}$ & $\begin{array}{c}\text { C. HS Drop } \\
(\%) \\
\end{array}$ & \\
\hline $\begin{array}{l}\text { Boy } \times \\
\text { Black } \times \text { Married (A1) }\end{array}$ & $\begin{array}{c}0.35 \\
(1.30)\end{array}$ & $\begin{array}{l}-0.42 \\
(1.04)\end{array}$ & $\begin{array}{c}0.06 \\
(1.04)\end{array}$ & \\
\hline $\begin{array}{l}\text { Boy } \times \\
\text { Hispanic } \times \text { Married (A2) }\end{array}$ & $\begin{array}{l}-0.23 \\
(2.21)\end{array}$ & $\begin{array}{c}4.37 \\
(1.71)\end{array}$ & $\begin{array}{l}-4.14 \\
(1.89)\end{array}$ & * \\
\hline $\begin{array}{l}\text { Boy } \times \\
\text { Black } \times \text { HS graduate }(B 1)\end{array}$ & $\begin{array}{l}-0.99 \\
(1.38)\end{array}$ & $\begin{array}{c}1.91 \sim \\
(1.14)\end{array}$ & $\begin{array}{l}-0.91 \\
(1.19)\end{array}$ & \\
\hline $\begin{array}{l}\text { Boy } \times \\
\text { Hispanic } \times \text { HS graduate }(B 2)\end{array}$ & $\begin{array}{l}-0.91 \\
(2.38)\end{array}$ & $\begin{array}{c}0.17 \\
(1.85)\end{array}$ & $\begin{array}{c}0.74 \\
(2.10)\end{array}$ & \\
\hline $\begin{array}{l}\text { Boy } \times \\
\text { Black } \times \text { College graduate (C1) }\end{array}$ & $\begin{array}{l}-0.14 \\
(2.06)\end{array}$ & $\begin{array}{c}1.64 \\
(1.64)\end{array}$ & $\begin{array}{l}-1.50 \\
(1.61)\end{array}$ & \\
\hline $\begin{array}{l}\text { Boy } \times \\
\text { Hispanic } \times \text { College graduate }(C 2)\end{array}$ & $\begin{array}{c}0.84 \\
(3.02)\end{array}$ & $\begin{array}{c}0.27 \\
(2.27)\end{array}$ & $\begin{array}{l}-1.11 \\
(2.52)\end{array}$ & \\
\hline Boy $\times$ Black & $\begin{array}{l}-4.04 \quad * * \\
(1.22)\end{array}$ & $\begin{array}{c}0.64 \\
(1.02)\end{array}$ & $\begin{array}{c}3.41 \\
(1.09)\end{array}$ & $* *$ \\
\hline Boy $\times$ Hispanic & $\begin{array}{l}-0.79 \\
(2.13)\end{array}$ & $\begin{array}{l}-3.11 \sim \\
(1.68)\end{array}$ & $\begin{array}{c}3.90 \\
(1.94)\end{array}$ & * \\
\hline Boy & $\begin{array}{ll}-9.80 & * * \\
(0.84) & \end{array}$ & $\begin{array}{c}6.36 \quad * * \\
(0.64)\end{array}$ & $\begin{array}{c}3.44 \\
(0.79)\end{array}$ & $* *$ \\
\hline $\mathrm{H}_{0}(\mathrm{~A} 1=\mathrm{A} 2=0)$ & 0.95 & 0.03 & 0.08 & \\
\hline $\mathrm{H}_{0}(\mathrm{~B} 1=\mathrm{B} 2=0)$ & 0.75 & 0.24 & 0.64 & \\
\hline $\mathrm{H}_{0}(\mathrm{C} 1=\mathrm{C} 2=0)$ & 0.96 & 0.60 & 0.62 & \\
\hline $\mathrm{H}_{0}(\mathrm{~A}=\mathrm{B}=\mathrm{C}=0)$ & 0.97 & 0.09 & 0.22 & \\
\hline \# children & & 161,537 & & \\
\hline
\end{tabular}

Note: This table presents the results of OLS models for the set of singletons born in 1992-1993. On-time high school completion takes on a value of one hundred if a student obtains a high school diploma within four years of entering, and is zero otherwise. $5+$ years of high school takes on a value of one hundred if the student is enrolled in high school more than four years after entry but has not yet dropped out, and is zero otherwise. High school dropout takes on a value of one hundred if a student does not earn a high school diploma and is no longer enrolled in high school $5+$ years after entry, and is zero otherwise. All columns include main effects for race-ethnicity of mother, child year and month of birth, maternal age at birth, birth order, maternal education, and marital status at birth. P-values associated with the Wald tests of coefficient equality are reported at the bottom of the table. Robust standard errors are in parentheses. Point estimates marked ${ }^{* *},{ }^{*}$, and $\sim$ are statistically significant at the 1,5 , and 10 percent levels, respectively. 


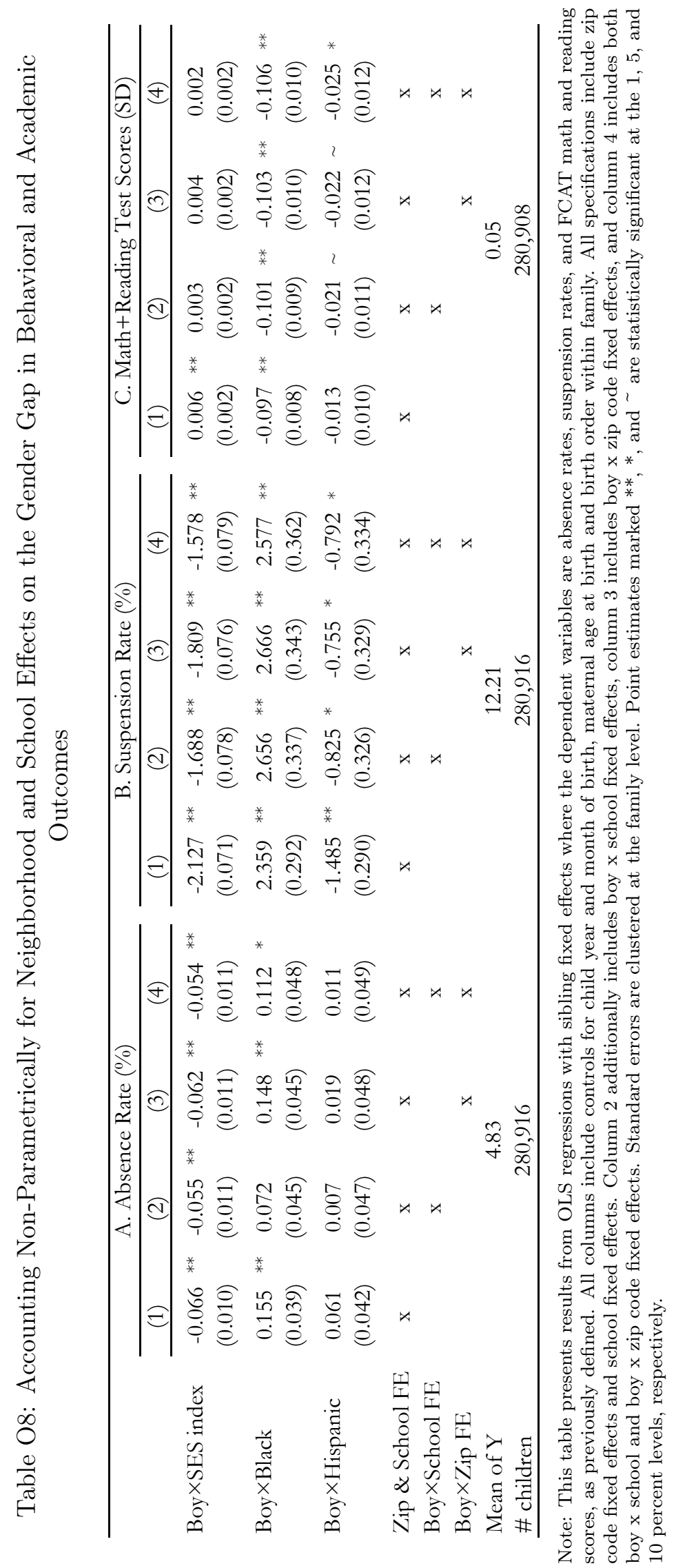

